Recomendação de conteúdo baseada em interações multimodais

\author{
Arthur Fortes da Costa
}




\title{
Recomendação de conteúdo baseada em interações multimodais
}

\author{
Arthur Fortes da Costa
}

Orientadora: Prof. Dr. Marcelo Garcia Manzato

Dissertação apresentada ao Instituto de Ciências Matemáticas e de Computação - ICMC-USP, como parte dos requisitos para obtenção do título de Mestre em Ciências - Ciências de Computação e Matemática Computacional. VERSÃO REVISADA 
Ficha catalográfica elaborada pela Biblioteca Prof. Achille Bassi e Seção Técnica de Informática, ICMC/USP, com os dados fornecidos pelo(a) autor(a)

Fortes da Costa, Arthur
Recomendação de conteúdo baseada em interações
multimodais / Arthur Fortes da Costa; orientador
Marcelo Garcia Manzato. -- São Carlos, 2014.
90 p.
Dissertação (Mestrado - Programa de Pós-Graduação
em Matemática) -- Instituto de Ciências Matemáticas
e de Computação, Universidade de São Paulo, 2014.
1. Sistemas de Recomendação. 2. Ensemble
Learning. 3. Interações Multimodais. 4. Filtragem
Colaborativa. I. Garcia Manzato, Marcelo, orient.
II. Título.




\section{Agradecimentos}

A realização desta dissertação marca o fim de uma importante etapa da minha vida. Gostaria de agradecer a todos aqueles que contribuíram de forma decisiva para a sua concretização

À Universidade de São Paulo, especialmente ao Instituto de Ciências Matemáticas e Computacionais, manifesto apreço pela possibilidade de realização do presente trabalho e por todos os meios colocados à disposição. Agradeço igualmente a excelência da formação prestada e conhecimentos transmitidos,úteis para esta dissertação.

Ao professor Marcelo Manzato pela disponibilidade, colaboração, conhecimentos transmitidos, capacidade de compreensão e estímulo ao longo de todo o trabalho.

Aos professores do Programa de Pós-Graduação em Computação, pela oportunidade de crescimento, aprendizado, realização profissional e pessoal e pela confiança em mim depositada.

À minha namorada Yasmin Antunes Juhaz e a sua família, pelo apoio e compreensão durante o desenvolvimento da dissertação.

À todos os meus amigos que sempre estiveram presentes me aconselhando e incentivando com carinho e dedicação.

Por último, manifesto um grande reconhecimento à minha família pelo apoio incondicional ao longo destes anos. Expresso sentimento idêntico em relação a todos os meus amigos de longa data.

À todas as pessoas que, direta ou indiretamente, contribuíram para a execução dessa Dissertação de Mestrado, meu muito obrigado! 
A oferta de produtos, informações e serviços a partir de perfis de usuários tem tornado os sistemas de recomendação cada vez mais presentes na Web, aumentando a facilidade de escolha e de permanência dos usuários nestes sistemas. Entretanto, existem otimizações a serem feitas principalmente com relação à modelagem do perfil do usuário. Geralmente, suas preferências são modeladas de modo superficial, devido à escassez das informações coletadas, como notas ou comentários, ou devido a informações indutivas que estão suscetíveis a erros. Esta dissertação propõe uma ferramenta de recomendação baseado em interações multimodais, capaz de combinar informações de usuários processadas individualmente por algoritmos de recomendação tradicionais. Nesta ferramenta desenvolveram-se quatro técnicas de combinação afim fornecer aos sistemas de recomendação, subsídios para melhoria na qualidade das predições em diversos domínios.

Palavras-chave: Perfis de Usuários, Sistemas de Recomendação, Interações de Usuário, Técnicas de Combinação. 
Providing products, information and services from user profiles has made the recommendation systems to be increasingly present, increasing the ease of selection and retention of users in Web services. However, there are optimizations to be made in these systems mainly with respect to modeling the user profile. Generally, the preferences are modeled superficially, due to the scarcity of information collected, as notes or comments, or because of inductive information that is susceptible to errors. This work proposes a recommendation tool based on multimodal interactions that combines users' interactions, wich are processed individually by traditional recommendation algorithms. In this tool developed four combination of techniques in order to provide recommendation systems subsidies to improve the quality of predictions.

Keyword: User Profiles, Recommendation Systems, User Interactions, Ensemble Tecniques. 
1 Introdução 1

1.1 Contextualização . . . . . . . . . . . . . . . . . . . . . . 1

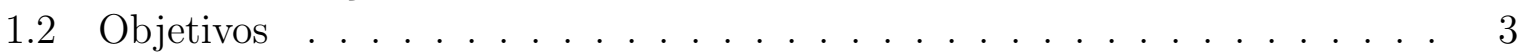

1.3 Metodologia . . . . . . . . . . . . . . . . . . 3

1.4 Contribuições da Pesquisa . . . . . . . . . . . . . . . . . . . 4

1.5 Organização do Trabalho . . . . . . . . . . . . . . . . 5

2 Sistemas de Recomendação $\quad 6$

2.1 Contextualização . . . . . . . . . . . . . . . . . . . . 6

2.2 Técnicas de Filtragem Aplicadas a Sistemas de Recomendação . . . . . . . 8

2.3 Recomendação Baseada em Filtragem Colaborativa . . . . . . . . . . . . . 10

2.3.1 Fatoração de Matrizes . . . . . . . . . . . . . . . . . . . . . . . 12

2.3.2 Modelo de Vizinhança . . . . . . . . . . . . . . . . . . . . . . 12

2.3.3 Algoritmos de Recomendação . . . . . . . . . . . . . . . . . . . . . 13

2.3.3.1 Notações . . . . . . . . . . . . . . . . . . . . . . . . . . . . . . . . . . . . . 14

2.3.3.2 SVD + S . . . . . . . . . . . . . . . 14

2.3.3.3 $\mathrm{BPR} \mathrm{MF} \ldots \ldots \ldots \ldots \ldots$

2.4 Pesquisas Relacionadas . . . . . . . . . . . . . . . . . . . . . . 18

2.5 Considerações Finais . . . . . . . . . . . . . . . . . . . . 20

3 Geração de Perfis de Usuário $\quad 21$

3.1 Contextualização . . . . . . . . . . . . . . . . . . . . . . . . 21

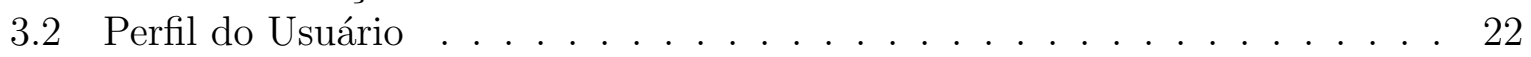

3.2 .1 Reputação . . . . . . . . . . . . . . . . . . . . 24

3.2 .2 Geração e Manutenção do Perfil do Usuário . . . . . . . . . . . . . 25

3.3 Tipos de Interação . . . . . . . . . . . . . . . . . . . . . . . . 26

3.3.1 Etiquetagem Social . . . . . . . . . . . . . . . . . . . . 26

3.3.2 Feedback dos Usuários . . . . . . . . . . . . . . . . . . . . . 28

3.3.3 Interações Multimodais . . . . . . . . . . . . . . . . . . . . . . 32

3.4 Métodos de Combinação de Interação de Usuários . . . . . . . . . . . . . . 33

3.4 Empilhamento. . . . . . . . . . . . . . . . . . . 34

3.4 .2 Classificador Ótimo de Bayes . . . . . . . . . . . . . . . . . . . . 34

3.4.3 Bootstrap Agregado . . . . . . . . . . . . . . . . 35 


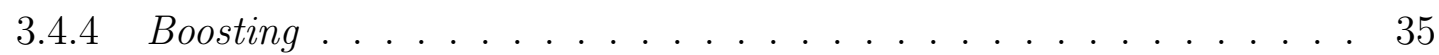

3.5 Considerações Finais . . . . . . . . . . . . . . . . . . . . 35

4 Proposta de Solução $\quad 37$

4.1 Contextualização . . . . . . . . . . . . . . . . . . . . . . 37

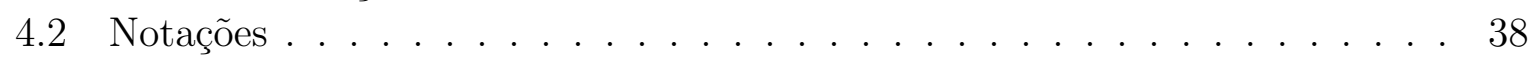

4.3 Técnicas Baseadas em Heurísticas . . . . . . . . . . . . . . . . 38

4.3.1 Técnica Baseada em Etiquetas . . . . . . . . . . . . . . . . . . 39

4.3.2 Técnica Baseada em Médias . . . . . . . . . . . . . . . . . . 40

4.4 Técnica Baseada em Aprendizagem . . . . . . . . . . . . . . . . 41

4.4.1 Etapa 1: Divisão de Dados e Execução de Algoritmos Unimodais . 42

4.4.2 Etapa 2: Aprendizagem de Pesos Para Cada Tipo de Interação . . . 43

4.4.3 Etapa 3: Combinação de Ranques e Recomendação Final de Itens 43

4.5 Técnica de Recomendação Colaborativa Baseada em Grupos . . . . . . . . 44

4.5.1 Representação dos Dados . . . . . . . . . . . . . . . . . . 45

4.5.2 Encontrar Vizinhos Mais Próximos . . . . . . . . . . . . . . . 46

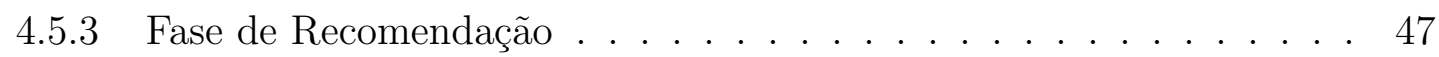

4.6 Considerações Finais . . . . . . . . . . . . . . . . . . . . . . . . . 47

5 Experimentos e Resultados $\quad 49$

5.1 Metodologia de Avaliação . . . . . . . . . . . . . . . . . . 49

5.1 .1 Ferramentas Utilizadas . . . . . . . . . . . . . . . . . 50

5.1 .2 Base de Dados . . . . . . . . . . . . . . . . 50

5.1 .3 Avaliação em Sistemas de Recomendação . . . . . . . . . . . . . . . 51

5.1.3.1 Metodologia de Estimativa de Desempenho . . . . . . . . 51

5.1.3.2 Métricas de Avaliação e Validação . . . . . . . . . . . . . 52

5.2 Estudo 1: Base de Dados LastFM . . . . . . . . . . . . . . . . . . . 54

5.2.1 Base de Dados Experimental . . . . . . . . . . . . . . . . 54

5.2 .2 Avaliação da Base de Dados de Treinamento . . . . . . . . . . . . 55

5.2 .3 Experimentos Realizados . . . . . . . . . . . . . . 58

5.2.3.1 Técnicas Existentes na Literatura . . . . . . . . . . . . . 59

5.2.3.2 Técnicas Baseadas em Heurísticas . . . . . . . . . . . . 60

5.2.3.3 Técnica Baseada em Aprendizagem . . . . . . . . . . . . 61

5.2.3.4 Técnica de Recomendação Colaborativa Baseada em Grupos 61

5.2 .4 Conclusões do Estudo $1 \ldots \ldots$. . . . . . . . . . . . . 63

5.3 Estudo 2: Base de Dados MovieLens . . . . . . . . . . . . . . 66

5.3.1 Base de Dados Experimental . . . . . . . . . . . . . 66

5.3 .2 Avaliação da Base de Dados de Treino . . . . . . . . . . . . . . . . 67

5.3.3 Experimentos Realizados . . . . . . . . . . . . . . 69

5.3.3.1 Técnicas Existentes na Literatura . . . . . . . . . . . . 71

5.3.3.2 Técnicas Baseadas em Heurísticas . . . . . . . . . . . . . 72

5.3.3.3 Técnicas Baseadas em Aprendizagem . . . . . . . . . . . 73

5.3.3.4 Técnica de Recomendação Colaborativa Baseada em Grupos 73

5.3 .4 Conclusões do Estudo 2 . . . . . . . . . . . . . . . . . . 74

5.4 Considerações Finais . . . . . . . . . . . . . . . . . . 77 
6 Conclusões e Trabalhos Futuros $\quad 78$

6.1 Resumo do trabalho . . . . . . . . . . . . . . . . . 78

6.2 Contribuições da Pesquisa . . . . . . . . . . . . . . . . . . . . . . . 79

6.2.1 Conclusões e Aplicações . . . . . . . . . . . . . . . . . . . . . . . . 80

6.2.2 Trabalhos Publicados . . . . . . . . . . . . . . . . 81

6.3 Trabalhos Futuros . . . . . . . . . . . . . . . . . . . . . 83

$\begin{array}{lr}\text { Referências } & 90\end{array}$ 
2.1 Modelo do processo de recomendação proposto por Terveen et al. $\quad$. . . . . 7

2.2 Representação da primeira abordagem de filtragem colaborativa proposta por (Kajimoto et al., 2007) . . . . . . . . . . . . . . . . . . 11

2.3 Representação da segunda abordagem de filtragem colaborativa proposta por (Kajimoto et al., 2007) . . . . . . . . . . . . . . . . . 12

2.4 Matrizes de usuários por itens e de itens por itens do algoritmo BPR MF. . 17

3.1 Modelo representativo GUMO . . . . . . . . . . . . . . . . . . . 23

3.2 Visão estrutural dos dez determinantes da Reputação de Rein . . . . . . . 24

3.3 Estratégias de recomendação. . . . . . . . . . . . . . . . . . . . . 31

4.1 Exemplo de técnica baseada em etiquetas. . . . . . . . . . . . . . . . 40

4.2 Visualização esquemática da técnica de aprendizagem. . . . . . . . . . . . . . 42

4.3 Visualização esquemática da técnica de recomendação baseada em grupos. 45

5.1 Divisão do conjunto de usuários em dois subconjuntos: treinamento e teste 51

5.2 Esquema da metodologia usada na avaliação . . . . . . . . . . . . . 52

5.3 Número de interações feitas por usuários nas bases de treinamento do LastFM ( $n$ representa o número de interações). . . . . . . . . . . . . . 56

5.4 Histórico de visualização. . . . . . . . . . . . . . . . . 57

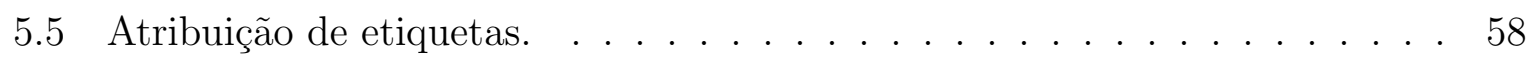

5.6 Conjuntos concatenados. . . . . . . . . . . . . . . . . . 58

5.7 Gráficos e tabelas comparativas de MAP em cada tipo de interação na base do LastFM. . . . . . . . . . . . . . . . . . . . . . . . . 59

5.8 Gráficos e tabelas comparativas de precisão em cada tipo de interação na base do LastFM. . . . . . . . . . . . . . . . . . . . . . . . . 59

5.9 Gráficos e tabelas comparativas de MAP nas técnicas baseadas em heurísticas na base do LastFM. . . . . . . . . . . . . . . . . . . . . . 60

5.10 Gráficos e tabelas comparativas de precisão nas técnicas baseadas em heurísticas na base do LastFM. . . . . . . . . . . . . . . . . . . . . . 61

5.11 Gráfico comparativo de MAP e precisão na técnica baseada em aprendizagem na base do LastFM. . . . . . . . . . . . . . . . . . . . . 62 
5.12 Gráficos e tabelas comparativas de MAP na técnica baseada em grupos na base do LastFM. . . . . . . . . . . . . . . . . . . . . . . . . . 62

5.13 Gráficos e tabelas comparativas de precisão na técnica baseada em grupos na base do LastFM. . . . . . . . . . . . . . . . . . . . . . . . . . 63

5.14 Gráfico e tabela comparativa de MAP entre as técnicas apresentadas na base do LastFM. . . . . . . . . . . . . . . . . . . . . . . . 64

5.15 Gráfico e tabela comparativa de precisão entre as técnicas apresentadas na base do LastFM. . . . . . . . . . . . . . . . . . . . . . . . . . . . . 64

5.16 Número de interações feitas por usuários nas bases de treinamento do MovieLens ( $n$ representa o número de interações). . . . . . . . . . . . . 68

5.17 Avaliação das notas sobre filmes nos conjuntos de treinamento do MovieLens ( $n$ representa o número de interações). . . . . . . . . . . . . . . . 69

5.18 Avaliação das atribuições de etiquetas sobre filmes nos conjuntos de treinamento do MovieLens ( $n$ representa o número de interações). . . . . . . . 70

5.19 Avaliação do histórico de visualização sobre filmes nos conjuntos de treinamento do MovieLens ( $n$ representa o número de interações). . . . . . . . . 70

5.20 Avaliação do conjunto de todas as interações sobre filmes nos conjuntos de treinamento do MovieLens ( $n$ representa o número de interações). . . . . . 70

5.21 Gráficos e tabelas comparativas de MAP e precisão em cada tipo de interação na base do MovieLens. . . . . . . . . . . . . . . . . . . . . 71

5.22 Gráficos e tabelas comparativas de MAP e precisão nas técnicas baseadas em heurísticas na base do MovieLens. . . . . . . . . . . . . . . . . . 72

5.23 Gráfico comparativo de MAP e precisão na técnica baseada em aprendizagem na base do MovieLens. . . . . . . . . . . . . . . . . . . 73

5.24 Gráficos e tabelas comparativas de MAP e precisão na técnica baseada em grupos na base do MovieLens. . . . . . . . . . . . . . . . . 74

5.25 Gráfico e tabela comparativa de MAP entre as técnicas apresentadas na base do MovieLens. . . . . . . . . . . . . . . . . . . . . . . 75

5.26 Gráfico e tabela comparativa de precisão entre as técnicas apresentadas na base do MovieLens. . . . . . . . . . . . . . . . . . . . . 76 


\section{Lista de Tabelas}

2.1 Pesquisas relevantes dos sistemas de recomendação. . . . . . . . . . . . . . . 19

3.1 Caracterização dos métodos de aquisição de marcações. . . . . . . . . . . . 28

3.2 Características de feedback explícito e implícito. . . . . . . . . . . . . . 30

4.1 Matriz de interação de usuários. . . . . . . . . . . . . . . . . . . 46

5.1 Configuração da base de dados LastFM após sua divisão em teste e treinamento com usuários ativos. . . . . . . . . . . . . . . . 55

5.2 Representação individual de cada tipo de interação, no qual foram eliminados aqueles usuários com um só interação na base LastFM (usuários não ativos). . . . . . . . . . . . . . . . . . . 55

5.3 Desvio Padrão para a métrica de MAP na base do LastFM . . . . . . . . . 65

5.4 Desvio Padrão para a métrica de precisão na base do LastFM. . . . . . . . 65

5.5 Configuração da base de dados MovieLens após sua divisão em Teste e Treino com usuários ativos. . . . . . . . . . . . . . . . . . 67

5.6 Representação individual de cada tipo de interação, no qual foram eliminados aqueles usuários com um só interação na base MovieLens (usuários não ativos). . . . . . . . . . . . . . . . . . . . . 6 67 67

5.7 Desvio Padrão para a métrica de MAP na base do MovieLens. . . . . . . . 75

5.8 Desvio Padrão para a métrica de precisão na base do MovieLens. . . . . . . 76 


\section{Lista de Siglas}

SR Sistemas de Recomendação

FI Filtragem de Informação

AM Aprendizagem de Máquina

FC Filtragem Colaborativa

FBC Filtragem Baseada em Conteúdo

FH Filtragem Híbrida

SFC Sistemas de Filtragem Colaborativa

FM Fatoração de Matrizes

SVD Decomposição em Valores Singulares

BPRMF Bayesian Personalized Ranking With Matrix Factorization

SVM Support Vector Machine

MAP Mean Average Precision 


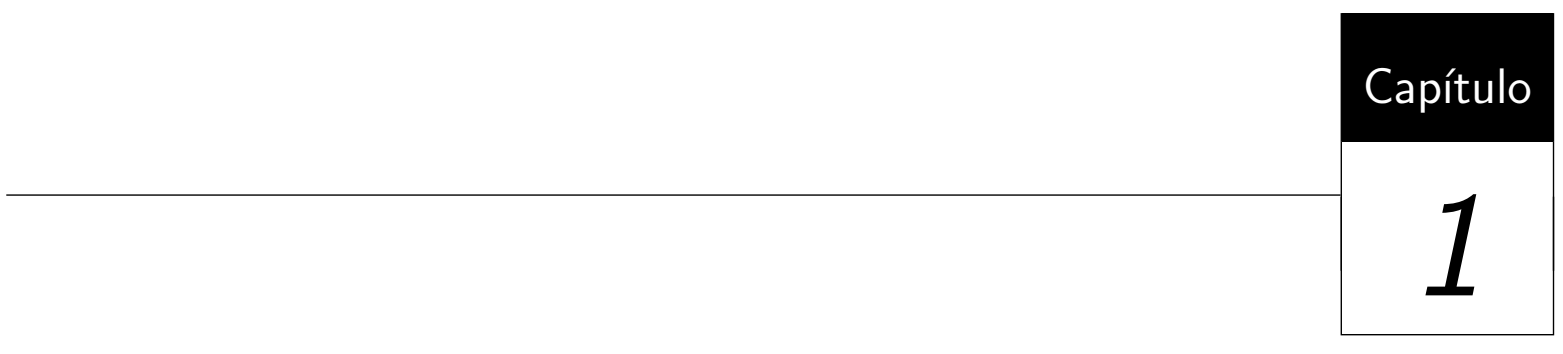

Introdução

\subsection{Contextualização}

O aumento da disponibilidade de dados na Web fez com que o consumo de itens relevantes se tornasse um desafio para os usuários, causando sobrecarga de informação. Em resposta a este problema, surgiram os sistemas de recomendação (SR), que são uma tecnologia de filtragem da informação utilizada para prever classificações de preferência de itens. Geralmente a saída desses sistemas consiste em ranques personalizados de itens suscetíveis ao interesse do usuário, ou a predição de notas que o usuário poderia atribuir a determinado item (Ricci et al., 2011).

Os mecanismos de recomendação tradicionais procuram construir um perfil de interesses para cada indivíduo, com base nas interações do mesmo com o sistema, que podem ser explícitas, implícitas ou híbridas. Técnicas baseadas em informações explícitas coletam dados explícitos fornecidos pelos usuários, tais como o preenchimento de formulários ou a classificação de conteúdo. Esta abordagem é geralmente considerada mais precisa, considerando que as informações obtidas são fornecidas diretamente pelos usuários; no entanto, exigem um maior esforço por parte deles (Bar et al., 2013). Por outro lado, as abordagens que capturam informações implícitas coletam indiretamente as interações do indivíduo durante a sua navegação no sistema, como histórico de navegação e movimento do mouse. As informações implícitas dos usuários são uma fonte mais abundante de dados por serem armazenadas automaticamente pelo sistema; no entanto, uma análise do com- 
portamento do usuário deve ser realizada para inferir preferências positivas ou negativas. A abordagem híbrida, por sua vez, é a combinação dos dois tipos de interação para obter uma quantidade maior e mais exata de informações.

Nos últimos anos, essas abordagens surgiram como uma possível solução para o problema da sobrecarga de informação, pois adotam técnicas de modelagem de perfis diferentes para coletar informações sobre as preferências dos usuário. No entanto, dada a multiplicidade das preferências, necessidades e complexidade dos bancos de informações atuais, nenhum dos métodos citados anteriormente é adequado para todos os casos, mesmo que estes se mostrem razoavelmente eficazes em representar as necessidades de informação do indivíduo (Arapakis et al., 2009).

Tal fato é ocasionado basicamente por quatro razões: primeiramente, as abordagens existentes geralmente representam os interesses do indivíduo em termos de um vetor único de perfil, que ocasiona baixa coleta de dados, resultando no armazenamento redundante e processamento de assinaturas que se sobrepõem, e com especificações excessivamente largas de necessidade de informação (Ricci et al., 2011). Em segundo, os sistemas existentes normalmente exigem que os usuários especifiquem explicitamente seus perfis, muitas vezes com um conjunto de palavras-chave ou categorias, delegando a complexa tarefa ao usuário de fornecer informações exatas e corretas. A terceira razão recai no estado da arte desses sistemas, que são geralmente construídos no pressuposto de que os usuários alteram seus interesses com pouca frequência, o que proporciona falhas na recomendação ao longo do tempo. Por fim, a principal razão é que, dado que o usuário normalmente expressa suas preferências de diversas maneiras, tanto explicitamente, quanto implicitamente, os modelos existentes na literatura, que serão apresentados nos Capítulo 2 e 3 , utilizam apenas um número limitado de interações para a recomendação personalizada.

Mecanismos capazes de unificar todas ou boa parte das interações dos usuários poderiam oferecer melhorias significativas nos sistemas de recomendação, tendo em vista que seu perfil seria mais completo e conciso, dado que certos tipos de interação nunca são as mesmas ao longo do acesso ao sistema, podendo variar de acordo com o seu humor ou tendências da sociedade (Adomavicius et al., 2011). Desta forma, quanto mais informações coletadas pelo sistema e mais atualizado for o seu perfil, mais precisa será a recomendação gerada para tal usuário.

Uma possível solução para se unificar os diferentes tipos de informação é a utilização de métodos de combinação (do inglês ensemble). Um método de combinação é responsável por combinar as previsões de diferentes algoritmos para se obter uma previsão final. O método mais básico de combinação é calcular a previsão final simplesmente como a média sobre todas as previsões no conjunto (Bar et al., 2013). Melhores resultados podem ser obtidos se a previsão final for determinada por uma combinação linear das previsões 
do conjunto. Neste caso, os pesos da combinação tem de ser determinados por algum procedimento de otimização, em geral, por regressões lineares ou logísticas, porém nem todos os métodos de combinação disponíveis são práticos para sistemas de recomendação em larga escala, pois a grande quantidade e variedade dos dados demanda um estudo mais aprofundado.

Sendo assim, a principal motivação para essa pesquisa é a utilização e combinação de diversos tipos de informações fornecidas pelos usuários, afim de tornar seu perfil mais preciso e favorecer a recomendação de conteúdo personalizada.

\subsection{Objetivos}

Este trabalho tem como objetivo principal o desenvolvimento de uma ferramenta de recomendação baseado em interações multimodais, que realiza a combinação de ranques produzidos com base nas interações unimodais dos usuários durante o acesso ao sistema. Tal ferramenta tem como objetivo fornecer recomendações mais precisas de acordo com os interesses dos usuários, e ao mesmo tempo, manter a escalabilidade do sistema utilizando algoritmos simples e com baixo custo computacional durante o processamento.

\subsection{Metodologia}

Diversos procedimentos orientaram a realização dessa pesquisa científica. Nessa seção são apresentadas as principais etapas, bem como as estratégias adotadas para que fosse possível a conclusão dessa dissertação.

A primeira etapa compreendeu a realização de uma revisão bibliográfica em livros, artigos e em entrevistas informais com alguns especialistas, no sentido de obter a fundamentação teórica necessária para essa pesquisa.

Na etapa seguinte, desenvolveram-se os protótipos das técnicas de combinação para a ferramenta, abrangendo todas as fases de desenvolvimento de um sistema, ou seja, as fases de levantamento dos requisitos, especificação, modelagem e descrição da ferramenta, codificação, prototipagem e implementação. Nesta fase também foi desenvolvido o módulo de avaliação que foi usado nas demais fases do projeto.

Durante a realização dessa pesquisa, dois estudos foram fundamentais para validação do modelo proposto. Os estudos foram conduzidos em diferentes bases de dados, baseados nos seguintes objetivos:

- Estudo 1: Teve como objetivo principal validar o modelo proposto na base de Dados do Het Rec LastFM $2 k$ (Cantador et al., 2011), que contém interações de etiquetas e 
histórico dos usuários. Para isso, foram conduzidos estudos de caso a fim de confrontar as técnicas desenvolvidas na ferramenta com elas mesmas e com os algoritmos existentes na literatura. Esse estudo foi conduzido a partir da análise off-line dos dados, sem a participação de usuários.

- Estudo 2: Foi utilizado para validação final da proposta com um número maior de interações do usuário. Os processos metodológicos conduzidos nesse segundo estudo envolvem o uso da base de dados do Het Rec MovieLens 2k (Cantador et al., 2011), também conduzido a partir da análise off-line dos dados.

Esses experimentos, detalhados no Capítulo 5, foram fundamentais para coleta e interpretação dos dados, a fim de avaliar o protótipo desenvolvido e verificar a viabilidade da hipótese que orienta essa pesquisa.

\subsection{Contribuições da Pesquisa}

As principais contribuições desse trabalho com relação a sistemas de recomendação são:

- A combinação de diferentes interações do usuário como fator importante para gerar recomendações;

- A possibilidade de integração mais rápida de novos usuários na comunidade, um problema relacionado a sistemas de recomendação pela filtragem colaborativa, onde o usuário precisa avaliar vários itens para começar a receber recomendações. Este trabalho apresenta um modelo que possibilita aos novos usuários na comunidade receberem recomendações a partir de qualquer tipo de interação que ele faça no sistema;

- A apresentação de uma ferramenta de recomendação baseado na multimodalidade de interações dos usuários, contendo três técnicas de combinação, integração com bibliotecas de recomendação, métodos de avaliação e testes estatísticos;

- A indicação de caminhos para aprofundamento de pesquisas com sistemas de recomendação utilizando diversos tipos de interação dos usuários;

- A publicação, até o momento, de três trabalhos apresentando as técnicas desenvolvidas;

- A apresentação dos resultados obtidos a partir de dois estudos que contribuíram para verificar a viabilidade da solução proposta para o problema apresentado, e que podem servir como base para a realização de novos estudos e trabalhos futuros. 


\subsection{Organização do Trabalho}

O Capítulo 2 abrange um referencial teórico da área de sistemas de recomendação, explicitando definições e embasamentos gerais necessários para o desenvolvimento do projeto. O terceiro capítulo trata da construção e manutenção do perfil de usuário em um sistema de recomendação, apresentando seus principais métodos de interação, ressaltando a obtenção, modelagem e combinação das informações fornecidas por eles. Os métodos de interação e combinação apresentados neste capítulo são de crucial importância para a obtenção de informações sobre o usuário e para a criação de um perfil representativo de suas preferências, que é o enfoque desta pesquisa. O Capítulo 4 apresenta as técnicas desenvolvidas que constituem a ferramenta de recomendação, como proposta solução, a fim de recomendar itens com base em diferentes tipos de interação do usuário. Os experimentos e a avaliação das técnicas propostas são apresentados no Capítulo 5, sendo que foram desenvolvidos dois Estudos objetivando validar o modelo, utilizando métricas de cobertura e precisão. Por fim, o último capítulo desta dissertação apresenta a conclusão e propostas para trabalhos futuros. 
Neste capítulo é feita uma introdução de sistemas de recomendação. Para isso, inicialmente é apresentada sua evolução no tempo através de pesquisas relevantes na área, suas técnicas principais para aplicação, bem como a identificação dos problemas mais comuns dos sistemas de recomendação.

\subsection{Contextualização}

Os sistemas de recomendação (SR) representam uma tecnologia que utiliza técnicas estatísticas e de aprendizado de máquina, com o objetivo de efetuar recomendações de itens a usuários, baseando-se em um histórico de atividades anteriores. Os SR tornaram-se uma importante área de investigação em meados da década de 90, tendo como primeiro sistema divulgado publicamente o Tapestry em 1992, que consistia na seleção de documentos de e-mail (Ricci et al., 2011).

A tarefa da recomendação pode ser vista como um problema de previsão: o sistema tenta prever a relevância de determinados itens a um usuário e depois ordena-os de acordo com os valores de relevância previstos. A importância de um item é normalmente representada por um valor numérico que reflete o grau de interesse previsto do usuário neste item. O resultado de um SR é normalmente um conjunto de itens ordenados de maneira decrescente pela importância prevista para um determinado usuário (Mobasher, 2007). 
Uma recomendação pode se basear nas preferências de um usuário ou pode ser dirigida a um grupo de usuários, no caso de uma sugestão feita a um amigo, ou para um público em geral. Para a pessoa que recebe a recomendação, ela funciona como um filtro ou uma visão particular de um universo de possibilidades geralmente inacessível. Ela pode levar em consideração também a preferência de quem está à procura de sugestões e não apenas de quem a faz. É possível até mesmo fazer recomendações baseadas nas opiniões de outras pessoas. Alguém que não é admirador do gênero jazz, por exemplo, pode recomendar discos deste gênero baseando-se no que seus amigos, que apreciam tal estilo, costumam ouvir. A recomendação ainda pode incluir explicações sobre como ela foi gerada para permitir que o seu recebedor a avalie.

A Figura 2.1 ilustra o modelo geral para o processo de recomendação apresentado por Terveen et al. (Terveen et al., 1997), com algumas adaptações.

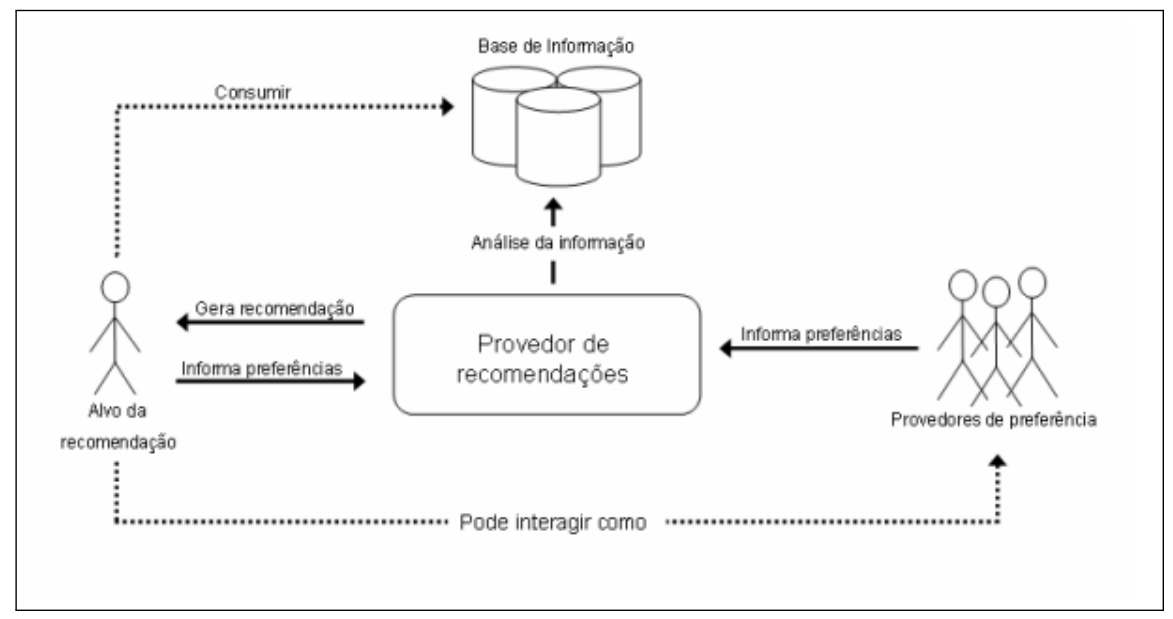

Figura 2.1: Modelo do processo de recomendação. (Traduzido de (Terveen et al., 1997))

Os elementos envolvidos no processo são:

- Alvo da recomendação: principal ator do processo e destinatário da recomendação. Ele pode apenas receber passivamente as sugestões ou pode fornecer também suas opiniões sobre os itens da base de informação.

- Base de informação: onde se encontra todo o universo de escolhas e onde o alvo da recomendação deseja encontrar a informação de seu interesse.

- Provedor de recomendações: agente que seleciona e recomenda os itens da base de informação que têm maior relevância para o alvo da recomendação. Para identificar quais são estes itens, o provedor pode se basear nas preferências informadas pelo próprio alvo da recomendação, nas preferências de outras pessoas e/ou no conteúdo dos itens. 
- Provedores de preferência: todo processo de recomendação está baseado em indicadores humanos de preferência. Assim, os provedores de preferência são tipicamente um conjunto de pessoas, cujas opiniões o provedor de recomendações pode se basear para fazer as sugestões.

São chamados de sistemas de recomendação os sistemas de informação que automatizam ou dão suporte computacional a alguma das partes do processo descrito acima. Eles podem assumir o papel do provedor de recomendações, fornecendo recomendações aos usuários baseadas em seus interesses e possivelmente levando em consideração também as opiniões de outros usuários. Neste caso, os sistemas de recomendação empregam técnicas de filtragem de informação e de inteligência computacional na realização das tarefas de sugestão.

Os SR fornecem suporte à criação e ao compartilhamento de recomendações e opiniões entre as pessoas (Terveen et al., 1997), tendo como objetivo facilitar o processo de comunicação das sugestões entre a própria comunidade de usuários do sistema.

\subsection{Técnicas de Filtragem Aplicadas a Sistemas de Re- comendação}

Tradicionalmente, os sistemas de recomendação empregam técnicas de filtragem de informação (FI) e aprendizado de máquina (AM) para gerar recomendações apropriadas aos interesses do usuário a partir da representação de seu perfil (Thakur et al., 2009). No entanto, outras técnicas, como Redes Neurais, Redes Bayesianas e Regras de Associação, também são utilizadas na filtragem dos itens de informação (Adomavicius et al., 2011).

O processo de filtragem de informação envolve a realização de duas atividades: encontrar as informações de que o usuário necessita (filtering in) e/ou eliminar as informações desnecessárias (filtering out). As três formas mais utilizadas de como essas atividades podem ser realizadas são:

- Filtragem Baseada em Conteúdo (FBC): seleciona a informação baseada no conteúdo dos elementos filtrados. Um filtro de mensagens eletrônicas que envie para a lixeira mensagens que contenham palavras indesejadas é um exemplo de filtragem baseada em conteúdo.

- Filtragem Colaborativa (FC): é baseada no relacionamento entre as pessoas e nos seus julgamentos subjetivos a respeito da informação a ser filtrada. Um exemplo simples é a seleção de mensagens eletrônicas com base na relação entre remetente e destinatários de uma mensagem. 
- Filtragem Híbrida (FH): consiste-se em combinar o método baseado em conteúdo e o baseado em filtragem colaborativa.

A recomendação baseada em conteúdo e a recomendação baseada em filtragem colaborativa apresentam alguns problemas inerentes (Ricci et al., 2011)(Adomavicius et al., 2011):

- Problemas em filtragem baseada em conteúdo:

- Usuário Novo: se o usuário é novo, ele não tem histórico de interações, logo não é possível computar uma recomendação baseada em suas escolhas prévias;

- Superespecialização: se um usuário costuma avaliar itens com as mesmas características, o sistema sempre recomenda itens semelhantes aos já avaliados, assim o usuário nunca é surpreendido com recomendações diferentes;

- Análise limitada pelo contexto: está relacionada às características (atributos) dos itens, as quais são utilizadas para diferenciá-los. As características são informadas manualmente ou coletadas automaticamente, o que pode ser mais difícil, pois alguns itens são objetos complexos. E ainda, se existem itens com características idênticas, não há como diferenciá-los.

- Problemas em filtragem colaborativa:

- Item Novo: se um item é novo, ele não foi avaliado por nenhum outro usuário, logo não pode ser utilizado na computação da recomendação;

- Usuário Novo: se um usuário é novo, ele não avaliou nenhum item, logo não pode ser utilizado na localização de usuários semelhantes;

- Esparsidade: usuários tendem a avaliar poucos itens (os registros das avaliações são esparsos nas tabelas de dados), o que traz dificuldades para localizar usuários semelhantes ou itens semelhantes, dependendo da abordagem de recomendação colaborativa. É através das avaliações que se computa o grau de semelhança entre usuários ou entre itens;

- Ovelha Negra: denominação atribuída àqueles usuários com gostos raros. Devido a isso, é difícil localizar usuários com preferências similares.

Por outro lado, esses métodos de filtragem têm as seguintes vantagens:

- A filtragem baseada em conteúdo não depende da avaliação feita por outros usuários, logo não há problemas em recomendar itens novos, itens pouco avaliados ou itens para usuários com preferências raras;

- A filtragem colaborativa contorna o problema da superespecialização e da análise limitada pelo contexto. 
Dessa maneira, a abordagem típica utilizada quando se tem uma grande e completa base de dados, é a utilização das duas formas de recomendação citadas numa abordagem híbrida. Assim, aproveitam-se as vantagens de ambos os métodos, e consegue-se contornar os problemas que ambos apresentam quando utilizados individualmente.

Este trabalho utiliza exclusivamente os métodos baseados em filtragem colaborativa, uma vez que tem como propósito gerar recomendações somente com base nas interações feitas pelos usuários durante sua navegação. A seção à seguir apresenta detalhadamente as principais características dessa técnica de recomendação.

\subsection{Recomendação Baseada em Filtragem Colaborativa}

A técnica de filtragem colaborativa realiza a recomendação de itens aos usuários, de acordo com avaliações feitas previamente por um grupo de usuários que possuem preferências similares às dele. Assim, a função de um sistema de filtragem colaborativa (SFC) é identificar usuários similares ao alvo da recomendação e sugerir itens que este grupo selecionado avaliou como relevantes e que ainda não tenham sido consumidos pelo usuário alvo (Ricci et al., 2011). O processo de sugestão está apoiado inteiramente na similaridade entre os usuários de sistema e não na similaridade dos itens de informação.

As bases de dados de sistemas de recomendação devem conter informações sobre o histórico de ações de seus usuários, como os itens que foram buscados, acessados, avaliados, comprados, entre outros. Estas interações servem como informações para o sistema que as analisam para fazer as recomendações e tais interações podem ser classificadas como explícitas ou implícitas. No primeiro caso, o usuário expressa diretamente o seu gosto, por exemplo, quando um usuário atribui uma nota a um determinado produto. Já no segundo caso, o usuário expressa indiretamente o seu gosto, como no caso de uma visualização de um produto. Os tipos de interações serão descritos com mais detalhes no Capítulo 3.

O objetivo principal dos SFC's é extrair o conhecimento coletivo existente nestas bases de dados através da detecção de padrões interessantes contidos nelas (Adomavicius et al., 2011). Desta forma, é possível classificar os itens de acordo com a percepção humana de qualidade, sendo esta uma tarefa complexa de ser realizada de forma algorítmica, sem interferência humana. Nos sistemas de filtragem colaborativa, os perfis dos usuários são armazenados em vetores de avaliações para os itens. Estes vetores tendem a aumentar continuamente à medida em que os usuários interagem com o sistema. Alguns sistemas levam em consideração dinâmicas temporais para amortizar os desvios no padrão de interesse dos usuários com o passar do tempo. As avaliações podem ser binárias, tais como positivo e negativo, ou valoradas de acordo com o nível de preferência. Dentre os sistemas 
mais conhecidos que utilizam esta abordagem, é possível citar o Netflix ${ }^{1}$, o MovieLens ${ }^{2}$ e a Amazon ${ }^{3}$.

Segundo Kajimoto et al. (Kajimoto et al., 2007), a Filtragem Colaborativa permite dois tipos de abordagens. A primeira determina recomendações baseadas em conteúdo consumido por usuários com o mesmo padrão de consumo do usuário atual (Figura 2.2). É utilizada principalmente em sistemas de comércio eletrônico, como Amazon e Submarino ${ }^{4}$. A segunda determina recomendações baseadas nas classificações realizadas por outros usuários dentro de um grupo restrito de conteúdo, ordenadas pela soma da relevância de tais classificações (sistema de votação com pesos) (Figura 2.3). É utilizada principalmente em sistemas de notícias, como o Digg ${ }^{5}$. Em geral, este tipo de abordagem oferece recomendações menos pessoais e mais dirigidas a um grupo determinado de usuários, restritos a um tema. Em contrapartida, sua implementação enfrenta menos problemas de escalabilidade e, no geral, é mais viável.

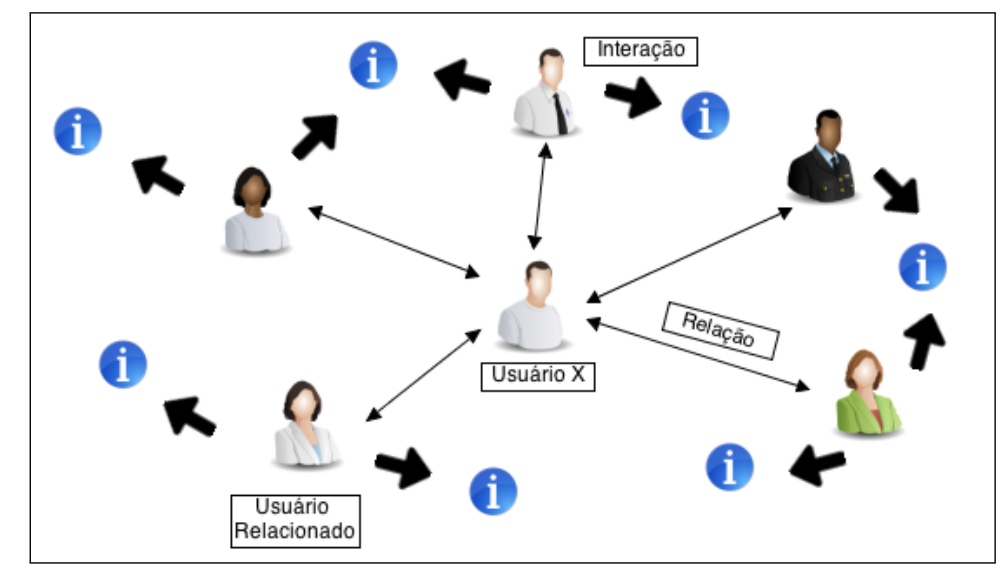

Figura 2.2: Primeira abordagem. (Adaptado de (Kajimoto et al., 2007))

Na busca por técnicas mais robustas, os sistemas de recomendação baseados em filtragem colaborativa procuram otimizar todo o cálculo e armazenamento necessário nos sistemas baseados em memória, criando um modelo em que o cálculo da recomendação seja mais rápido e escalável. Isto é importante devido à exigência de grandes sistemas, nos quais a recomendação é crucial para o negócio e para que ela seja apresentada ao usuário no momento da sua navegação (Koren et al., 2009). Desta maneira, surgiram as técnicas de Fatoração de Matrizes e Modelo de Vizinhança, que serão abordadas nas próximas subseções.

\footnotetext{
${ }^{1}$ http://www.netflix.com

${ }^{2}$ http://www.movielens.umn.edu

${ }^{3}$ http://www.amazon.com

${ }^{4}$ http://www.submarino.com.br/

${ }^{5}$ http://www.digg.com/
} 


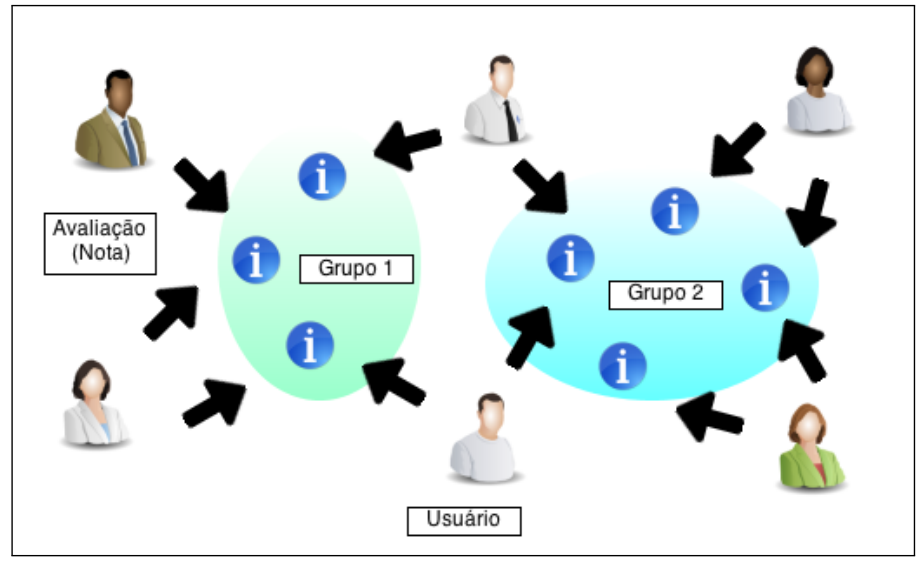

Figura 2.3: Segunda abordagem. (Adaptado (Kajimoto et al., 2007))

\subsubsection{Fatoração de Matrizes}

A Fatoração de Matrizes (FM) consiste em um modelo multiplicativo com vários fatores, tornando-se bastante adequado para aplicação em sistemas de recomendação já que estes possuem duas entidades de interesse: usuários e itens (Koren et al., 2009). Existem dois parâmetros recebidos pelo algoritmo, como mencionado anteriormente: as épocas de treinamento e os atributos latentes a serem aprendidos. Este modelo realiza a decomposição de uma matriz no espaço vetorial em duas matrizes no espaço de fatores latentes, além de mapear os usuários e itens para um espaço latente de dimensão $k$ e assim, as interações entre usuários e itens tornam-se produtos escalares neste espaço.

Como vantagem, a FM apresenta uma aprendizagem relativamente rápida, sendo que, uma vez ajustado e treinado o modelo, as predições podem ser feitas em tempo real, caso o valor de $k$ seja baixo. Entretanto, o modelo de Fatoração de Matrizes apresenta problemas como o relacionado ao novo usuário ou item, no qual o sistema não é capaz de realizar inferências para usuários ou itens sobre os quais ainda não se reuniram informações suficientes. Além disso, essa abordagem pode se tornar suscetível a sobreajuste (do Inglês overfitting) (Koren et al., 2009).

\subsubsection{Modelo de Vizinhança}

A técnica de Modelo de Vizinhança (do Inglês Neighborhood Models) procura estimar qualificações desconhecidas baseando-se no histórico de qualificações de usuários parecidos ou com algum tipo de relação (Töscher et al., 2008). Neste método é utilizada uma medida de similaridade entre itens, geralmente baseada no Coeficiente de Correlação de Pearson ou na distância do cosseno, ambas responsáveis por mensurar a tendência dos usuários em qualificar dois itens similarmente. 
Com a métrica de similaridade, são determinados os $k$ itens qualificados pelo usuário mais similares ao item $i$, a fim de se quer estimar a qualificação a qual este usuário daria a ele. O valor previsto é então dado por determinada média ponderada sobre as qualificações destes $k$ itens similares (vizinhança). Neste momento é feito o ajuste para os efeitos que devem ser considerados (Töscher et al., 2008).

Estes métodos são intuitivos e relativamente simples de serem implementados, podendo ser aplicados tanto para usuários como para itens.

\subsubsection{Algoritmos de Recomendação}

Em filtragem colaborativa, os algoritmos de recomendação seguem duas linhas, das quais uma tem por objetivo sugerir itens a um usuário e a outra predizer notas a esses itens. Essas abordagens costumam ser amplamente utilizadas, possibilitando aos sistemas efetuarem recomendações ao comparar as preferências de um usuário com grupos de outros usuários, e procurarem itens com características similares aos que o usuário já demonstrou interesse no passado.

Um ponto importante é que esses algoritmos somente são aplicáveis quando existe grande volume de dados nas bases envolvidas, sendo isso necessário para garantir que a metodologia seja eficiente, já que são feitas abstrações matemáticas e, quanto mais dados, mais apurada a função de abstração, e portanto, mais correto o resultado.

A construção das preferências do usuário nesses mecanismos pode ser feita através da captura de dados implícitos, explícitos ou ambos. A coleta de informações implícitas busca extrair dados sobre o usuário de forma automática, muitas vezes sem seu conhecimento enquanto ele utiliza o sistema. Já a coleta de informações explícitas consiste em utilizar os dados fornecidos manualmente pelo usuário sobre si ou sobre suas preferências, como no caso de uma avaliação feita através de notas atribuídas a itens que ele já consumiu. Os tipos de interação dos usuários em um sistema serão apresentados no próximo capítulo.

Geralmente, os dados implícitos são processados por algoritmos de recomendação de itens, enquanto os dados explícitos (referentes a avaliações envolvendo notas) são tratados por algoritmos de predição de notas. Particularmente neste trabalho, o conjunto de recomendadores utilizados foi restringido a um par de modelos disponíveis na literatura: o SVD ++ (Koren et al., 2009) (Predição de notas), e o BPR MF (Rendle et al., 2009) (Recomendação de itens). Estes modelos foram escolhidos porque oferecem bons resultados para os tipos de dados utilizados. 


\subsubsection{Notações}

Este trabalho utilizou as mesmas notações do trabalho de (Koren et al., 2009), onde foram utilizadas letras de índices especiais para distinguir: um usuário $u$; um item conhecido $i$; um item desconhecido $j$. A sigla $r_{u i}$ é utilizada para se referir a qualquer avaliação explícita ou implícita de um usuário $u$ para um item $i$. No primeiro caso, é um inteiro ou decimal fornecido pelo usuário que indica o quanto ele gostou do conteúdo; no segundo, é apenas um booleano que indica se o usuário consumiu ou visitou o conteúdo. A previsão do sistema sobre a preferência do usuário $u$ ao item $i$ é representada por $\hat{r}_{u i}$, que é um valor de ponto flutuante gerado pelo algoritmo recomendador. O conjunto de pares $(u, i)$ para o qual $r_{u i}$ é conhecido é representado por $K=\left\{(u, i) \mid r_{u i}\right.$ é conhecido $\}$.

Conjuntos adicionais utilizados neste trabalho são: $N(u)$ para indicar o conjunto de itens para os quais o usuário $u$ proporcionou um retorno implícito, e $\bar{N}(u)$ para indicar o conjunto de itens que são desconhecido para o usuário $u$.

Como os dados de avaliação são escassos, os modelos se tornam propensos a sobreajuste. Assim, para resolver este problema, a regularização é aplicada de modo em que as estimativas são reduzidas para os padrões da linha de base, na qual $\lambda_{1}, \lambda_{2}, \ldots$ são constantes usadas para regularização, definidas experimentalmente.

\subsubsection{SVD++}

Em sistemas de recomendação, uma questão importante é como integrar as diferentes formas de interações do usuário nos modelos, a fim de refletir com precisão suas preferências (Koren et al., 2009). Geralmente, os algoritmos utilizam apenas informação explícita, como notas atribuídas por usuários sobre itens que ele visitou. Um exemplo é o aplicativo do Netflix, que permite aos usuários escolher e atribuir uma determinada quantidade de estrelas aos filmes que já assistiu. O sistema, por sua vez, constrói e controla o perfil do usuário, considerando cada classificação em seus interesses pessoais.

Por outro lado, pode-se argumentar que se por algum motivo os usuários não fornecerem quaisquer anotações de suas preferências explicitamente, problemas como a partida fria e o novo usuário poderão surgir. Consequentemente, suas interações implícitas poderiam ser exploradas, já que esta é uma fonte mais abundante de informações, e reflete indiretamente a opinião do usuário (Ricci et al., 2011).

Em vista disto, Koren (Koren et al., 2009) desenvolveu um modelo que utiliza tanto interação implícita, quanto a interação explícita do usuário. O algoritmo proposto integra esses dois tipos, considerando as notas atribuídas por usuários sobre itens visitados e também, o histórico de navegação do indivíduo. Essa última informação foi simulada pelo 
autor, por estar ausente nos conjuntos de dados adotados durante o experimento. Logo, um item só é considerado como visitado caso um usuário tivesse atribuído uma nota à ele.

$\mathrm{O}$ algoritmo SVD++ integra as interações citadas anteriormente em um modelo de fatoração de matrizes que representa as preferências do usuário, no qual cada usuário $u$ está associado a um vetor de fatores de usuários representado por $p_{u} \in \mathbb{R}^{f}$, e cada item $i$ com um vetor de fatores de itens $q_{i} \in \mathbb{R}^{f}$ :

$$
\hat{r}_{u i}=b_{u i}+p_{u}^{T} q_{i},
$$

onde $b_{u i}$ é definido como $b_{u i}=\mu+b_{u}+b_{i}$ e indica as estimativas de diferenças de usuários e itens em comparação com a média global $\mu$. Todos os parâmetros são estimados através da função de minimização do erro quadrático:

$$
\begin{gathered}
\min _{p_{*}, q_{*}, b_{*}} \sum_{(u, i) \in K}\left(r_{u i}-\mu-b_{u}-b_{i}-p_{u}^{T} q_{i}\right)^{2} \\
+\lambda\left(b_{u}^{2}+b_{i}^{2}+\left\|p_{u}\right\|^{2}+\left\|q_{i}\right\|^{2}\right) .
\end{gathered}
$$

Com base na Equação 2.1, Koren estendeu este modelo básico, a fim de considerar a informação implícita. O autor usou um vetor de fatores adicionais $y_{i} \in \mathbb{R}^{f}$, e também o conjunto $N(u)$ que contém todos os itens que o usuário $u$ tem em seu histórico de navegação. Assim, o modelo SVD ++ é definido como:

$$
\hat{r}_{u i}=b_{u i}+q_{i}^{T}\left(p_{u}+|N(u)|^{-\frac{1}{2}} \sum_{j \in N(u)} y_{j}\right) .
$$

Desta forma, as preferências do usuário $u$ são representadas por uma combinação das informações explícita e implícita. O vetor de fatores de usuários $p_{u}$ é aprendido com as classificações explícitas, sendo este complementado pela soma de $y_{j}$, que representa a interação implícita. Mais uma vez, os parâmetros são definidos através da minimização da função erro quadrático associado através de gradiente, como mostrado no Algoritmo 1 (Koren et al., 2009), onde $\alpha$ é o taxa de aprendizagem.

Conforme descrito anteriormente, uma limitação do modelo SVD++ é que, embora ele combine as interações implícita e explícita dos usuários, o seu método de treino só funciona caso o usuário tiver fornecido notas aos itens (o conjunto $K$ ), o que nem sempre acontece, pois classificar itens demanda esforço por parte dos indivíduos. Sendo assim, o algoritmo não consegue processar itens que o usuário tenha apenas visualizado ou feito outro tipo de interação não relacionado a notas. Dado este problema, a seção a seguir apresenta o algoritmo BPR MF, que considera tanto itens positivos como itens negativos relacionados ao usuário. 
Entrada: Notas conhecidas $(u, i) \in K$

Saída: Parâmetros aprendidos $b_{u}, b_{i}, p_{u}, q_{i}, y_{i}$

para count $=1, \ldots$,\#Interações faça

para cada $(u, i) \in K$ faça

$\mid \begin{aligned} & \hat{r}_{u i} \leftarrow b_{u i}+q_{i}^{T}\left(p_{u}+|N(u)|^{-\frac{1}{2}} \sum_{j \in N(u)} y_{j}\right) ; \\ & e_{u i} \leftarrow r_{u i}-\hat{r}_{u i} ; \\ & b_{u} \leftarrow b_{u}+\alpha\left(e_{u i}-\lambda_{1} \cdot b_{u}\right) ; \\ & b_{i} \leftarrow b_{i}+\alpha\left(e_{u i}-\lambda_{2} \cdot b_{i}\right) ; \\ & p_{u} \leftarrow p_{u}+\alpha\left(e_{u i} q_{i}-\lambda_{3} \cdot p_{u}\right) ; \\ & q_{i} \leftarrow q_{i}+ \\ & \alpha\left(e_{u i}\left(p_{u}+|N(u)|^{-\frac{1}{2}} \sum_{j \in N(u)} y_{j}\right)-\lambda_{4} \cdot q_{i}\right) ;\end{aligned}$

para todo $j \in N(u)$ faça

fim

$y_{j} \leftarrow y_{j}+\alpha\left(e_{u i}|N(u)|^{-\frac{1}{2}} q_{i}-\lambda_{6} \cdot y_{j}\right)$

fim

fim

Algoritmo 1: Aprendizagem do SVD++ através do gradiente descendente.

\subsubsection{BPR MF}

A abordagem do algoritmo BPR MF (sigla do termo Bayesian Personalized Ranking with Matrix Factorization) (Rendle et al., 2009) consiste na construção de uma classificação personalizada de itens para um usuário somente de acordo com as suas interações implícitas (por exemplo, navegação, cliques, etc). Uma característica importante deste tipo de interação é que são conhecidas somente as observações positivas; os itens não observados/conhecidos por um usuário podem ser considerados uma interação negativa ou nula.

Neste cenário, Rendle et al. (Rendle et al., 2009) desenvolveram um modelo onde as entradas representadas pelos itens conhecidos por um usuário são positivas, e o restante são negativas. O modelo proposto forneceria então pesos positivos somente para os itens observados, e o restante dos elementos classificados com pontuação negativa. Neste último caso, os valores atribuídos aos itens não conhecidos não influenciariam na classificação, pois os pesos finais desses itens ficariam próximos de zero.

Considerando este problema, os autores propuseram um método genérico para os modelos de aprendizagem para o ranque personalizado (Rendle et al., 2009). Ao invés de treinar o modelo usando apenas os pares de usuário $\times$ item, eles também consideram a ordem relativa entre um par de itens, de acordo com as preferências do usuário. Infere-se que, se um item $i$ foi visto pelo usuário $u$, e $j$ não foi $\left(i \in N(u)\right.$ e $j \in \bar{N}(u)$ ), então $i>_{u} j$, o que significa que ele tem maior interesse em $i$ do que em $j$. A Figura 2.4 apresenta um exemplo deste método. É importante mencionar que quando $i$ e $j$ são desconhecidos, equivalentes, ou ambos conhecidos para um usuário, então é impossível inferir qualquer conclusão sobre a sua importância relativa. 


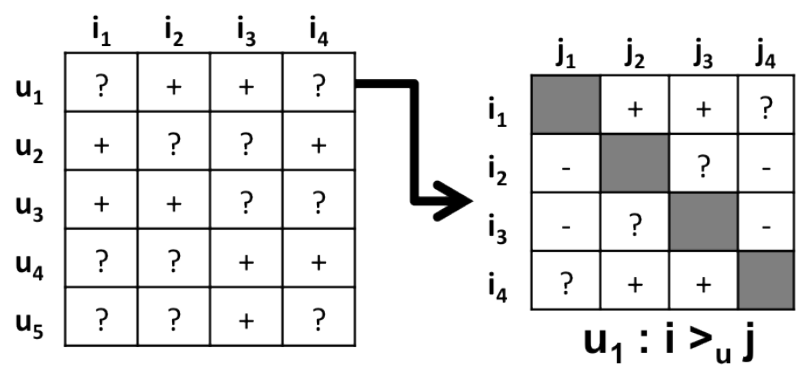

Figura 2.4: A matriz do lado esquerdo representa a dados observados $K$. A abordagem cria uma relação de pares específicas do usuário $i>_{u} j$ entre dois itens. $\mathrm{Na}$ matriz do lado direito, o sinal de mais indica que o usuário $u$ tem mais interesse no item $i$ de $j$; o sinal negativo indica que ele prefere artigo $j$ mais que $i$; e o ponto de interrogação indica que nenhuma conclusão pode ser inferida entre ambos os itens.

Para estimar se o usuário prefere um item a outro, os autores propuseram uma análise Bayesiana utilizando a função de similaridade $p\left(i_{u} j \mid \theta\right)$ e a probabilidade prévia para o parâmetro do modelo $p(\theta)$. O critério de otimização final, BPR-Opt, é definido pela Equação 2.4:

$$
\text { BPR-Opt }:=\sum_{(u, i, j) \in D_{K}} \ln \sigma\left(\hat{s}_{u i j}\right)-\Lambda_{\Theta}\|\Theta\|^{2},
$$

onde $\hat{s}_{u i j}:=\hat{r}_{u i}-\hat{r}_{u j}$ e $D_{K}=\{(u, i, j) \mid i \in N(u) \& j \in \bar{N}(u)\}$. $\Theta$ representa o parâmetro do modelo, $\Lambda_{\Theta}$ é uma constante de regularização e $\sigma$ é a função logística, definida como: $\sigma(x)=1 /\left(1+e^{-x}\right)$.

Para aprender o modelo, os autores também propuseram uma variação da técnica de gradiente estocástico, denominado LearnBPR, que escolhe aleatoriamente amostras de $D_{K}$ para ajustar $\Theta$. O Algoritmo 2 mostra uma visão geral deste, onde $\alpha$ é a taxa de aprendizagem.

\section{Entrada: $D_{K}$}

Saída: Parâmetros aprendidos $\Theta$

Inicializar $\Theta$ com valores aleatórios

para count $=1, \ldots$,\#Interações faça

Escreva $(u, i, j)$ em $D_{K}$

$$
\begin{aligned}
& \hat{s}_{u i j} \leftarrow \hat{r}_{u i}-\hat{r}_{u j} \\
& \Theta \leftarrow \Theta+\alpha\left(\frac{e^{-\hat{s}_{u i j}}}{1+e^{-\hat{s}_{u i j}}} \cdot \frac{\partial}{\partial \Theta} \hat{s}_{u i j}-\Lambda_{\Theta} \Theta\right)
\end{aligned}
$$

fim

Algoritmo 2: Aprendizagem através do Algoritmo LearnBPR.

Neste trabalho, a abordagem BPR considera a regra de predição $\hat{r}_{u i}$ como o modelo de fatoração simples definido na Equação 2.1. Desta forma, tem-se $\hat{s}_{u i j}:=\hat{r}_{u i}-\hat{r}_{u j}$, onde 
$\hat{r}_{u i}=b_{i}+p_{u} q_{i}$ e $\hat{r}_{u j}=b_{j}+p_{u} q_{j}$. A partir disso, são feitos os cálculos das derivadas parciais em relação a $\hat{s}_{u i j}$ :

$$
\frac{\partial}{\partial \Theta} \hat{s}_{u i j}= \begin{cases}1 & \text { if } \Theta=b_{i}, \\ -1 & \text { if } \Theta=b_{j}, \\ q_{i}-q_{j} & \text { se } \Theta=p_{u}, \\ p_{u} & \text { se } \Theta=q_{i}, \\ -p_{u} & \text { se } \Theta=q_{j}, \\ 0 & \text { caso contrário. }\end{cases}
$$

que é então aplicada ao Algoritmo 2 para aprender o conjunto de parâmetros $\Theta$.

\subsection{Pesquisas Relacionadas}

A popularização da Internet causou um impacto no número de páginas publicadas na rede. Por um lado, a quantidade de informações disponíveis configura uma imensa fonte de dados, por outro, a dificuldade encontrada pelos usuários na Web para localizar recursos que atendam aos seus interesses é um problema que os sistemas de recomendação vem tentando solucionar. Os sistemas de recomendação possuem, especificamente, dados de contexto, que são as informações que o sistema tem antes de iniciar o processo de recomendação; os dados de entrada, que são as informações que os usuários precisam comunicar ao sistema visando a geração das recomendações; e um algoritmo que combina os dados de contexto e os dados de entrada para produzir sugestões (Ricci et al., 2011). De uma forma geral, estes sistemas buscam adquirir opiniões ou preferências sobre itens de usuários, e usar estas opiniões para apresentar itens que possam ser de interesses de outros usuários. A partir desta descrição geral, nota-se que os sistemas de recomendação precisam de, basicamente, duas questões para poder funcionar de maneira apropriada: informações sobre as preferências dos usuários e um método para determinar se um item é relevante para um usuário.

Nos últimos anos, diversos trabalhos apresentaram propostas para sistemas de recomendação baseados no perfil de interesse do usuário, apesar de essa identificação não ser uma tarefa fácil. Afim de apresentar a evolução e uma revisão bibliográfica da área de sistemas de recomendação, a Tabela 2.1 apresenta as principais pesquisas relacionadas a perfil e interações de usuários que contribuíram para esta pesquisa, discutindo as características e oferecendo exemplos ao longo do tempo. 
Tabela 2.1: Pesquisas relevantes dos sistemas de recomendação.

\begin{tabular}{|c|c|c|}
\hline Tempo & Pesquisas marcantes e exemplos & Características \\
\hline 1992 & $\begin{array}{l}\text { Filtragem Colaborativa (Início); Pes- } \\
\text { quisa: Tapestry (Goldberg et al., } \\
\text { 1992) }\end{array}$ & $\begin{array}{l}\text { Usuários interagem com algoritmos } \\
\text { para receber recomendações; Reco- } \\
\text { mendação não personalizada. }\end{array}$ \\
\hline $1994-1997$ & $\begin{array}{l}\text { Pesquisas: GroupLens (Resnick et } \\
\text { al., 1994); Ringo/Firefly (Shardanand } \\
\text { e Maes, 1995); Sistemas de recomen- } \\
\text { dação (Resnick e Varian, 1997); Re- } \\
\text { des sociais (Kautz et al., 1997); Exem- } \\
\text { plos: Amazon.com (Compras) e Clas- } \\
\text { sMates(Rede Social) }\end{array}$ & $\begin{array}{l}\text { Sistemas utilizam dados históricos } \\
\text { de outros usuários para gerar as re- } \\
\text { comendações. Mas os dados não } \\
\text { são acessíveis aos usuários; Centra- } \\
\text { lização na busca por informação ou } \\
\text { venda de produtos; Recomendação } \\
\text { personalizada para cada usuário. }\end{array}$ \\
\hline $2000-2004$ & $\begin{array}{l}\text { Pesquisa: Sistemas de reputação } \\
\text { (Resnick et al., 2000); Recomenda- } \\
\text { ção baseada em etiquetas (Johansson, } \\
\text { 2003) Exemplo: Epinions.com }\end{array}$ & $\begin{array}{l}\text { Utilização da experiência do usuá- } \\
\text { rio na comunidade influenciando na } \\
\text { relevância da sua opinião, e essa } \\
\text { relevância utilizada para recomen- } \\
\text { dar informações; utilização de infor- } \\
\text { mações baseadas em comentários de } \\
\text { usuários. }\end{array}$ \\
\hline $2005-2007$ & $\begin{array}{l}\text { Pesquisas: Sistemas de combinação } \\
\text { social (Terveen e McDonald, 2005); Re- } \\
\text { des de confiança (Massa e Hayes, 2005); } \\
\text { Extração de semântica dos dados para } \\
\text { recomendação (Anand et al., 2007) } \\
\text { Exemplos: LastFM }{ }^{6} \text { e Del.icio.us }{ }^{7}\end{array}$ & $\begin{array}{l}\text { Construção de redes sociais; Utiliza- } \\
\text { ção da semântica dos dados; Usuá- } \\
\text { rios interagem com outros usuá- } \\
\text { rios; Conteúdo de interação utili- } \\
\text { zado para encontrar informação ou } \\
\text { conectar com pessoas; Informações } \\
\text { de outras pessoas expostas e atuali- } \\
\text { zadas em tempo real. }\end{array}$ \\
\hline $2008-2014$ & $\begin{array}{l}\text { Pesquisas: Fatoração de Matrizes } \\
\text { (Koren et al., 2009); Algoritmo base- } \\
\text { ado em modelo bayesiano (BPRMF) } \\
\text { (Rendle et al., 2009); Factorization } \\
\text { Machines (Rendle, 2012); Métodos de } \\
\text { combinação em SR (Ristoski et al., } \\
\text { 2014) Fatos: Prêmio Netflix; Combi- } \\
\text { nações de recomendadores; Ascensão } \\
\text { de redes sociais. }\end{array}$ & $\begin{array}{l}\text { Surgimento de vários algoritmos e } \\
\text { modelos de recomendação; Foco na } \\
\text { interação do usuário, com inter- } \\
\text { face simples, amigável e acessível; } \\
\text { Recomendação transparente, usuá- } \\
\text { rio tem controle das recomendações } \\
\text { que recebe; Fidelização de usuários } \\
\text { através de melhores recomendações; } \\
\text { Foco na vida social do usuário. }\end{array}$ \\
\hline Tendênicas & Exemplo: Google Now & $\begin{array}{l}\text { Explorar novos métodos de intera- } \\
\text { ção do usuário; Combinação de vá- } \\
\text { rios tipos de metadados de items } \\
\text { com vários tipos de interações de } \\
\text { usuários; Recomendação em contex- } \\
\text { tos específicos, como recomendação } \\
\text { em grupo. }\end{array}$ \\
\hline
\end{tabular}

Conforme observa-se nos trabalhos relacionados, a construção precisa do perfil do usuário é uma etapa muito importante em um processo de recomendação. Entretanto, a tarefa de informar características/preferências sobre determinados itens demanda um 
grande esforço por parte dos usuários. Além disso, a literatura apresenta poucas técnicas responsáveis por processar mais de um tipo de interação do usuário. Neste cenário, fica clara a necessidade em realizar uma modelagem do usuário de forma mais rápida e eficiente, de modo que exista a utilização de diferentes tipos de interação para gerar recomendações aos usuários.

\subsection{Considerações Finais}

Neste capítulo foram discutidos os principais conceitos envolvidos na área de sistemas de recomendação. Foram também discutidas as duas principais técnicas de filtragem mais amplamente empregadas nestes sistemas: filtragem baseada em conteúdo e filtragem colaborativa. Além disso, foi tratado também sobre como essas duas abordagens podem ser combinadas para superar limitações inerentes à utilização de uma delas isoladamente.

Em seguida, aprofundou-se a discussão sobre a recomendação baseada em filtragem colaborativa, apresentando trabalhos na área, traçando um panorama geral das técnicas mais utilizadas que foram subdivididas em KNN e fatoração de matrizes. Foram apresentados também alguns algoritmos de recomendação, entre eles os utilizados no desenvolvimento do trabalho.

Por fim, discutiram-se pesquisas e tendências relacionadas aos sistemas de recomendação, apresentando-se exemplos e revisões bibliográficas do assunto, destacando a importância do perfil do usuário no processo de geração de recomendações.

No entanto, é frequente nos sistemas de recomendação a necessidade de uma quantidade razoavelmente grande de avaliações no perfil antes de se tornarem capazes de gerar boas recomendações para o usuário. Além disso, existem poucas técnicas na literatura que exploram mais de um tipo de interação do usuário para gerar recomendação. Assim, torna-se importante a investigação de estratégias que possibilitem aprender sobre as preferências do usuário de maneira direta ou indireta. No próximo capítulo serão discutidas as principais formas de interação do usuário e como essas interações contribuem para a criação e manutenção do seu perfil de interesses. 


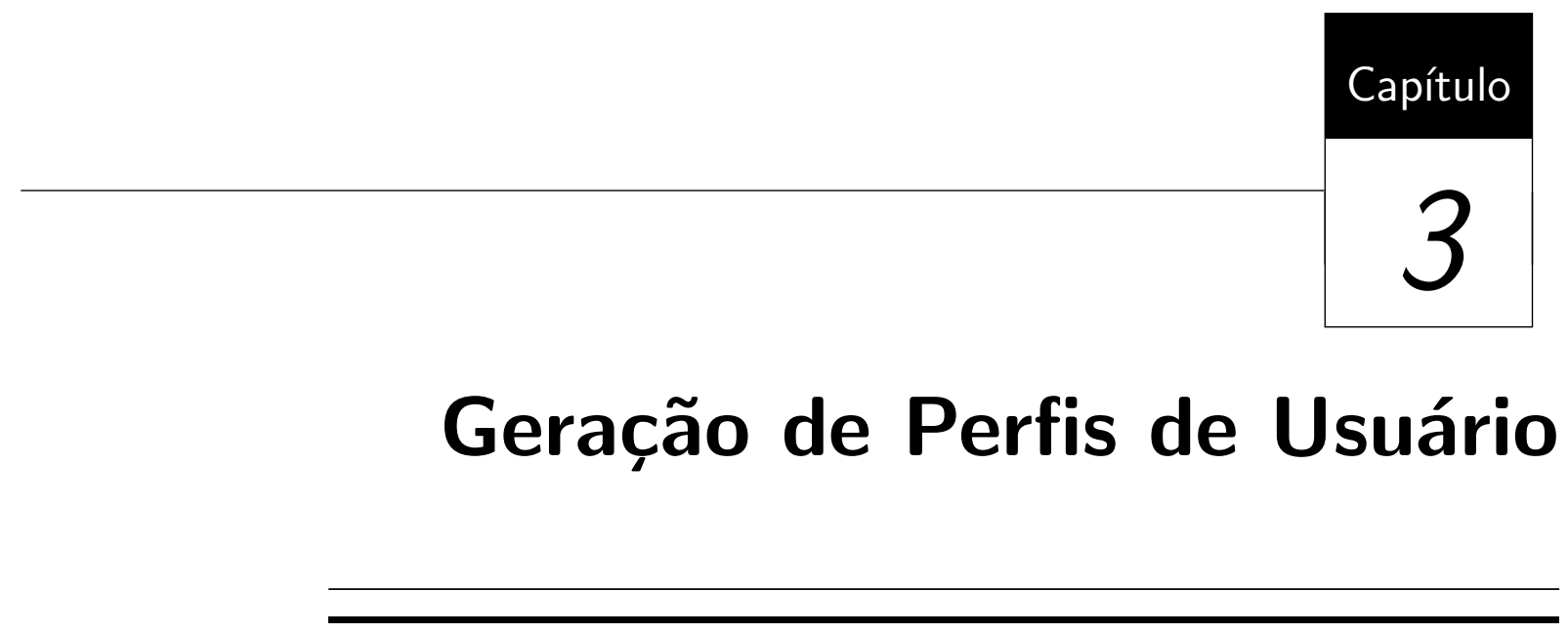

Nesse capítulo é apresentado como é feita a criação, modelagem e atualização dos perfis de usuários. São discutidos também os principais tipos de interação e os métodos de combinação que contribuem para que os sistemas de recomendação sejam capazes de sugerir itens relevantes para os usuários de acordo com seu perfil.

\subsection{Contextualização}

A estrutura de um sistema de recomendação consiste nas informações relacionadas a itens que o sistema tem antes de iniciar o processo de recomendação; nos dados de entrada que são as informações que os usuários precisam comunicar ao sistema, visando a geração das recomendações; e um algoritmo que combina os dados de contexto e os dados de entrada para produzir sugestões (Rein, 2005). De uma maneira geral, estes sistemas buscam adquirir opiniões ou preferências sobre itens de usuários, e usar estas opiniões para apresentar itens que possam ser de interesses de outros usuários. A partir desta descrição geral, nota-se que os sistemas de recomendação precisam de, basicamente, dois tipos de informação para poder funcionar de maneira apropriada: dados sobre as preferências dos usuários e um método para determinar se um item é relevante para seus interesses (Adomavicius et al., 2011). Normalmente, as preferências dos usuários compreendem informações externas como suas características pessoais (idade, sexo, localidade, etc.), seu histórico de navegação, e suas avaliações sobre os produtos. A forma para de- 
terminar se um item é interessante para um usuário ou não, depende do tipo de sistemas de recomendação.

Desta maneira, as técnicas de recomendação mais comuns podem ser agrupadas em três categorias distintas: baseada em conteúdo, colaborativa e a combinação de ambas. A abordagem baseada em conteúdo busca criar um perfil para cada usuário de forma a caracterizar sua natureza, porém essa estratégia demanda informações adicionais dos usuários e produtos que, muitas vezes, não estão disponíveis ou são difíceis de se coletar. Uma outra estratégia é a baseada no comportamento prévio dos usuários, sem a necessidade de se derivar um perfil para o mesmo. Neste caso, a abordagem se baseia apenas nas interações feitas pelo usuário e nas interações de usuários semelhantes à ele, não fazendo nenhuma simulação de preferências do usuário. As seções a seguir apresentam e detalham os métodos de geração e manutenção dos perfis dos usuários, apresentando os tipos de interação que contribuem para que os sistemas de recomendação sejam capazes de coletar as informações sobre o usuário, possibilitando assim, a sugestão de novos itens de acordo com seus interesses.

\subsection{Perfil do Usuário}

Para que seja possível recomendar produtos, serviços ou pessoas a um usuário, é necessário obter conhecimento sobre suas necessidades, preferências e afinidades. É essencial definir e identificar qual o tipo de informação será relevante para a geração de uma recomendação eficiente, para então capturar e armazenar as informações pessoais e comportamentais de um usuário. A definição do perfil e a coleta de informações são imprescindíveis para a geração de um recomendação mais concisa e aproximada das necessidades do indivíduo.

A formação eficiente da identidade virtual de um usuário necessita da correta definição de sua identidade interna (noção internalizada do "eu") e sua identidade social (versão projetada da internalização do "eu"). No mundo virtual, a identidade interna do usuário é definida por ele próprio, similar ao mundo real (algumas vezes também é descoberta através de técnicas de aprendizado de máquina). Enquanto a identidade social é definida pelos outros membros do mundo virtual. A identidade interna e a social são armazenadas no perfil do usuário (Cazella et al., 2009).

Perfis de usuários refletem o interesse deste em relação a vários assuntos, em um momento em particular. Cada termo que um perfil expressa é, em um certo grau, características de um usuário particular (Poo et al., 2003), incluindo todas as informações diretamente solicitadas a ele e aprendidas implicitamente durante sua interação na $W e b$. O perfil do usuário pode ser visto também como uma base de dados, onde a informação 
sobre uma pessoa, incluindo seus interesses e preferências, são armazenados e podem ser dinamicamente mantidos (Rousseau et al., 2006).

Atualmente existem diversos tipos de perfis de usuário na Internet e em sistemas off-line com diferentes graus de complexidade, sendo eles desenvolvidos nos mais variados contextos, como e-commerce, e-learning e e-community. Um dos primeiros trabalhos de modelagem de perfil de usuário foi o de Paiva e Self (Paiva e Self, 1995), que desenvolveram um modelo de usuário chamado TAGUS, com a finalidade de uma modelagem mais adequada dos alunos para atividades de aprendizado. Considerando ainda definições de modelo de usuário, Heckmann e Krueger (Heckmann e Krueger, 2003) propuseram uma Ontologia de um Modelo de usuário Geral (GUMO). O GUMO é um modelo ubíquo de modelo de usuário, incluindo muitos aspectos básicos deste, partindo desde a informação de contato, aspectos demográficos, habilidades fisio e psicológicas, estado emocional, estado mental e nutrição. A Ontologia de Heckmann e Krueger é muito rica e pode ser implementada de acordo com o interesse do projetista. A Figura 3.1 apresenta as dimensões básicas propostas por Heckmann e Krueger no GUMO.

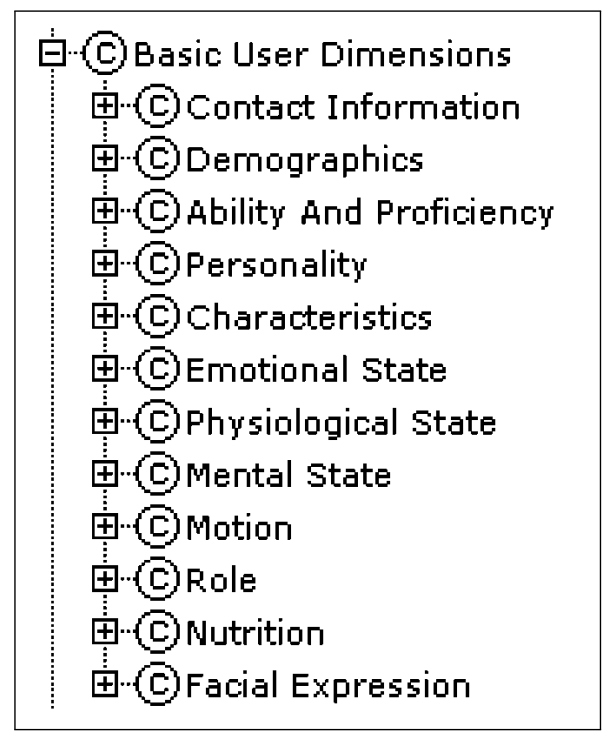

Figura 3.1: Modelo representativo GUMO (Heckmann e Krueger, 2003)

Kobsa (Kobsa, 2007) desenvolveu uma modelagem genérica de usuário, uma das mais reputadas, utilizada como um modelo para a criação de categorias de informação sobre o usuário, objetivando personalizar as aplicações Web. Para gerar as recomendações e personalizar o ambiente ao usuário, os sistemas de recomendação necessitam da identidade interna do indivíduo que é definida pelo seu perfil. Porém, é necessária também a identidade social que é definida pela reputação do usuário, como se apresenta a seguir. 


\subsubsection{Reputação}

A reputação de um usuário em um sistema de recomendação é definida como a coleção de informações recebidas sobre o comportamento efetuado pelos participantes de uma comunidade (Cazella et al., 2009). A reputação geralmente auxilia as pessoas a escolherem parceiros, produtos e serviços na Web. Nas redes sociais, por exemplo, os usuários encorajam os comportamentos confiáveis, discriminando a participação de pessoas desabilitadas moralmente ou desonestas. Segundo Rein (Rein, 2005), a reputação pode ser também definida como um completo sistema de informações sobre a confiança do usuário, que inclui todos os aspectos de um modelo de referência. Esse modelo de referência é baseado em dez aspectos determinantes: conhecimento, experiência, credenciais, endosso, contribuidor, conexões, sinais, feedback, contexto e valores sociais, como ilustrado na Figura 3.2 .

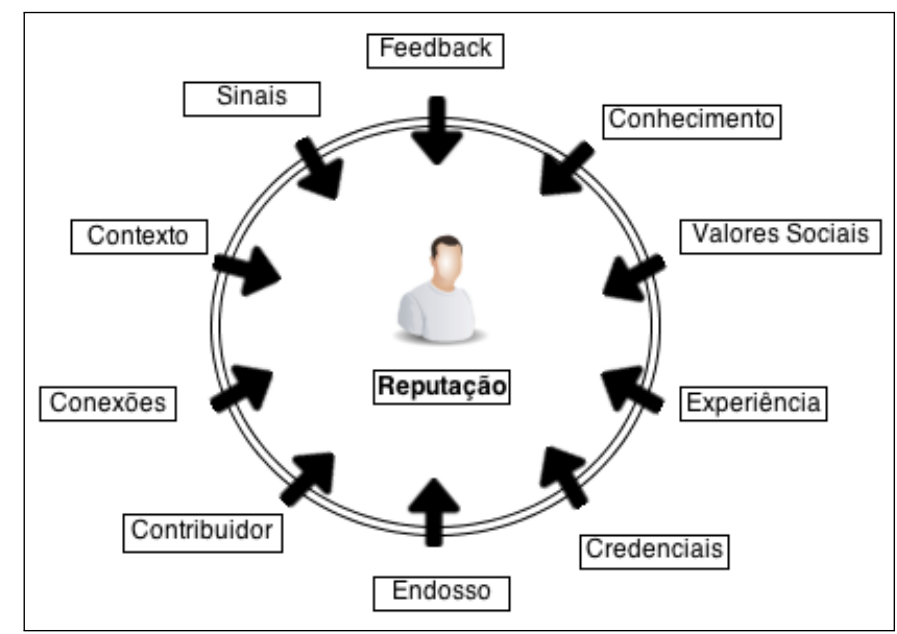

Figura 3.2: Visão estrutural dos dez determinantes da Reputação de Rein, adaptado de (Rein, 2005)

A visão estrutural de Rein descreve as funcionalidades e comportamentos essenciais do ser humano que são desejáveis e efetivos, para possivelmente ser representado através de uma reputação explícita e fácil de ser medida no usuário.

A reputação é geralmente aplicada para gerenciar o comportamento do usuário durante um processo comercial envolvendo compra e venda de produtos e/ou serviços, e também durante processos sociais como combinações em comunidades virtuais e redes sociais. Em processos comerciais, como no eBay ${ }^{1}$ e Mercado Livre ${ }^{2}$, um consumidor compra um certo produto de alguém e em seguida, opcionalmente, ele pode deixar uma avaliação ou comentário a respeito do produto comprado e/ou do comportamento do vendedor durante

\footnotetext{
${ }^{1}$ www.ebay.com

${ }^{2}$ www.mercadolivre.com.br
} 
o processo de venda. Em contraste, em situações de redes sociais como Twitter ${ }^{3}$, LinkedIn $^{4}$ e Facebook ${ }^{5}$, usuários são membros de comunidades ou grupos virtuais, onde são capazes de coletar, gerenciar e promover reputações de usuários entre seus clientes e contatos da comunidade ou rede. Isto é, usuários (prestadores de serviço) que têm perfil na rede de reputação, que é também uma rede social, podem ser marcados e ranqueados pelos seus clientes e/ou contatos. Usuários podem ser encontrados através de marcações em e-mail ou, também, alguém pode encontrar um contato de um prestador de serviço simplesmente procurando em tags na própria rede de reputação.

Pode-se considerar a reputação como uma extensão de um perfil de usuário (Cazella et al., 2009). Ela utiliza o mesmo tipo de informação armazenada, porém o conjunto de outra pessoa (amigo, cliente do usuário, entre outros). Neste caso, a identidade é determinada pelos traços de personalidade do usuário informados por ele mesmo para seu perfil, e informados por uma outra pessoa para determinar sua reputação. Dessa maneira, o perfil pode prever necessidades e comportamentos em um ambiente computacional, enquanto a sua reputação permite a criação de relações de confiança entre membros de uma sociedade em um ambiente computacional.

\subsubsection{Geração e Manutenção do Perfil do Usuário}

A personalização de um sistema requer que se possa identificar o usuário no momento em que este acessa o sistema. Na Web, duas das maneiras mais habituais de identificação de usuário são:

- Identificação no servidor: normalmente disponibiliza ao usuário uma área de cadastro com informações pessoais, tais como: nome, data de nascimento, sexo, endereço e outros. Além disso, solicita obrigatoriamente um login e senha. Estas informações ficam armazenadas em um banco de dados no servidor. Sempre que o usuário acessar o sistema, ele poderá fazer sua identificação/autenticação informando seu login anteriormente cadastrado. Este mecanismo permite que o sistema identifique com mais precisão o usuário que nele se conecta.

- Identificação no cliente: utiliza normalmente cookies, um mecanismo pelo qual o sistema consegue identificar que determinado computador está se conectando novamente a ele. Este método assume que a máquina conectada é utilizada sempre pela mesma pessoa. Logo, ao identificar a máquina, o sistema está na realidade identificando seu usuário. Trata-se de um mecanismo mais simples do que a identi-

\footnotetext{
${ }^{3}$ www.twitter.com.br

${ }^{4}$ www.likedin.com.bt

${ }^{5}$ www.facebook.com.br
} 
ficação através do servidor, porém menos confiável, principalmente se o computador identificado for utilizado por mais de uma pessoa.

Depois de identificado o usuário, é possível coletar dados sobre este de forma implícita ou explícita, permitindo, desta maneira, a geração e manutenção de seu perfil. Na modalidade de coleta explícita, o usuário indica espontaneamente o que é de seu interesse. Na modalidade implícita, através de ações do usuário inferem-se informações sobre suas necessidades e preferências. Por exemplo, armazenando-se dados de navegação (páginas consultadas, produtos visualizados e outros) é possível detectar que ele se interessa por determinados assuntos. Através desta técnica, é possível conhecer melhor as suas preferências sem que eles tenham que fornecer informações explicitamente, e em seguida utilizar estes dados para fazer recomendações.

\subsection{Tipos de Interação}

A seguir, são discutidos os tipos de interações unimodais dos usuários abordados por este trabalho para gerar recomendação de itens baseado em seus perfis de interesse.

\subsubsection{Etiquetagem Social}

Os sistemas de Etiquetagem Social (do Inglês Social Tagging), têm crescido em popularidade na Web nos últimos anos por conta de sua simplicidade para categorizar e recuperar o conteúdo usando etiquetas (do Inglês tags). O crescente número de usuários que fornecem informações sobre si mesmos por meio de atividades de etiquetagem, é consequência do surgimento de abordagens de perfis baseados em marcação (Musto et al., 2009), os quais assumem que os usuários expõem suas preferências por determinados conteúdos através de interações utilizando etiquetas.

As etiquetas fornecidas pelos usuários, em geral, são uma forma de interação que expressa preferências e interesses dos usuários e que auxiliam significativamente os sistemas de recomendação em retornar os itens mais relevantes para aquele usuário. Com a introdução de etiquetagem social, a relação binária habitual entre usuários e itens, que é largamente explorada por SR tradicionais, transforma-se em uma relação ternária entre usuários, itens e etiquetas.

A qualidade das etiquetas pode afetar diretamente o desempenho da recomendação. Quando utilizadas colaborativamente, a etiquetagem social pode representar as preferências de um grupo de usuários; porém é suscetível a problemas, tais como a dispersão (os usuários tendem a fornecer um número limitado de etiquetas, polissemia (etiquetas são sujeitas a múltiplas interpretações), ou idiossincrasia (etiquetas usadas para fins de 
organização pessoal como "ler", por exemplo). Todos esses problemas podem prejudicar a qualidade das recomendações e geralmente são causados pela maneira pela qual as etiquetas são capturadas e manipuladas (Zhang et al., 2010). Apesar de conterem um valor semântico, as etiquetas podem também ser utilizadas como interações implícitas, de maneira que leva-se em consideração somente se o usuário atribuiu uma etiqueta a determinado item ou não. Nesta abordagem considera-se apenas o esforço do usuário de fornecer informações a determinado item, não sendo necessário um processamento linguístico, como análise de sentimento, para a recomendação.

Dentre os principais métodos de aquisição de etiquetas, tem-se:

- Etiquetas especialistas (Tagging Expert): esta abordagem depende de um pequeno número de especialistas, que irão associar palavras aos itens, usando, principalmente, vocabulários estruturados. Nesse método, geralmente os especialistas fornecem etiquetas objetivas e que abrangem múltiplos aspectos daquele item. Pandora $^{6}$ é um exemplo relevante de um sistema que utiliza especialistas para associarem palavras-chave a músicas. A principal vantagem da utilização de especialistas é a coerência do vocabulário gerado. Por outro lado, existe o custo de trabalho manual, o que é simultaneamente demorado e caro.

- Etiquetas com base em jogos: é uma ideia inovadora, que iniciou-se com o ESPGame $^{7}$, para utilizar os usuários em jogos de classificação de itens. No caso do ESPGame, dois jogadores observam simultaneamente a mesma imagem e o jogo pede para ambos entrarem com palavras-chave até que ambos entrem com a mesma palavra. Depois do sucesso da ESPGame, apareceram vários outros (por exemplo, ListenGame $^{8}$ ) no domínio da música. Através da parceria de duas ou mais pessoas, o conjunto resultante de marcações tem o potencial de ser muito preciso. O problema desse método é que os jogadores, optando por maior pontuação, podem sacrificar a qualidade de etiquetas. Por exemplo, podem introduzir marcações mais gerais no lugar de palavras mais específicas, apenas para aumentar a probabilidade de ganhar um número maior de pontos em uma partida.

- Etiquetas baseadas em conteúdo: artifícios como endereços de um recurso (do Inglês Uniform Resource Locator - URL), trilhas sonoras, comentários, etc., possuem um conteúdo rico. Por meio da coleta dessas informações e convertendo esses dados em uma representação adequada, as etiquetas podem ser geradas através de algoritmos de mineração de dados. A vantagem de se utilizar marcações baseadas

\footnotetext{
${ }^{6} \mathrm{http}: / /$ www.pandora.com/

${ }^{7}$ http://www.gwap.com/gwap/gamesPreview/

${ }^{8}$ http://www.listengame.org/
} 
em conteúdo é que nenhum usuário necessita estar diretamente envolvido durante o processo de aquisição de etiquetas. As desvantagens são que essas palavras-chave podem conter ruídos, seu cálculo é intensivo, e os usuários são obrigados a concordar com as etiquetas geradas pelos algoritmos.

Na Tabela 3.1, são apresentadas as principais vantagens e desvantagens das abordagens descritas. Embora a etiquetagem social seja propensa a idiossincrasia, dispersão e problemas de partida fria, a qualidade de etiquetas geralmente melhora com um grande número de usuários. Além disso, novos sistemas, bem como os que utilizam métodos como os jogos de anotação, representam um paradigma de computação com um enorme potencial para resolver os problemas de sistemas baseados em conteúdo para aquisição de etiquetas. Entretanto, ao contrário de computadores, os usuários necessitam de algum incentivo para participar da "computação coletiva" e alimentar esses sistemas.

Tabela 3.1: Caracterização dos métodos de aquisição de marcações.

\begin{tabular}{|c|l|l|}
\hline Método & Vantagens & Desvantagens \\
\hline Etiquetagem Social & $\begin{array}{l}\text { Escalável, Preferências ge- } \\
\text { rais de grupos de usuários }\end{array}$ & $\begin{array}{l}\text { Idiossincrasia, Polisse- } \\
\text { mia, Arranque frio }\end{array}$ \\
\hline Experts & Etiquetas Precisas & $\begin{array}{l}\text { Não escalável, Processo } \\
\text { Manual }\end{array}$ \\
\hline Jogos & $\begin{array}{l}\text { Preferências gerais de gru- } \\
\text { pos de usuários, Potencial- } \\
\text { mente escalável }\end{array}$ & $\begin{array}{l}\text { Arranque frio, Propensa a } \\
\text { manipulação }\end{array}$ \\
\hline Mineração de dados & $\begin{array}{l}\text { Automação, Evita o arran- } \\
\text { que frio }\end{array}$ & $\begin{array}{l}\text { Ruídos, computacional- } \\
\text { mente caro }\end{array}$ \\
\hline
\end{tabular}

Durao et al. (Durao e Dolog, 2010), desenvolveram um sistema de recomendação baseado em etiquetagem multi-fatorial, composto por fatores lexicais e relevâncias de palavras-chave buscadas por usuários para o cálculo da similaridade. Shepitsen et al. (Shepitsen et al., 2008) propuseram um sistema de recomendação personalizado usando agrupamento hierárquico. Nesta abordagem, os autores utilizam um pré-processamento nas marcações pesquisadas pelos usuários e no agrupamento de etiquetas da base de dados para gerar uma recomendação personalizada. Zhang et al. (Zhang et al., 2010) tiveram como objetivo no seu trabalho integrar a difusão em gráficos tripartidos usuário $\times$ item $\times$ marcações, para melhorar a recomendação de técnicas do estado da arte.

\subsubsection{Feedback dos Usuários}

Todos os sistemas de recomendação, exigem um modelo baseado nos interesses dos usuários a fim de poderem gerar uma lista de itens relevantes de maneira mais precisa. Uma 
abordagem comum para a construção de um modelo é através do feedback do usuário, explícita ou implicitamente. Feedback explícito, como escalas de avaliação, formulários de identificação e comentários, fornecem aos usuários um mecanismo para expressar de forma inequívoca os seus interesses em itens. Por outro lado, o feedback implícito é gerado pelo próprio SR, através de inferências que o mesmo faz sobre o comportamento do usuário. O que constitui o feedback implícito depende do domínio da aplicação: normalmente, ele será um ou vários parâmetros observáveis e mensuráveis, que surgem das interações do usuário com o SR. A maioria das pesquisas em SR concentrou-se em usar um ou o outro tipo de feedback, poucas pesquisas até o momento combinaram vários tipos de feedbacks ao mesmo tempo.

A fim de desenvolver um sistema de recomendação eficaz e eficiente, preferências de usuários precisam ser conhecidas e trabalhadas com técnicas de aprendizado de máquina. No entanto, é difícil obter uma relação suficiente e representativa de uma população de usuários. A dificuldade de se obter feedback explícito pode ser parcialmente explicada pelo esforço cognitivo que essa tarefa requer, além de outros fatores, como a falta de incetivo ao usuário em responder formulários ou avaliações. Por outro lado, o feedback implícito é abundante. Em termos de modelagem de interesses dos usuários, é geralmente aceito que o feedback explícito seja mais preciso que o feedback implícito (Amatriain et al., 2009). Uma possível razão para isso é que as informações explícitas possuem ferramentas de domínios independentes, são objetivas, estruturadas e bem definidas. Como exemplo, pode-se citar a escala de Likert ${ }^{9}$. Em contraste, um sistema de feedback implícito baseia-se na aplicação de ferramentas de domínio dependentes e metodologias para capturar e interpretar informações implícitas dos usuários. Normalmente, o sistema irá observar as ações do usuário e fazer inferências sobre seus interesses com base nessas ações. Por exemplo, em um sistema de recomendação de música como o Last $F M^{10}$, se um usuário ouve uma trilha 5 vezes, o sistema pode inferir que o usuário tem interesse em músicas daquele artista.

Há semelhanças e diferenças entre estes dois tipos de feedback, como pode-se ver na Tabela 3.2. Ambos sofrem de ruído (Anand et al., 2007), e são sensíveis ao contexto do usuário, embora não no mesmo grau. Em termos de diferenças, feedback explícito é escasso enquanto o feedback implícito é abundante. A informação explícita é geralmente mais precisa do que a informação implícita na representação dos interesses do usuário (embora este é dependente do domínio e da aplicação RS). Além disso, o feedback explícito pode ser positivo ou negativo, ao contrário do feedback implícito, que é apenas positivo. Além

\footnotetext{
${ }^{9} \mathrm{~A}$ escala Likert ou escala de Likert, é um tipo de escala de resposta psicométrica usada habitualmente em questionários, e é a escala mais usada em pesquisas de opinião. Ao responderem um questionário baseado nesta escala, os perguntados especificam seu nível de concordância com uma afirmação. Esta escala de Likert tem esse nome devido à publicação de um relatório e questionários explicando seu uso, por Rensis Likert.

${ }^{10} \mathrm{http}: / /$ www.lastfm.com.br/
} 
disso, o feedback explícito tende a concentrar-se em ambos os lados da escala de avaliação, já que os usuários são mais propensos a expressar suas preferências, de modo que esta seja totalmente a favor ou contra um item (Amatriain et al., 2009).

Tabela 3.2: Características de feedback explícito e implícito.

\begin{tabular}{|l|l|l|}
\hline & Feedback Explícito & Feedback Implícito \\
\hline Acurácia & Alta & Baixa \\
\hline Abundância & Baixa & Alta \\
\hline Sensível ao Contexto & Sim & Sim \\
\hline $\begin{array}{l}\text { Expressividade de preferên- } \\
\text { cia do usuário }\end{array}$ & Positiva e Negativa & Positiva \\
\hline Referência de medição & Absoluta & Relativa \\
\hline
\end{tabular}

O objetivo de um sistema de recomendação é auxiliar os usuários a encontrarem objetos de informação desejáveis. Essa tarefa combina inferência e previsão, e as Figuras 3.3(a) e 3.3(b) mostram estratégias alternativas para realizar isso. A Figura 3.3(a) mostra uma estratégia em que a fase de inferência pretende produzir classificações similares aos que um usuário teria atribuído a um item, e depois a fase de predição utiliza as médias estimadas para prever futuras classificações. Já a Figura 3.3(b) mostra uma estratégia alternativa em que as observações anteriores são utilizadas para prever o comportamento do usuário em resposta à informação nova, e em seguida, a fase de inferência procura estimar o valor da informação com base no comportamento previsto.

Em um sistema de recomendação, a estratégia mostrada na Figura 3.3(a) iria caracterizar cada item, usando as avaliações relatadas por outros usuários, enquanto que a estratégia mostrada na Figura 3.3(b) iria caracterizar cada item, utilizando as classificações previstas, baseadas em interações do próprio usuário ou de um grupo com características semelhantes a esse usuário. Os sistemas de recomendação, com base na segunda estratégia, podem ser mais flexíveis já que os usuários participantes podem desenhar diferentes inferências a partir das mesmas observações, caso estes não compartilhem um conjunto comum de objetivos. Por outro lado, sistemas de recomendação relacionados à primeira estratégia teriam, provavelmente, mais contexto disponível localmente para interpretação das observações que estariam disponíveis em outros pontos da rede. Assim, poderia valer a pena considerar abordagens híbridas em que alguma interpretação preliminar é realizada localmente quando a observação é feita e, em seguida, inferências adicionais são atraídas para outros pontos da rede.

No feedback implícito, a informação é inferida a partir do comportamento do usuário, sem necessariamente ter sido informado que tal atividade será usada como feedback. Portanto, o usuário não está avaliando a relevância pelo sistema, mas está apenas satisfazendo às suas necessidades. Comportamentos como a seleção de um item, a repetição de acesso 


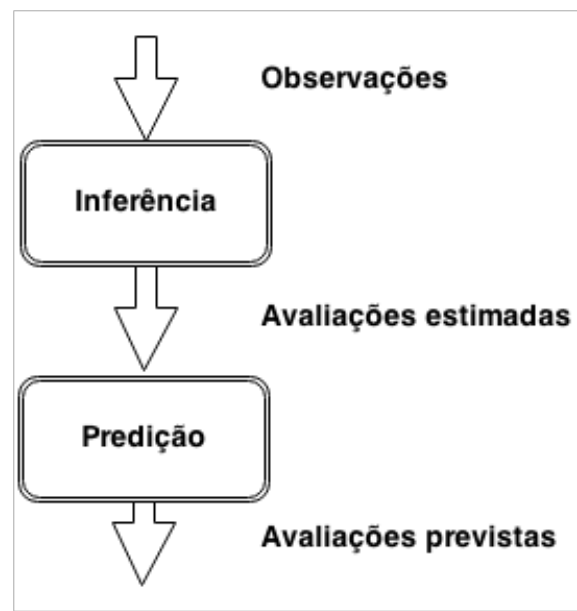

(a) Estratégia de estimação classificação.

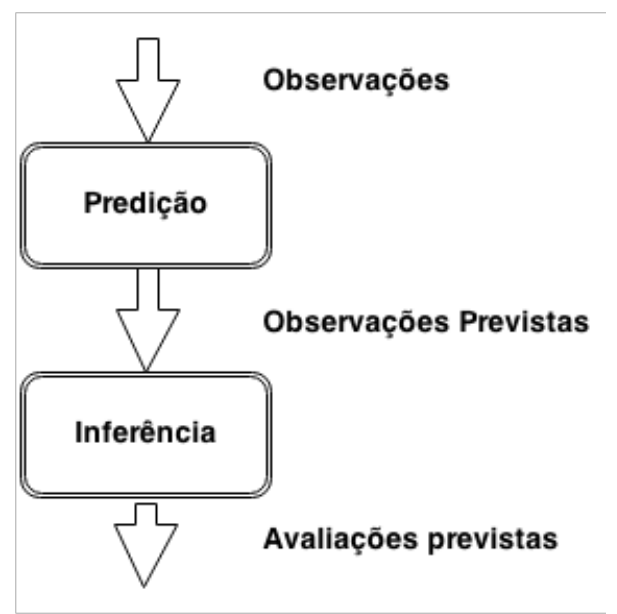

(b) Estratégia de predição de observações.

Figura 3.3: Estratégias de recomendação.

a um item, ou o ato de salvar este, tornam-se informações relevantes que podem gerar um perfil mais concreto do usuário do que quando utilizam-se as informações explícitas como, por exemplo, notas de avaliação (Peska e Vojtas, 2013).

Existem diversos trabalhos que focam nos feedbacks dos usuários. Um exemplo interessante é o trabalho de Jawasher et al. (Jawaheer et al., 2010), no qual são analisadas as características de feedback do usuário implícito e explícito no contexto do serviço de música Last FM. Os autores também relatam alguns experimentos usando técnicas de filtragem colaborativa padrão em dados implícitos e explícitos; no entanto, seus resultados não são conclusivos devido a limitações no conjunto de dados. Em particular, deve-se notar que o serviço de músicas Last FM utiliza apenas a realimentação explícita disponível nos perfis dos artistas e dos usuários deste serviço, e que esta realimentação é limitada a categorias binárias (gostei/ não gostei). Estes dados são muito escassos e, como relatam os autores, quase inexistentes para alguns utilizadores ou artistas.

Recentemente Peskas e Vojtas (Peska e Vojtas, 2013) realizaram vários experimentos off-line com dados reais de usuários de um site de agência de viagens, confirmando que o tratamento de feedback implícito negativo, como o fato de um usuário não acessar um item, pode melhorar significativamente a qualidade da recomendação. Manzato (Manzato, 2013) propôs um algoritmo denominado "gSVD ++", que explora o feedback implícito de usuários por considerar não só o espaço latente de fatores que descrevem o utilizador e produto, mas também os metadados disponíveis associados ao conteúdo. Estas descrições são uma fonte importante para a construção de um perfil de usuário que contém informações relevantes e significativas sobre suas preferências. Recentemente Manzato et al. estenderam essa 
técnica para considerar tanto itens conhecidos como itens desconhecidos pelos usuários, denominando a mesma de "BPR gSVD++" (Manzato et al., 2014).

\subsubsection{Interações Multimodais}

Dados os problemas citados na seção anterior, começaram a ser desenvolvidos estudos na área de interações multimodais que resultaram em trabalhos como o de Johansson (Johansson, 2003), responsável por desenvolver o MADFILM, um sistema de recomendação de filmes que aborda a integração da recomendação e organização de informação, através de interações explícitas e implícitas dos usuários. Arapakis et al. (Arapakis et al., 2009) propuseram uma nova interface de busca de vídeo que poderia prever a relevância tópica de um vídeo, através da análise de aspectos afetivos do comportamento do usuário envolvendo características da sua face. Uma recente contribuição para a área foi o trabalho de Denis et al. (Parra e Amatriain, 2011), no qual foi desenvolvido um estudo analisando a relação entre os retornos implícitos e explícitos para extração de preferências de um usuário, resultando na construção de um modelo chamado Walk Talk para os sistemas de recomendação.

Na busca por técnicas mais robustas, os sistemas de recomendação baseados em modelo procuram otimizar todo o cálculo e armazenamento necessário nos sistemas baseados em memória, criando um modelo em que o cálculo online da recomendação seja mais rápido e escalável. Isto é importante devido à exigência de grandes sistemas nos quais a recomendação é crucial para o negócio e para que ela seja apresentada ao usuário no momento da sua navegação no site.

Desta forma, o algoritmo SVD++ apresentado na Seção 2.3.3.2 foi um trabalho desenvolvido com base na multimodalidade de interações, pois utiliza informações explícitas e implícitas dos usuários para melhorar a previsão de notas. O algoritmo usa as notas atribuídas pelos usuários para itens como informação explícita, e como informação implícita, o histórico de navegação do usuário.

No trabalho de Rendle et al. (Rendle, 2012), os colaboradores propõem uma técnica chamada Factorization Machines (FM), responsável por combinar as vantagens de Support Vector Machines (SVM) com modelos de fatoração. Esta técnica consegue considerar tanto informações dos itens como informações dos usuários para gerar a recomendação. Entretanto, o cálculo de similaridade entre as informações é feito através de comparação de pares, o que ocasiona resultados não tão precisos, por não levar em consideração a semântica dos dados.

Em pesquisa recente, Domingues et al. (Domingues et al., 2013) desenvolveram um sistema multimodal para recomendação de música que combina o uso (acesso à $W e b$ ) e conteúdo (ou seja, recursos de áudio e marcas textuais). Parte das interações foi feita em 
tempo real com usuários reais em um site de música comercial. Combinando os dados do sistema, concluiu-se que este trouxe melhores resultados do que os obtidos nos sistemas baseados em conteúdo, levando-o a ter maior taxa de aceitação, de atividade e fidelidade do usuário.

\subsection{Métodos de Combinação de Interação de Usuários}

Sistemas de recomendação podem ser estendidos de várias maneiras objetivando melhorar a compreensão dos usuários e itens, incorporando, por exemplo, novos tipos de interação no processo de recomendação e fazendo a combinação entre elas. Uma dessas melhorias é o suporte a multi-critérios de interações, de modo a proporcionar maior flexibilidade e tipos menos intrusivos de recomendações (Ricci et al., 2011).

A Combinação (do Inglês Ensemble) é uma abordagem de aprendizado de máquina que utiliza uma combinação de modelos semelhantes a fim de melhorar os resultados obtidos por um único modelo. Na realidade, vários estudos recentes, como o de Jahrer et. al. (Jahrer et al., 2010), demonstram a eficácia da combinação de várias técnicas individuais e mais simples, concluindo que os métodos baseados em combinação superam qualquer algoritmo único, mais complexo.

Empiricamente, técnicas de combinação tendem a produzir melhores resultados quando há uma diversidade significativa entre os modelos. Muitos métodos de combinação, por isso, procuram promover a diversidade entre os modelos que deverão ser utilizados nessas combinações. Embora não intuitivos, algoritmos aleatórios (como árvores de decisões aleatórias) podem ser utilizados para produzir um conjunto muito mais forte do que algoritmos deliberados (como árvores de decisões de redução de entropia). Atualmente, tem-se utilizado uma variedade de algoritmos de aprendizagem forte, e que tem se mostrado mais eficazes do que o uso de técnicas que tentam enfraquecer os modelos, a fim de promover a diversidade (Jahrer et al., 2010).

Neste contexto, Bar et al. (Bar et al., 2013), propuseram um framework sistemático responsável por fazer a combinação dos resultados. Os autores empregam uma técnica de combinação, que consiste em utilizar os resultados gerados a partir de um único algoritmo (conjunto homogêneo) através de métodos de aprendizagem linear. Eles demonstraram a eficácia deste framework, aplicando seu método em vários algoritmos beseados em filtragem colaborativa, fazendo a comparação do resultados gerado pelo framework e os demais.

Recentemente, o trabalho de Petar el al. (Ristoski et al., 2014), discute o desenvolvimento de um sistema híbrido multi estratégia, de recomendação de livros utilizandoLinked Open Data. A abordagem proposta baseia-se na formação de recomendadores base indivi- 
duais, e escores de popularidade geral como recomendadores genéricos. Os resultados dos recomendadores individuais são combinados usando agregação de ranque. Neste trabalho, os autores mostraram que a abordagem proporciona resultados muito bons em diferentes configurações de recomendação e também permite a incorporação de diversidade de recomendações. No entanto, o trabalho se limita aos tipos de interações, restringindo o algoritmo a processar somente itens com notas.

As seções a seguir discutem outros métodos conhecidos e bastante utilizados de combinação de dados existentes na literatura.

\subsubsection{Empilhamento}

Empilhamento (do Inglês Stacking), envolve a formação de um algoritmo de aprendizagem para combinar as previsões de vários outros algoritmos de aprendizagem (Jahrer et al., 2010). Como passo inicial, todos os algoritmos são treinados usando os dados disponíveis no treinamento; em seguida, um algoritmo de combinação é treinado para fazer uma previsão final com todas as previsões dos outros algoritmos como entradas adicionais.

Essa técnica normalmente produz um melhor desempenho do que qualquer um dos modelos treinados (Jahrer et al., 2010). Ela tem sido utilizada com sucesso em ambas as tarefas supervisionadas de aprendizagem (regressão) e aprendizagem não supervisionada (estimativa de densidade). Também tem sido utilizada para estimar a taxa de erro de Bootstrap (do Inglês bagging's). As duas melhores performances na competição Netflix, utilizaram método de combinação baseado em Empilhamento, onde os autores combinavam ranques de diferentes tipos de interação em um só.

\subsubsection{Classificador Ótimo de Bayes}

O classificador ótimo de Bayes é um conjunto de todas as hipóteses do espaço hipótese (Jahrer et al., 2010). Em média, nenhum outro conjunto pode superar isso, então ele é o conjunto ideal, no qual em cada hipótese é dado um voto proporcional à probabilidade de que o conjunto de dados de treinamento será amostrado a partir de um sistema, se esta hipótese fosse verdadeira. Para facilitar dados de treinamento de tamanho finito, o voto de cada hipótese também é multiplicado pela probabilidade anterior a essa hipótese. O classificador ótimo de Bayes pode ser expresso pela seguinte equação:

$$
y=\operatorname{argmax}_{c_{j} \in C} \sum_{h_{i} \in H} P\left(c_{j} \mid h_{i}\right) P\left(T \mid h_{i}\right) P\left(h_{i}\right)
$$

onde $y$ é a classe prevista, $C$ é o conjunto de todas as classes de possíveis, $H$ é o espaço hipótese, $P$ refere-se a uma probabilidade, e $T$ é o conjunto de dados de treinamento. 
Como uma técnica de combinação, o classificador ótimo de Bayes representa uma hipótese que não necessariamente está em $H$. A hipótese representada pela classificador, no entanto, é uma hipótese ótima dentre todas as outras combinadas.

Sendo assim, o classificador não é implementado para quase nenhum caso, tendo em vista que:

- A maioria dos espaços de hipóteses interessantes são grandes demais para repetir, como exigido pelo argmax;

- Muitas hipóteses produzem apenas uma classe, eao invés de uma probabilidade para cada classe, como exigido pelo termo $P\left(c_{j} \mid h_{i}\right)$;

- Calcular uma estimativa imparcial da probabilidade do conjunto de treinamento dado uma hipótese $P\left(T \mid h_{i}\right)$;

- Não é trivial estimar a probabilidade prévia para cada hipótese $P\left(h_{i}\right)$ raramente é viável.

\subsubsection{Bootstrap Agregado}

Bootstrap Agregado, muitas vezes abreviado como Bootstrap, implica em ter cada modelo na votação conjunto, com o mesmo peso (Tiroshi et al., 2012). A fim de promover o modelo de variância, o Bootstrap treina cada modelo no conjunto usando um subconjunto amostrado aleatoriamente do conjunto de treino.

\subsubsection{Boosting}

A técnica de Boosting implica gradativamente em construir um conjunto através da formação de cada instância de um novo modelo, para enfatizar as instâncias de treinamento dos modelos anteriores (Boim e Milo, 2011). Em alguns casos, o Boosting tem sido mostrado para produzir uma melhor precisão do que o Bootstrap, mas também tende a ser mais suscetível à sobreajuste dos dados de formação. A implementação mais comum de Boosting é Adaboost, apesar de alguns algoritmos recentes terem sido relatados como mais adequados para alcançar melhores resultados.

\subsection{Considerações Finais}

Neste capítulo, foram descritas as técnicas e métodos para a construção consistente de perfis de usuários, e como tais podem ser úteis para auxiliar a busca por informação relevante. Inicialmente, contextualizaram-se a modelagem e relevância desses perfis para uma correta 
previsão de acordo com as preferências do usuário. Em seguida, apresentaram-se as formas de interações utilizadas neste trabalho, destacando e debatendo trabalhos relacionados a respeito dessas técnicas, inclusive sobre a combinação delas. Por fim, apresentaram-se técnicas de combinação, responsáveis por combinar diversos métodos de interações juntos, e as pesquisas mais relevantes destas técnicas.

A partir do que foi apresentado neste capítulo, é possível notar a importância dos métodos de interação para os sistemas de recomendação e a necessidade de se explorar mais estas técnicas, dado que, quanto mais informações concisas e relevantes no perfil de um usuário, maior será a probabilidade de se gerar boas recomendações para ele. A combinação desses métodos de interação de acordo com os trabalhos citados ao longo deste capítulo, podem melhorar consideravelmente os resultados dos sistemas de recomendação e construir perfis de usuários dinâmicos, e bem mais próximos das reais preferências dos usuários.

No entanto, os trabalhos apresentados não medem o significado do efeito das variáveis retornadas, nem propõem um modelo genérico para a criação de um sistema de recomendação que possa deter diversos métodos de interações disponíveis. Neste contexto, o próximo capítulo apresenta uma proposta que visa sanar a deficiência da geração de recomendação a partir de diversos tipos de interações de usuários. 


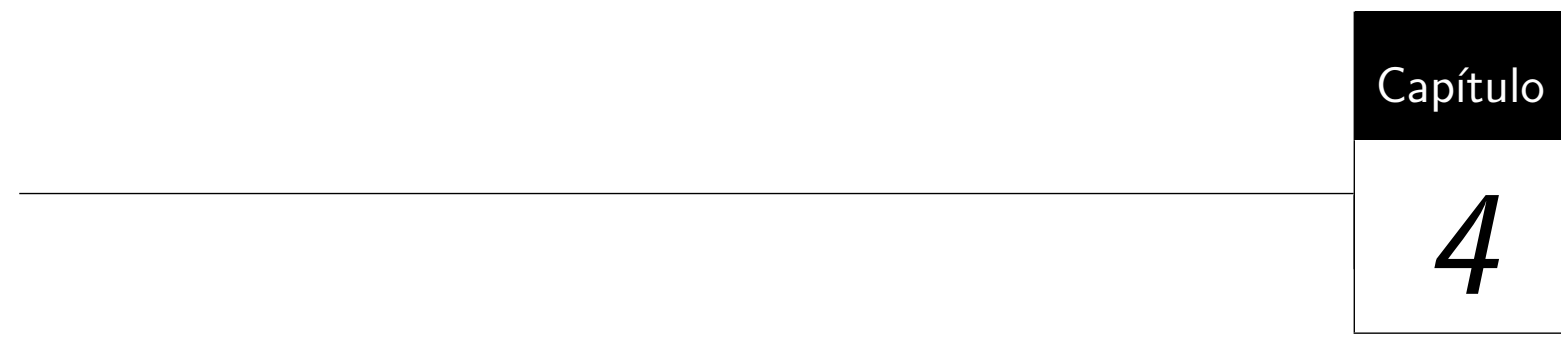

\section{Proposta de Solução}

Neste capítulo, é apresentado uma ferramenta de recomendação baseado na combinação de vários tipos de interação desenvolvidos durante a pesquisa. Essa ferramenta é constituída de quatro protótipos, que se sustentam na ideia de que quanto mais tipos de interações o usuário tiver no sistema, mais precisas serão as recomendações geradas a ele. Além disso, é definido o domínio de aplicação para o modelo, e detalhado um exemplo de como a ferramenta pode ser aplicada em um sistema de recomendação.

\subsection{Contextualização}

Durante o andamento da pesquisa apresentada neste trabalho, foi desenvolvido uma ferramenta que contém algumas técnicas responsáveis por processar diferentes tipos de interação, de modo a indicar inferências positivas ou negativas do usuário em relação ao conteúdo acessado. A ferramenta apresenta uma abordagem de pós-processamento, responsável por combinar os resultados de recomendações geradas a partir de cada tipo de interação feita pelo usuário. Além disso, nesta ferramenta implementaram-se os módulos de teste estatístico, validação cruzada e de métricas de avaliação, integrando também uma biblioteca de recomendação para o processamento de algoritmos unimodais.

As primeiras técnicas de combinação desenvolvidas para a ferramenta se basearam em heurísticas, fazendo a concatenação dos resultados individuais de cada interação, a partir das interações contidas na base de dados. Em seguida, a fim de tornar a ferramenta 
mais confiável e robusta, foram desenvolvidas técnicas de aprendizagem de máquina nos algoritmos existentes. Isso possibilitou que a ferramenta se tornasse capaz de aprender qual tipo de interação é mais relevante para usuário, e a partir disso, atribuir pesos para essas interações dinamicamente.

Por fim, desenvolveu-se uma abordagem para sistemas de recomendação com base nas preferências de grupos de usuários. Nesta técnica, calcula-se a semelhança entre os usuários a partir de suas diversas interações no sistema, e usa-se essa similaridade para agrupar usuários com interesses semelhantes. A recomendação é feita a partir de algoritmos colaborativos somente com as interações de cada grupo de usuários.

Tais técnicas serão apresentadas nas próximas seções, de acordo com a ordem cronológica que foram desenvolvidas.

\subsection{Notações}

Neste capítulo, estende-se as notações utilizadas do Capítulo 2. Afim de representar as interações dos usuários exploradas neste trabalho, define-se $R$ (u,notas), $R$ (u, histórico) e $R$ (u, etiquetas) os ranques gerados para o usuário $u$ para as interações: notas, histórico de navegação e etiquetas, respectivamente. Além disso, considerando cada tipo de interação, definem-se $r_{u, i}^{\text {etiquetas }}, r_{u, i}^{\text {histórico }}$ e $r_{u, i}^{\text {notas }}$ para representar os pesos dos pares $(u, i)$ em cada ranque.

Assim, os conceitos de ranque e peso são relacionados um com o outro, sendo que cada algoritmo unimodal gerará uma pontuação (peso), que é um ponto flutuante que representa o quanto um usuário gosta de um item, utilizando uma interação específica. Estes pesos são então classificados em ordem decrescente, formando o ranque dos itens, no qual o primeiro item é o mais relevante para o usuário de acordo com suas preferências. Desta forma, para cada usuário e para cada tipo de interação (etiquetas, histórico e notas), têm-se um ranque. Por exemplo, $R$ (u,etiquetas) contém uma lista de pares $(u, i)$ com pontuações correspondentes gerados por um algoritmo unimodal, com base na interação do usuário $u$ relacionada à etiquetagem.

\subsection{Técnicas Baseadas em Heurísticas}

Inicialmente foram desenvolvidas duas abordagens, que apesar dos resultados promissores demonstrados no Capítulo 5, foram baseados em um conjunto de heurísticas que funcionam melhor apenas em um domínio restrito. 


\subsubsection{Técnica Baseada em Etiquetas}

Na primeira abordagem desenvolvida (Da Costa et al., 2014), foi proposta uma técnica capaz de gerar recomendações com base nas interações multimodais do usuário, sempre que elas estão disponíveis. O sistema consiste em uma etapa de pós-processamento, que combina ranques gerados por diferentes recomendadores unimodais, os quais exploram os tipos de interação individualmente. Para isso, foram utilizados dois algoritmos: SVD++ e BPR MF, sendo que o primeiro é responsável por processar feedback explícito e o segundo, implícito. Nesta abordagem, o algoritmo prioriza os itens que aparecem mais de uma vez no $R$ (u,parcial), que é a concatenação dos ranques de tamanho $n$ de recomendações para um usuário, e os itens para os quais houve atribuição de etiquetas, como pode ser observado na Equação 4.1:

$$
r_{u, i}^{\text {final }}=\gamma \cdot\left(r_{u, i}^{\text {notas }}+r_{u, i}^{\text {histórico }}+\beta \cdot r_{u, i}^{\text {etiquetas }}\right)
$$

sendo que $\gamma$ representa a variável que pondera a frequência dos itens, e $\beta$ pondera os pesos atribuídos às etiquetas. Nesta abordagem considera-se apenas o uso da informação implícita das etiquetas, ou seja, leva-se em conta somente se o usuário atribuiu a etiqueta a um item, descartando o valor semântico da etiqueta.

Esta heurística é apoiada pelo fato de quanto maior a frequência do item $i$ em $R(u$, notas $)$, $R(u$,etiquetas $)$ e $R(u$, histórico $)$, mais este item se aproxima às preferências do usuário, pois este interagiu com o conteúdo de diversas maneiras. Nesta abordagem, verificou-se que ao atribuir uma maior importância para etiquetas (o parâmetro $\beta$ ), alcançam-se melhores resultados, uma vez que a atribuição de etiquetas a um item exige mais esforço por parte dos usuários do que simplesmente acessar um item ou atribuir uma nota. Logo, assumiu-se que quanto maior o número de etiquetas atribuídas a um item, maior seria sua relevância na técnica proposta.

A Figura 4.1 ilustra um exemplo da técnica proposta. Tendo em conta os ranques gerados para cada tipo de interação de um usuário específico, os pares $(u, i)$ são unificados em um único ranque, representado por $R(u$,parcial $)$. O ranque $R(u$, final $)$ é gerado a partir da Equação 4.1, que no exemplo, o item mais relevante é o item 7, pois tem a maior frequência no ranque parcial. O segundo item mais importante seria o item 1, pois aparece duas vezes no ranque parcial e possui mais etiquetas atribuídas que os demais itens. O item 10 estaria na terceira posição no ranque final por aparecer também duas vezes. E, finalmente, o último item do ranque seria o item 3, que apesar de ter uma frequência pequena tem um número relevante de etiquetas atribuídas a ele. 


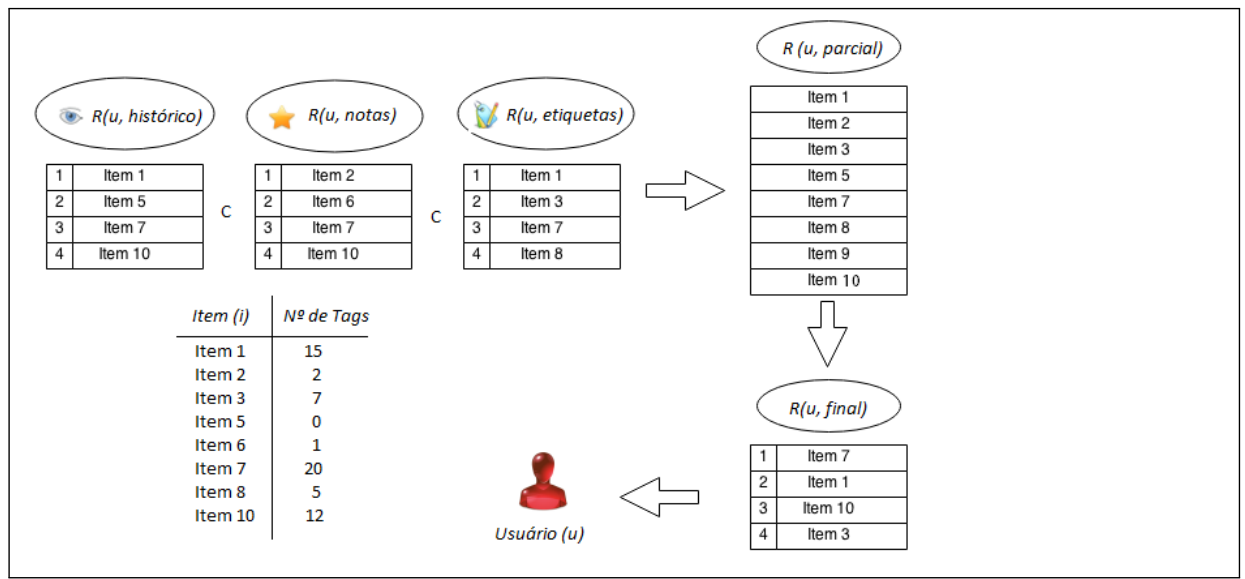

Figura 4.1: Exemplo de técnica baseada em etiquetas.

\subsubsection{Técnica Baseada em Médias}

No intuito de generalizar o uso dessa técnica para outras bases de dados e o uso de outros tipos de interação, desenvolveu-se uma segunda abordagem de combinação. Neste trabalho (Da Costa e Manzato, 2014), definiram-se $R(u, a), R(u, b)$ e $R(u, c)$ ranques gerados para um usuário $u$ para interações quaisquer: $a, b$ e $c$, respectivamente. Definiram-se também $r_{u, i}^{a}, r_{u, i}^{b}$ e $r_{u, i}^{c}$ para representar os pesos dos pares $(u, i)$ em cada ranque. Depois de gerar os ranques para cada tipo de interação, a técnica realiza a combinação dos pares $(u, i)$ de todos os ranques, como ilustrado no Algoritmo 3.

Entrada: $R(u, a), R(u, b), R(u, c)$

Saída: Ranque Final $R^{\prime}(u$, final $)$

$R(u$, parcial $) \leftarrow R(u, a) \cap R(u, b) \cap R(u, c)$

Compute $\operatorname{avg}_{R(u, a)}, \operatorname{avg}_{R(u, b)}$ and $\operatorname{avg}(u, c)$

para $(u, i) \in R(u$, parcial $)$ faça

se $r_{u, i}^{a} \geq a v g_{R(u, a)} \& r_{u, i}^{b} \geq \operatorname{avg} g_{R(u, b)}$ \& $r_{u, i}^{c} \geq \operatorname{avg} g_{R(u, c)}$ então

$\hat{r}_{u, i} \leftarrow\left(r_{u, i}^{a}+r_{u, i}^{b}+r_{u, i}^{c}\right) / 3$

fim

senão

$\hat{r}_{u, i} \leftarrow \max \left(r_{u, i}^{a}, r_{u, i}^{b}, r_{u, i}^{c}\right)$

fim

Insira $\hat{r}_{u, i}$ em $R(u$, final $)$

fim

$R^{\prime}(u$, final $) \leftarrow$ sort_desc $(R(u$, final $))$

Algoritmo 3: Algoritmo de combinação da segunda abordagem

O ranque parcial $R$ (u,parcial) é criado contendo todos os pares $(u, i)$ que ocorrem em todos os ranques isolados. Em seguida, os pesos de cada par $(u, i)$ pertencentes à $\mathrm{R}(u$, parcial $)$ são calculados, verificando se o peso de $r_{u, i}^{\cdot}$ é maior que a média de todos os pesos da interação correspondente. Caso todos os resultados satisfaçam a condição, 
define-se que o valor do peso final $\hat{r}_{u, i}$, é a média aritmética entre os três valores. Se isso não acontecer, então o valor final receberá o maior valor entre os pesos das interações. Por fim, os pares $(u, i)$ são classificados em ordem decrescente de acordo com seus pesos, resultando na classificação final, que será recomendada no top $N$.

A heurística utilizada nesta técnica também se baseia na frequência da aparição dos pares $(u, i)$, entretanto, ela procura tratar cada tipo de interação de maneira homogênea, atribuindo a mesma relevância para todos os termos da função. Essa abordagem também procura normalizar os pesos de itens relevantes (que possuam todos os tipos de interação) no ranque final utilizando uma média ponderada dos pesos, fazendo com que nenhum peso de qualquer interação se sobressaia aos demais.

\subsection{Técnica Baseada em Aprendizagem}

Como descrito na seção anterior, as abordagens desenvolvidas baseadas em heurísticas foram definidas para os domínios considerados e no conjunto de tipos de interações disponíveis. Desta maneira, apesar de apresentarem melhores resultados quando comparados com os recomendadores unimodais, essas abordagens apresentam dificuldade se forem utilizados outros tipos de interações, não sendo, portanto, genéricas o suficiente para qualquer domínio de aplicação. Assim, desenvolveu-se uma nova técnica na qual os parâmetros são aprendidos com base no comportamento de cada usuário, juntamente com sua interação no sistema (Da Costa Fortes e Manzato, 2014).

A aprendizagem das interações do usuário utilizada nesta abordagem é uma extensão do algoritmo BPR apresentado na Seção 2.3.3.3, responsável pelo processamento de feedback implícito a fim de gerar um perfil do usuário mais preciso. No entanto, em sua forma original, este modelo não pode processar e combinar mais de um tipo de interação. Por outro lado, o seu processo de aprendizagem pode ser utilizado para ajustar os parâmetros de um modelo de aprendizagem baseado em combinação. Desta forma, a combinação de interações, como etiquetas e o histórico de navegação de um usuário, pode ser feito para melhorar a recomendação final. Assim, para cada tipo de interação é usado um recomendador unimodal qualquer para gerar ranques isolados, e em seguida, faz-se a combinação dos resultados gerados utilizando uma extensão do algoritmo Learn BPR apresentado no Algoritmo 2. A Figura 4.2 ilustra o esquema geral da abordagem proposta.

Como ilustrado na Figura 4.2, serão gerados $n$ ranques para cada usuário, sendo que cada um deles é calculado com base em uma interação particular. Em seguida, esses 


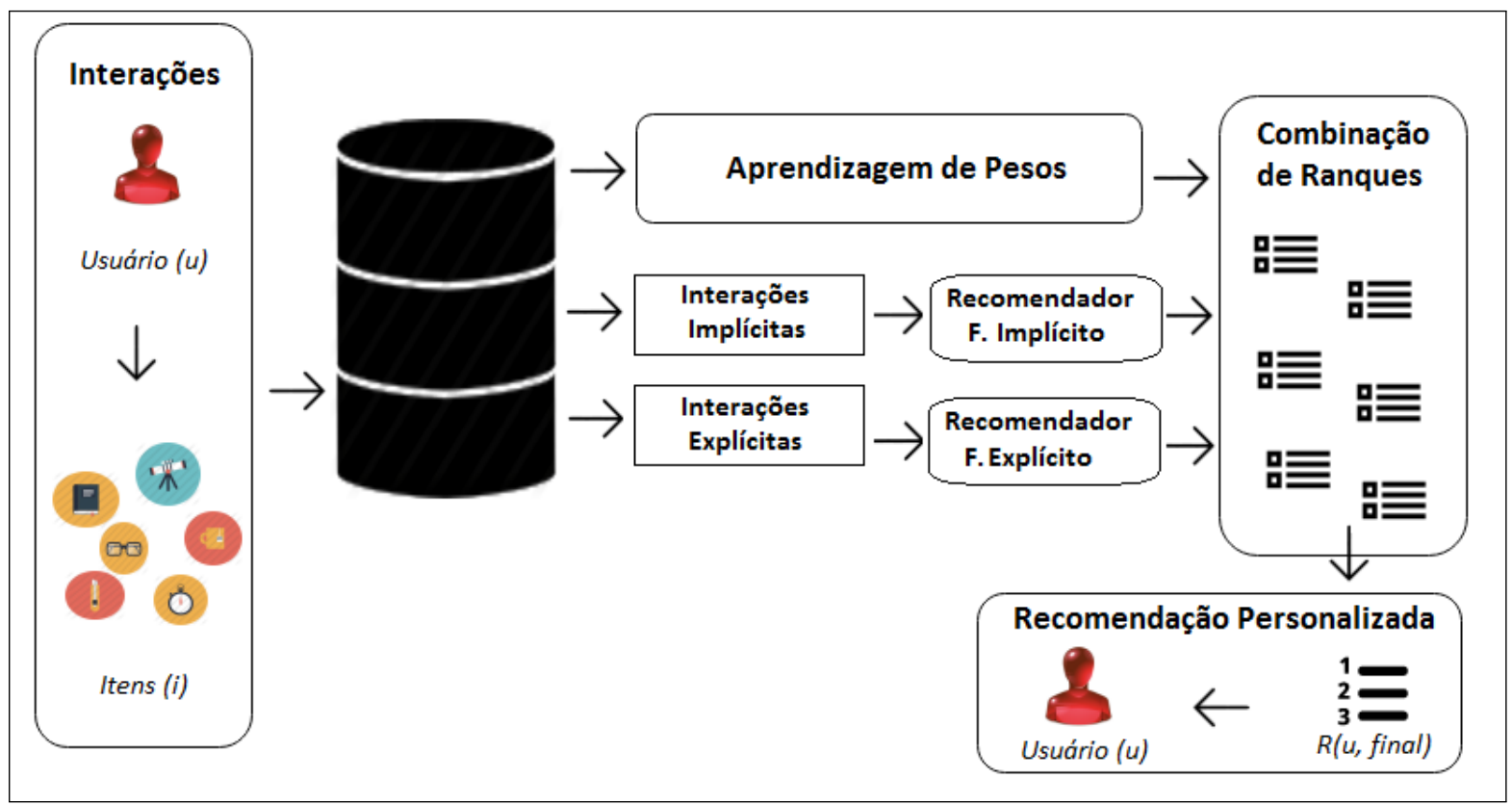

Figura 4.2: Visualização esquemática da técnica de aprendizagem.

ranques são combinados utilizando os pesos aprendidos pelo algoritmo. A Equação 4.2 é responsável por calcular os pesos de cada par $(u, i)$, representado por $r_{u, i}^{\text {final}}$ :

$$
\hat{r}_{u, i}^{f i n a l}=\beta_{a} \cdot r_{u, i}^{a}+\beta_{b} \cdot r_{u, i}^{b}+\ldots+\beta_{n} \cdot r_{u, i}^{n}
$$

onde $\beta_{a}, \beta_{b}, \ldots, \beta_{n}$ são pesos gerados a partir do aprendizado de cada tipo de interação. Assim, a abordagem proposta apresenta três etapas: a primeira é responsável pela divisão da base de dados e execução dos algoritmos unimodais e suas respectivas etapas de aprendizagem e recomendação. A segunda etapa é responsável pela aprendizagem dos parâmetros de cada tipo de interação, cujos parâmetros $\beta_{a}, \beta_{b}, \ldots, \beta_{n}$ são aprendidos com a mesma amostra de treinamento utilizada para processar as interações individualmente. Por fim, a terceira pela aplicação desses parâmetros no processo de combinação apresentados na Equação 4.2. As próximas subseções descrevem as três etapas em mais detalhes.

\subsubsection{Etapa 1: Divisão de Dados e Execução de Algoritmos Unimo- dais}

Na primeira etapa, a base de dados é divida em conjuntos de treinamento e teste, sendo o último também dividido em dois subconjuntos, onde a primeira parte representa um conjunto verdade tendo como foco a validação da técnica e a segunda é utilizada para a aprendizagem dos pesos na Etapa 2. Nesta fase, cada tipo de interação do conjunto de treinamento é processado pelo seu respectivo algoritmo de recomendação. 
A abordagem proposta permite a integração de diversos tipos de algoritmos nesta primeira etapa. No caso da técnica baseada em aprendizagem, recomenda-se que no uso de algoritmos que utilizam etapas de aprendizagem durante seu processo de recomendação, as variáveis e constantes utilizadas sejam as mesmas tanto para o algoritmo quanto para a técnica.

\subsubsection{Etapa 2: Aprendizagem de Pesos Para Cada Tipo de Interação}

Dada a etapa anterior, neste passo, os pesos gerados a partir de cada tipo de interação, representados por $r_{u, i}^{a}, r_{u, i}^{b}, \ldots, r_{u, i}^{n}$, são então aplicados na Equação 4.3, que é responsável pelo cálculo do peso final da combinação.

$$
\hat{s}_{u i j}:=\beta_{a}\left(r_{u, i}^{a}-r_{u, j}^{a}\right)+\beta_{b}\left(r_{u, i}^{b}-r_{u, j}^{b}\right)+\ldots+\beta_{n}\left(r_{u, i}^{n}-r_{u, j}^{n}\right) .
$$

Isto é viabilizado pela estratégia natural do BPR, na qual em uma interação particular, seleciona-se aleatoriamente um par de itens $i$ e $j$ para um usuário $u$, sendo $i$ um item conhecido e $j$ um item desconhecido.

Para treinar os parâmetros $\beta_{a}, \beta_{b}, \ldots, \beta_{n}$, utiliza-se o Learn BPR, como explicado anteriormente. O ajuste dos pesos é obtido através do seguinte cálculo existente no algoritmo:

$$
\beta_{\theta} \leftarrow \beta_{\theta}+\alpha\left(\frac{e^{-\hat{s}_{u i j}}}{1+e^{-\hat{s}_{u i j}}} \cdot \frac{\partial}{\partial \beta_{\theta}} \hat{s}_{u i j}-\Lambda_{\beta_{\theta}} \beta_{\Theta}\right)
$$

onde $\theta$ representa o tipo de interação, $\alpha$ é a taxa de aprendizagem, $\Lambda_{\beta_{\theta}}$ a constante de regularização e $\hat{s}_{u i j}=\hat{r}_{u i}-\hat{r}_{u j}$. Assim, cada par $(u, i)$ de cada tipo de interação terá um peso $\beta$ equivalente. Desta forma, tem-se:

$$
\frac{\partial}{\partial \beta_{\theta}} \hat{s}_{u i j}= \begin{cases}r_{u, i}^{a}-r_{u, j}^{a} & \text { se } \beta_{\theta}=\beta_{a} \\ r_{u, i}^{b}-r_{u, j}^{b} & \text { se } \beta_{\theta}=\beta_{b} \\ \cdots & \\ r_{u, i}^{n}-r_{u, j}^{n} & \text { se } \beta_{\theta}=\beta_{n}\end{cases}
$$

que é aplicado no Learn BPR, para aprendizado dos pesos. Assim, novos itens poderão ser preditos a partir de sua aplicação na Equação 4.2.

\subsubsection{Etapa 3: Combinação de Ranques e Recomendação Final de Itens}

A etapa de combinar ranques consiste na agregação dos pesos dos ranques gerados pelos algoritmos unimodais para cada tipo de interação. Para cada usuário que pertence ao conjunto de dados, os resultados são computados a cada item de suas interações. Esses 
pesos, por sua vez, são ponderados com os parâmetros do conjunto $\left(\beta_{a}, \beta_{b}, \ldots, \beta_{n}\right)$, responsáveis por dar relevância para o tipo de interação que o usuário tem em relação a esse item. Finalmente, estes valores são classificados em ordem decrescente resultando na classificação final, que será recomendada em top $N$. Este processo pode ser visto no Algoritmo 4.

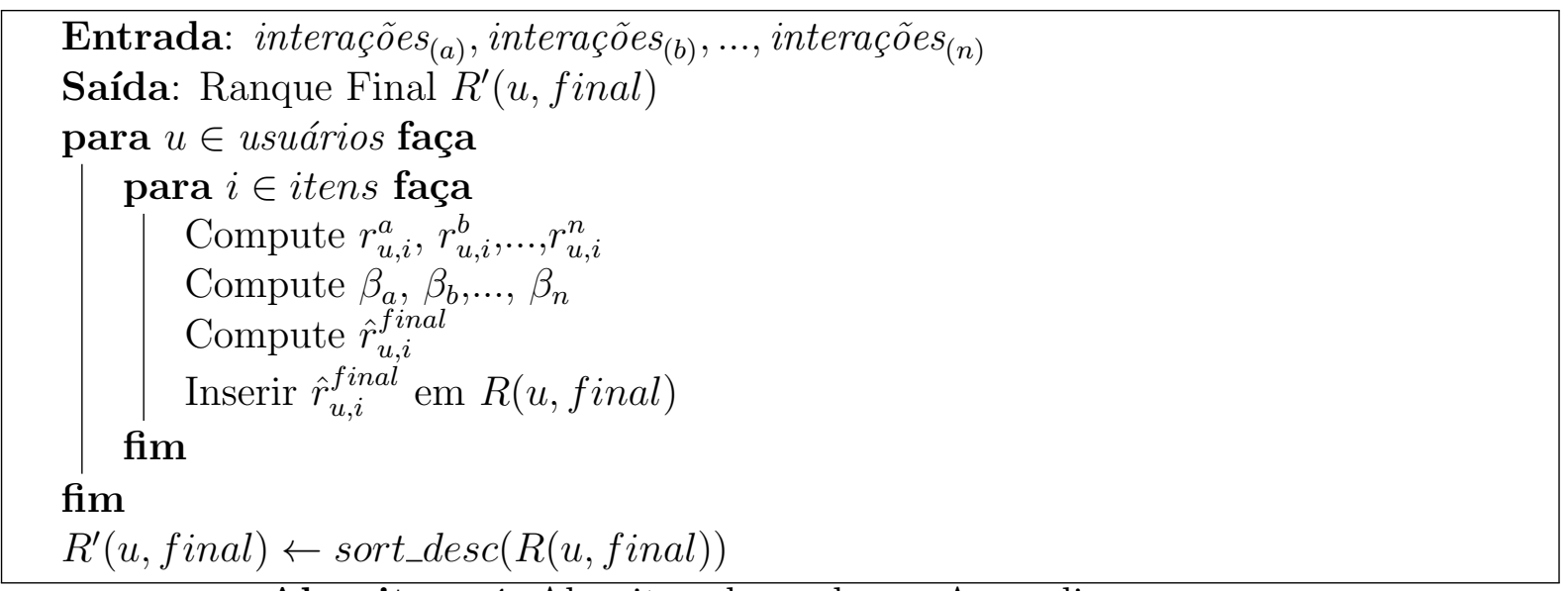

Algoritmo 4: Algoritmo baseado em Aprendizagem.

\subsection{Técnica de Recomendação Colaborativa Baseada em Grupos}

A técnica anterior apresenta uma limitação referente à capacidade dos algoritmos unimodais: caso esses algoritmos não consigam processar um determinado tipo de interação, a mesma não poderá ser utilizada nesta abordagem. Baseado nisto, propôs-se uma técnica capaz de gerar recomendações com base nas preferências do grupo ao qual um usuário mais se assemelha, utilizando diversos tipos de interações. A estrutura consiste em uma etapa de pré-processamento para combinar os usuários em grupos de acordo com suas similaridades, baseadas nas interações com os itens de um sistema, e em seguida, gerar a recomendação. Para isso, utiliza-se um algoritmo de agrupamento de dados capaz de gerar grupos com base no cálculo da distância entre os usuário e um algoritmo de recomendação baseado em filtragem colaborativa. O algoritmo de agrupamento de dados é responsável por gerar grupos com base na semelhança entre os utilizadores, enquanto que o de recomendação é utilizado para gerar as recomendações baseadas em cada grupo. A Figura 4.3 ilustra todas as etapas envolvidas na técnica proposta.

Para o primeiro passo são coletadas todas as interações que os usuários realizaram e, a partir delas, gera-se uma matriz de usuário por item, na qual cada célula desta matriz é um vetor que contém todas as interações de um usuário com determinado item. Esta matriz 


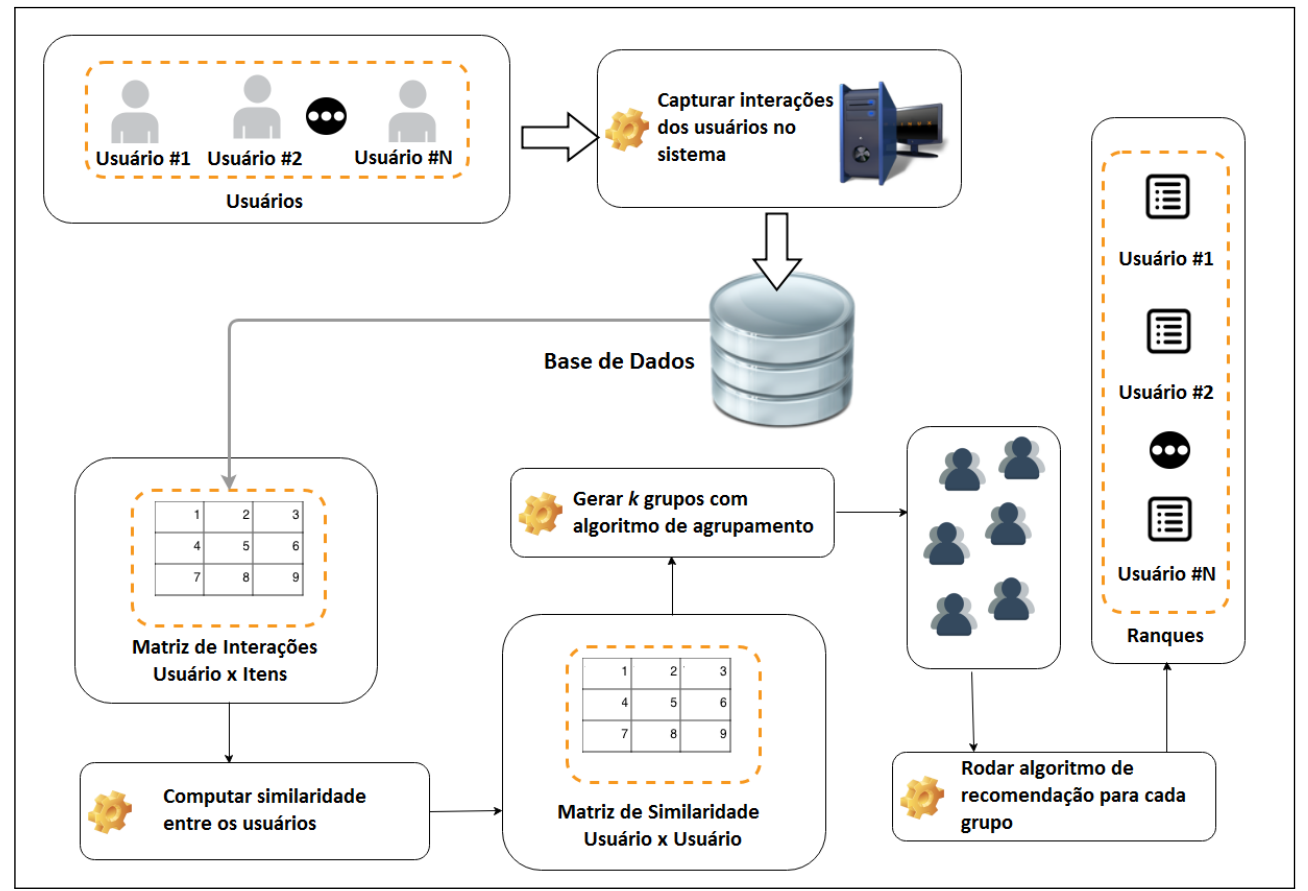

Figura 4.3: Visualização esquemática da técnica de recomendação baseada em grupos.

é então utilizada para calcular a semelhança de usuários utilizando alguma medida de distância, como cosseno ou Pearson, sendo que a matriz resultante é uma matriz usuário por usuário, utilizada pelo módulo de agrupamento para gerar os grupos de usuários. Cada um destes grupos corresponde a usuários que tenham interesses semelhantes sobre temas específicos. Por fim, com base nesses grupos, calculam-se recomendações particulares para cada usuário no conjunto de dados. Existem três fases no algoritmo: a representação de dados; encontrar os vizinhos mais próximos; e geração de recomendação.

\subsubsection{Representação dos Dados}

O modelo de representação dessa técnica é construído para representar as interações dos usuários sobre os itens do banco de dados. Os dados de entrada do algoritmo são apresentados por uma matriz, $M \times N$, onde $M$ é o número de usuários e $N$ o de itens. As células desta matriz representam as interações feitas pelos usuários em itens. Diferentes métodos podem ser utilizados para representar as interações, como foi apresentado no Capítulo 3.

A Tabela 4.1 representa a matriz de interações de usuários, onde $i t_{j}^{M, N}$ é o tipo de interação que um usuário fez sobre um determinado item. Caso não tenha nenhuma interação $j$ com um item, o seu valor no vetor de interações é 0 , caso contrário, este valor será preenchido de acordo com o tipo de interação. Por exemplo, se o utilizador acessou um item, um peso 1 será atribuído ao vetor na posição daquela interação; caso negativo, será atribuído um valor igual a 0 . 
Tabela 4.1: Matriz de interação de usuários.

\begin{tabular}{|c|c|c|c|c|}
\hline & $\begin{array}{l}\text { Item } \\
1\end{array}$ & $\begin{array}{l}\text { Item } \\
2\end{array}$ & $\ldots$ & Item $N$ \\
\hline Usuário 1 & $\begin{array}{ll}i t_{1}^{1,1} & \\
i t_{2}^{1,1} & \\
i t_{j}^{1,1} & \end{array}$ & $\begin{array}{ll}i t_{1}^{1,2} & \\
i t_{2}^{1,2} & \ldots \\
i t_{j}^{1,2} & \end{array}$ & $\ldots$ & $\begin{array}{ll}i t_{1}^{1, N} & \\
i t_{2}^{1, N} & \ldots \\
i t_{j}^{1, N} & \end{array}$ \\
\hline Usuário 2 & $\begin{array}{ll}i t_{1}^{2,1} & \\
i t_{2}^{2,1} & \ldots \\
i t_{j}^{2,2} & \end{array}$ & $\begin{array}{ll}i t_{1}^{2,2} & \\
i t_{2}^{2,2} & \ldots \\
i t_{j}^{2,2} & \end{array}$ & $\cdots$ & $\begin{array}{ll}i t_{1}^{2, N} & \\
i t_{2}^{2, N} & \ldots \\
i t_{j}^{2, N} & \\
\end{array}$ \\
\hline$\ldots$ & .. & $\ldots$ & $\ldots$ & $\ldots$ \\
\hline Usuário $M$ & $\begin{array}{l}i t_{1}^{M, 1} \\
i t_{2}^{M, 1} \\
i t_{j}^{M, 1}\end{array}$ & $\begin{array}{l}i t_{1}^{M, 2} \\
i t_{2}^{M, 2} \\
i t_{j}^{M, 2}\end{array}$ & $\ldots$ & $\begin{array}{ll}i t_{1}^{M, N} & \\
i t_{2}^{M, N} & \ldots \\
i t_{j}^{M, N} & \end{array}$ \\
\hline
\end{tabular}

\subsubsection{Encontrar Vizinhos Mais Próximos}

Nesta etapa, utiliza-se a matriz gerada no passo anterior para se calcular as distâncias entre os usuários da base. No cálculo de similaridade, deve-se utilizar métricas capazes de considerar todas as interações dos usuários (existentes ou não) em todos os itens de base. Calculada a distância entre todos os usuários da base, uma nova matriz $M \times M$ é gerada, responsável por representar a similaridade entre os usuários.

Depois de construir a matriz de similaridade entre os usuários, utiliza-se um algoritmo de agrupamento, como o K-means, para criar grupos de usuários com base nas preferências em comum. Neste método, primeiro são selecionados arbitrariamente valores para os pontos centrais iniciais dos $k$ centroides. Em seguida, cada indivíduo é atribuído a um grupo de tal forma que a distância entre ele e o centro de um agrupamento é minimizada. Então, para cada grupo, recalcula-se a média do grupo com base nos usuários que atualmente pertencem ao mesmo grupo. A média é agora considerada como o novo centro do grupo. Depois de encontrar novos centros, calcula-se novamente a distância de cada usuário aos grupos, a fim de encontrar a que grupo o usuário deve pertencer. A condição de parada depende do algoritmo que está sendo utilizado e das variáveis passadas a eles.

Ao fim do processo da criação dos $k$ grupos, verifica-se em cada grupo, se há pelo menos 10 itens, nos quais cada usuário nunca tenha tido nenhum tipo de interação. Caso isso ocorra, este grupo é concatenado a outro grupo com maior similaridade à ele. Assim, garante-se que todos os usuários recebam, pelo menos, dez novas recomendações baseadas nas preferências de seu grupo. 


\subsubsection{Fase de Recomendação}

Como apresentado anteriormente, a técnica tem a capacidade de utilizar diferentes algoritmos para gerar recomendação, logo nesta fase, escolhe-se um algoritmo de filtragem colaborativa para processar as interações de cada grupo de usuários e gerar uma lista de itens recomendados para cada usuário no grupo. O algoritmo será responsável pela montagem de uma matriz que contém todos os usuários e os itens de um determinado grupo $k$ composta por interações individuais de cada usuário, levando em conta tanto itens que ele teve algum tipo de interação, como os que ele não teve nenhum contato, para prever os itens de sua preferência.

\subsection{Considerações Finais}

Com o avanço da tecnologia surgem constantemente novas formas de interagir com os sistemas, possibilitando ao usuário escolher as formas mais cômodas de demonstrar suas preferências em relação ao conteúdo disponível. Com isso, torna-se cada vez mais necessário adotar novas práticas para auxiliar o usuário no processo de encontrar informações interessantes de acordo com as suas interações no sistema. Com esse propósito, nesse capítulo foi apresentado uma ferramenta de recomendação contendo quatro técnicas capazes de processar diversos tipos de interação do usuário para gerar uma recomendação mais precisa.

Inicialmente, apresentaram-se as técnicas baseadas em heurísticas, responsáveis por fazer um pós-processamento das recomendações geradas individualmente, e combiná-las de acordo com premissas deduzidas através de um estudo nas bases em que essas técnicas foram aplicadas. No entanto, apesar dos resultados dessas técnicas terem sido positivos quando comparadas ao processamento isolado de cada tipo de interação, como será visto no Capítulo 5, essas geralmente induzem a vieses e erros graves e recorrentes, quando realizadas em domínios diferentes dos quais foram aplicadas.

Em decorrência desse problema, desenvolveu-se uma nova abordagem a fim de processar e combinar qualquer tipo de interação de um usuário em um determinado sistema. Essa técnica também é baseada no pós-processamento dos resultados gerados individualmente para cada tipo de interação, porém utiliza uma técnica de aprendizagem de máquina para ponderar cada tipo de interação no momento da combinação dos ranques. Contudo, essa abordagem apresenta uma limitação no que se refere aos algoritmos unimodais, pois caso uma interação de um determinado tipo não consiga ser processada por um desses algoritmos, ela não poderá ser utilizada nessa abordagem. Por fim, foi apresentada uma abordagem de pré-processamento dessas interações dos usuários, a fim de solucionar o 
problema da técnica de aprendizado. Nesta abordagem, os usuários são agrupados de acordo com a similaridade de suas interações no sistema, e a recomendação é feita para cada usuário baseado nas preferências dos usuários de seu grupo.

No próximo capítulo, serão apresentados os experimentos e resultados da aplicação das técnicas propostas na ferramenta, bem como avaliações dessas abordagens quando comparadas com algoritmos unimodais, multimodais e entre elas mesmas. 


\section{Experimentos e Resultados}

Neste capítulo são descritos os estudos realizados para verificar a viabilidade do modelo proposto, que teve como objetivo validar a hipótese que orienta este trabalho. Em cada estudo, é feita uma descrição da metodologia aplicada, os métodos de investigação utilizados e a interpretação dos resultados obtidos.

\subsection{Metodologia de Avaliação}

A avaliação apresentada neste trabalho consiste em confrontar as técnicas apresentadas no Capítulo 4, e também compará-las com algoritmos unimodais e multimodais apresentados no Capítulo 2. Durante a realização dessa pesquisa, dois estudos foram fundamentais para validação do modelo proposto, sendo que cada estudo foi conduzido de maneira a se atingir os seguintes objetivos:

- Verificar a aplicação das técnicas propostas em uma base de dados real;

- Verificar a eficácia da ferramenta, levando-se em consideração as métricas MAP e precisão;

- Verificar a validade das técnicas pela comparação de médias com o teste T-Student;

- Verificar a redução dos problemas dos sistemas de recomendação;

Os objetivos específicos envolvidos em cada estudo são: 
- Estudo 1: validar o modelo proposto na base de dados do Het Rec LastFM 2k (Cantador et al., 2011), que contém interações de etiquetas e histórico dos usuários. Para isso, foram conduzidos estudos de caso a fim de confrontar as técnicas desenvolvidas na ferramenta com elas mesmas e com os algoritmos existentes na literatura. Esse estudo foi conduzido a partir da análise off-line dos dados, sem participação de usuários.

- Estudo 2: validação final da proposta com um número maior de interações dos usuários. Os processos metodológicos conduzidos nesse segundo estudo envolvem o uso da base de dados do Het Rec MovieLens 2k (Cantador et al., 2011), também conduzido a partir da análise off-line dos dados.

As subseções a seguir apresentam os recursos utilizados durante o desenvolvimento deste trabalho.

\subsubsection{Ferramentas Utilizadas}

A ferramenta proposta neste trabalho foi desenvolvida em Python ${ }^{1}$ na versão 2.7, utilizando as bibliotecas $\mathrm{NumPy}^{2}$ e $\mathrm{SciPy}^{3}$, responsáveis por otimizar e processar as estruturas matriciais. Os algoritmos de recomendação integrados na ferramenta, pertencem à biblioteca MyMediaLite (Gantner et al., 2011), uma ferramenta em código aberto, desenvolvida em $C \#$, com diversas funcionalidades e algoritmos para sistemas de recomendação. Entre esses algoritmos implementados, encontram-se o SVD++ proposto por Koren et al. (Koren et al., 2009) e o algoritmo BPR MF proposto por Rendle el al. (Rendle et al., 2009), utilizados neste trabalho.

\subsubsection{Base de Dados}

Durante os estudos realizados, foram utilizadas duas bases de dados como estudo de caso: a base do MovieLens $2 k$ e a da LastFM $2 k$, ambas resultantes do trabalho de Cantador et al. (Cantador et al., 2011).

- LastFM 2k: a base é composta por 92.826 relações de visualização de artistas por usuários, 186.479 interações de etiquetas atribuídas, 1.892 usuários e 18.022 artistas. Para os experimentos foram utilizados: i) quando o usuário atribui uma etiqueta ou não a um item; e ii) o histórico de visualização de itens, representado pelo acesso de um usuário a um determinado artista.

\footnotetext{
${ }^{1}$ https://www.python.org/

${ }^{2}$ www.numpy.org/

${ }^{3}$ www.scipy.org/
} 
- MovieLens 2k: contêm 800.000 notas, 10.000 interações de etiquetas aplicadas, 2.113 usuários e 10.197 filmes. Como interação explícita nesta base, foram utilizadas as notas que os usuários atribuíram aos itens, e como interação implícita consideraram-se: i) quando o usuário atribui uma etiqueta ou não a um item; e ii) o histórico de itens visitados, que é simulado por valores booleanos (visitou ou não), gerados pelas interações relacionadas às notas e a atribuição de etiquetas.

\subsubsection{Avaliação em Sistemas de Recomendação}

A avaliação em SR permite, através de estudos empíricos, dar indicações em relação ao fornecimento de boas ou más recomendações pelo modelo e, deste modo, analisar o comportamento e o desempenho do sistema quando testado num cenário real. Através da avaliação, podem ser comparadas diferentes técnicas e abordagens de recomendação, de modo a refiná-las e torná-las mais eficazes (Herlocker et al., 2000). As conclusões podem ser tiradas com base nos resultados obtidos em cada uma das abordagens. No contexto dos SR, existem diversas medidas que podem ser usadas na avaliação.

\subsubsection{Metodologia de Estimativa de Desempenho}

Existem várias metodologias de estimativa da desempenho que são adotadas em diversos artigos científicos da área. A metodologia utilizada neste trabalho consiste em usar o protocolo All-but-one (Breese et al., 1998), descrito da seguinte maneira:

1. O conjunto total de usuários é dividido em dois subconjuntos: treinamento e teste. Inicialmente, separam-se todos os usuários que contenham pelo menos dois itens avaliados, denominados de ativos $\left(u_{a}\right)$. Neste conjunto são então extraídos pares para teste e o restante compõe o conjunto treinamento, tal como representado na Figura 5.1. Nesta etapa é obrigatório garantir que todos os usuários que estejam no conjunto de teste pertençam também ao treinamento.

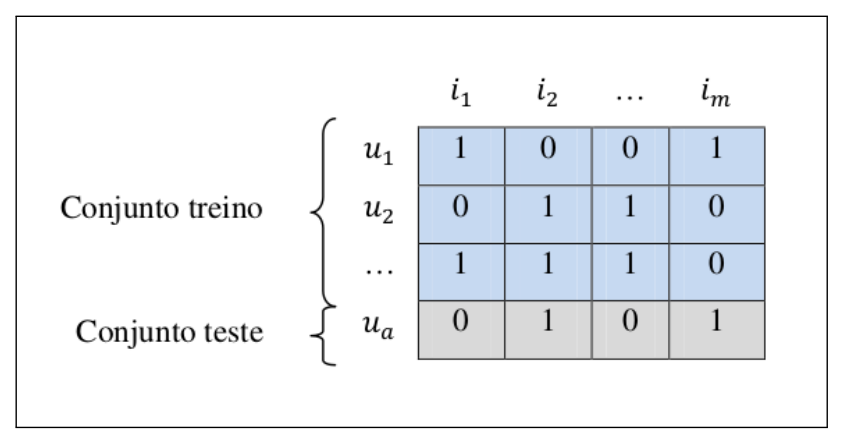

Figura 5.1: Divisão do conjunto de usuários em dois subconjuntos: treinamento e teste (Morais, 2012). 
2. Dos $n$ itens que pertencem ao usuário ativo no conjunto de teste, deve-se, de modo aleatório, "esconder" um item avaliado por ele (passar para 0), fazendo com que aquele item passe a ser desconhecido pelo usuário, como pode ser visto na Figura 5.2. Os itens relevantes, então, são os escondidos marcados como desconhecidos pelo protocolo.

\begin{tabular}{|c|c|c|c|c|c|c|c|c|c|}
\hline & $i_{1}$ & $i_{2}$ & $\ldots$ & $i_{m}$ & & $i_{1}$ & $i_{2}$ & $\ldots$ & $i_{m}$ \\
\hline \multirow{2}{*}{$\begin{array}{l}u_{1} \\
u_{2}\end{array}$} & 1 & 0 & 0 & 1 & \multirow{2}{*}{$\begin{array}{l}u_{1} \\
u_{2}\end{array}$} & 1 & 0 & 0 & 1 \\
\hline & 0 & 1 & 1 & 0 & & 0 & 1 & 1 & 0 \\
\hline \multirow{2}{*}{$\begin{array}{l}\cdots \\
u_{a}\end{array}$} & 1 & 1 & 1 & 0 & \multirow{2}{*}{$\begin{array}{l}\cdots \\
u_{a}\end{array}$} & 1 & 1 & 1 & 0 \\
\hline & 0 & & 0 & 1 & & 0 & 0 & 0 & 1 \\
\hline
\end{tabular}

Figura 5.2: Esquema resumido que representa parte da metodologia usada na avaliação (Morais, 2012).

Por esta razão, para que um usuário seja ativo, é necessário ter pelo menos dois itens iniciais: um para esconder e o outro para treinar o modelo.

3. Os algoritmos de recomendação unimodais são executados (tendo em conta os pressupostos anteriores), com o objetivo de recomendar itens ao usuário ativo em forma de ranque;

4. As técnica de combinação são então aplicadas para executar a concatenação dos ranques. Nesta etapa, a técnica baseada em aprendizado utiliza o conjunto de teste sem os pares escondidos para aprender o comportamento dos usuários.

5. A partir dos itens recomendados pelas técnicas, é contabilizado o número de acertos no ranque, isto é, dos itens escondidos que foram recomendados. Este valor é normalmente chamado de número de hits.

\subsubsection{Métricas de Avaliação e Validação}

Para medir a capacidade preditiva dos sistemas de recomendação neste trabalho, foram utilizados o Protocolo All-but-one (Breese et al., 1998) juntamente com a validação cruzada em 10 partições (do inglês 10-fold cross-validation), e as métricas de precisão e de MAP (Voorhees e Harman, 2005). Para fazer isso, as sessões no conjunto de dados são divididas aleatoriamente em 10 subconjuntos. Para cada partição, utiliza-se $n-1$ desses subconjuntos de dados para o treinamento e o restante para teste. O conjunto de treinamento $t_{r}$ é usado para construir o modelo de recomendação. Para cada usuário no conjunto de teste $T_{e}$, esconde-se aleatoriamente um item, chamado de amostra verdade 
$H$. Os demais itens representam o conjunto de itens observáveis, $O$, com base no qual a recomendação é feita. Em seguida, calcula-se precisão e o MAP da seguinte forma:

Precisão: porcentagem de itens recomendados que são relevantes. Essa métrica é calculada comparando, para cada usuário no conjunto de teste $T_{e}$, o conjunto de $R$ recomendações que o sistema faz, dado o conjunto de observáveis $O$ contra o conjunto $H$ :

$$
\operatorname{Precisa\tilde {o}}\left(T_{e}\right)=\frac{1}{\left|T_{e}\right|} \sum_{j=1}^{\left|T_{e}\right|} \frac{\left|R_{j} \cap H_{j}\right|}{\left|R_{j}\right|} .
$$

MAP (do inglês Mean Average Precision): calcula a precisão considerando a respectiva posição na lista ordenada de itens recomendados. Com essa métrica, obtém-se um único valor de precisão para um conjunto de teste $T_{e}$ :

$$
M A P\left(T_{e}\right)=\frac{1}{\left|T_{e}\right|} \sum_{j=1}^{\left|T_{e}\right|} \operatorname{AveP}\left(R_{j}, H_{j}\right)
$$

sendo que a precisão média (AveP) é dada por:

$$
\operatorname{AveP}\left(R_{j}, H_{j}\right)=\frac{1}{\left|H_{j}\right|} \sum_{r=1}^{\left|H_{j}\right|}\left[\operatorname{Prec}\left(R_{j}, r\right) \times \delta\left(R_{j}(r), H_{j}\right)\right]
$$

onde $\operatorname{Prec}\left(R_{j}, r\right)$ é a precisão para todos os itens recomendados até o ranque $r$. Além disso, $\delta\left(R_{j}(r), H_{j}\right)=1$, se o item previsto no ranque $r$ é um item relevante $\left(R_{j}(r) \in H_{j}\right)$ ou zero, caso contrário.

Para os experimentos realizados neste trabalho, foram computadas a Precisão@ $N$ e o MAP@ $N$, para $N$ igual a 1,3,5 e 10. Para cada abordagem e métricas utilizadas, os valores dos 10 folds são combinados utilizando a média, variância e desvio padrão dos dados. Para validar a comparação das técnicas e dos algoritmos no experimentos realizados, foi aplicado o teste estatístico T-Student que possui 95\% de nível de confiança (Mitchell, 1997).

A base foi divida em dois conjuntos: $80 \%$ para treinamento e $20 \%$ para teste. O conjunto de treinamento é utilizado para processar os algoritmos de recomendação isoladamente, além de ser utilizado pela técnica de aprendizado. Já o conjunto deteste, é responsável por simular o conjunto verdade dos usuários utilizando o protocolo All-but-one, ou seja, é responsável por simular as interações em tempo real do usuário, identificando qual próximo item o usuário irá acessar, dadas as suas interações anteriores no sistema. 


\subsection{Estudo 1: Base de Dados LastFM}

O primeiro estudo tem como objetivo validar o modelo proposto através da sua aplicação em uma base de dados real, contendo somente interações implícitas. Além disso, analisar quais critérios devem ser levados em consideração para aplicação das técnicas, e a relevância do uso e da combinação de diferentes interações para recomendar itens.

Conforme discutido por Herlocker et al. (Herlocker et al., 2000), avaliações de sistemas de recomendação podem ser realizadas com análises off-line, nos quais são utilizados conjuntos de dados históricos de um sistema de recomendação, em que testes são feitos e métricas são analisadas.

Os experimentos deste estudo basearam-se em uma adaptação de uma base real para comparar resultados das técnicas propostas atuando isoladamente, e os algoritmos já existentes na literatura. Dessa maneira, quatro experimentos foram conduzidos: o primeiro consistiu em utilizar as técnicas existentes na literatura; o segundo nas técnicas baseadas em heurísticas; o terceiro a técnica baseada em aprendizagem; e por fim, o quarto usando a técnica baseada em grupos.

\subsubsection{Base de Dados Experimental}

Para a realização dos experimentos do Estudo 1, foi necessária a utilização de uma base de dados com informações reais que possuíssem os seguintes requisitos:

a) Grande quantidade de usuários;

b) Grande quantidade de itens;

c) Grande quantidade de interações implícitas sobre itens.

Para atender a estes requisitos, optou-se pela adaptação da base de dados do LastFM $2 k$ (Cantador et al., 2011), que contém interações, como o histórico de visualização (se o usuário visualizou ou não um artista) e as atribuições de etiquetas (atribuiu ou não uma palavra chave a um artista). Uma vez que a base de dados do LastFM foi escolhida, foi necessário adaptá-la, a fim de obedecer aos critérios dos métodos de avaliação estipulados. Portanto, foram executadas as seguintes etapas:

- Unificar as interações de histórico e etiquetas como uma única base, tendo em vista que os dados contidos na base são apresentados isoladamente;

- O conjunto gerado com as duas interações foi dividido, de forma aleatória, em dois conjuntos diferentes: treinamento e teste, mantendo apenas os usuários ativos, ou 
seja, que possuíam pelo menos duas interações na base. A porcentagem usada nesta divisão foi, respectivamente, $80 \%$ e $20 \%$ do número total de interações, garantindo que todos os usuários que estavam no conjunto de teste, também deveriam estar no de treinamento;

- O conjunto teste foi utilizado para aplicar o protocolo All-but-one, no qual se esconde um item conhecido pelo usuário e constrói-se o conjunto verdade;

- O conjunto treinamento foi utilizado para aplicar as técnicas propostas e existentes, para gerar os ranques com recomendações personalizadas;

- O conjunto de recomendações geradas foi comparado com o conjunto verdade, através das métricas de MAP e precisão, descritas na Seção 5.1.3.

Com isso, as configurações da base de dados, após a divisão e processamento dos requisitos, ficaram conforme as Tabelas 5.1 e 5.2 .

Tabela 5.1: Configuração da base de dados LastFM após sua divisão em teste e treinamento com usuários ativos.

\begin{tabular}{|l|l|l|l|}
\hline & Interações & Usuários & Artistas \\
\hline LastFM & 163.897 & 1.892 & 18.022 \\
\hline Treino & 131.118 & 1.885 & 17.838 \\
\hline Teste & 32.779 & 1.885 & 8.598 \\
\hline
\end{tabular}

Tabela 5.2: Representação individual de cada tipo de interação, no qual foram eliminados aqueles usuários com um só interação na base LastFM (usuários não ativos).

\begin{tabular}{|l|l|l|l|l|}
\hline Tipo de Interação & Quantidade & \% & Usuários & Artistas \\
\hline Histórico de Visualização & 92.826 & 56,64 & 1.884 & 17.626 \\
\hline Etiquetas & 70.811 & 43,20 & 1.640 & 12.440 \\
\hline
\end{tabular}

Em seguida foi feita uma avaliação dos experimentos processados nos dados apresentados na base.

\subsubsection{Avaliação da Base de Dados de Treinamento}

As avaliações iniciais na base de dados de treino tem como objetivo evidenciar os problemas relativos aos sistemas de recomendação, como o relacionado ao novo usuário e às matrizes esparsas por falta de interações de usuários, além de analisar dados quantitativos, referentes à quantidade de interações por usuários, distribuição das interações, 
quantidade de interações por itens, entre outros. Para isso, os tipos de interação (conjunto de histórico e conjunto de etiquetas) foram analisados de forma isolada e em conjunto.

\section{Problema do Novo Usuário}

Neste experimento, consideram-se novos usuários aqueles que fizeram menos de 10 interações com itens da base. As Figuras 5.3(a) e 5.3(b) demonstram os gráficos que consideram cada tipo de interação individualmente, apresentando 94 usuários (4,99\%) do conjunto de histórico e 1038 usuários $(55,48 \%)$ do conjunto de etiquetas, como novos usuários.

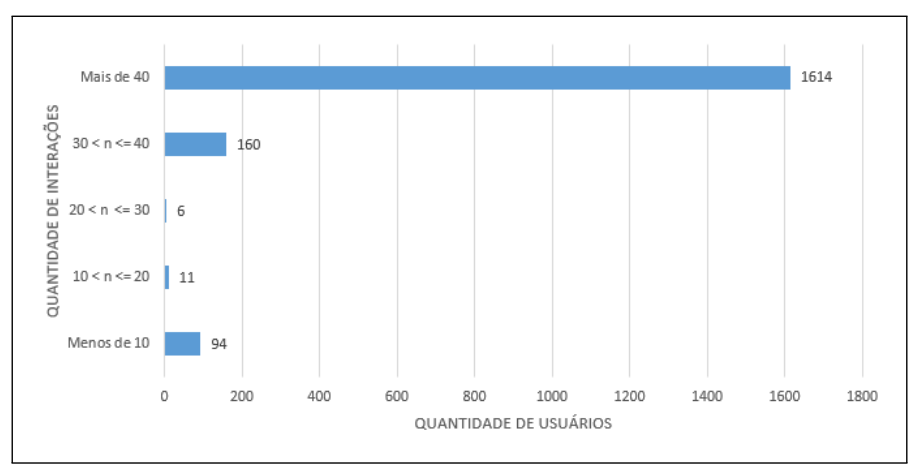

(a) Histórico de visualização.

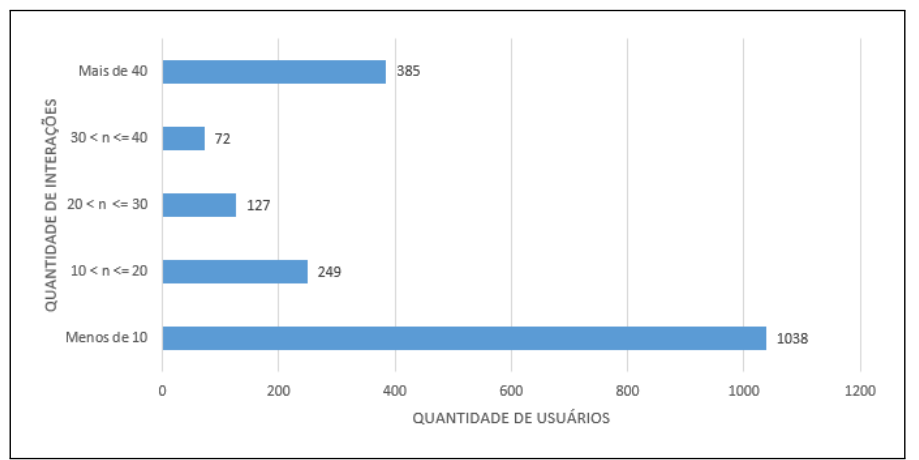

(b) Atribuição de etiquetas.

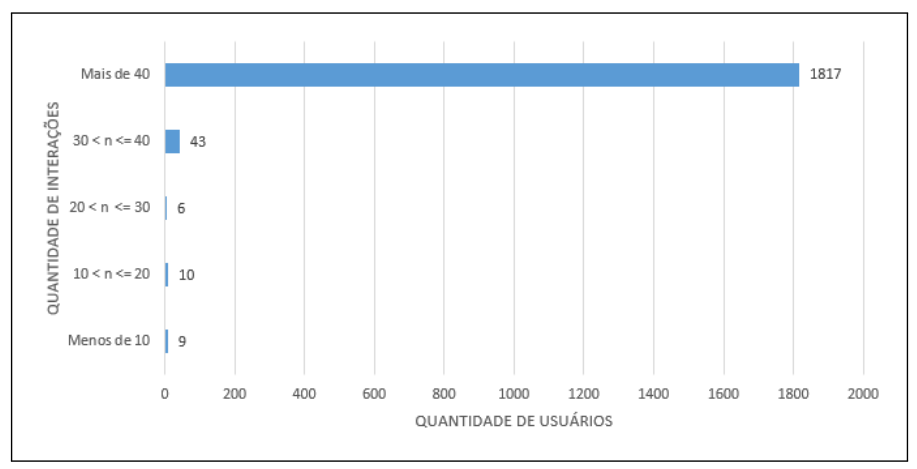

(c) Conjuntos concatenados.

Figura 5.3: Número de interações feitas por usuários nas bases de treinamento do LastFM ( $n$ representa o número de interações). 
Ao concatenar os dois tipos de interação presentes na base de dados em um só conjunto, surge um novo cenário representado na Figura 5.3(c), no qual se consegue reduzir o número de novos usuários no conjunto de treinamento. Dessa maneira, evidencia-se que a proposta de se utilizar multimodalidade de interações poderá trazer benefícios para a acurácia das recomendações.

\section{Matrizes esparsas}

Na Figura 5.4, que representa o conjunto treinamento de histórico de visualização, vê-se que $673(2,15 \%)$ dos artistas não receberam nenhuma interação, 10519 (58,37\%) obtiveram apenas 1 interação representando o maior grupo do conjunto, e os demais artistas que obtiveram mais de 2 interações, representam 39,48\%. No conjunto de treinamento de atribuição de etiquetas, apresentado na Figura 5.5, 5610 (31,13\%) dos artistas não receberam nenhuma interação, 4152 (23,04)\% obtiveram apenas uma interação associada e os demais que receberam mais de duas interações, representam 45,83\% do conjunto.

Para ser calculada a similaridade entre duas pessoas nos algoritmos de recomendação, é de grande importância a quantidade de itens, entre os quais o usuário tenha interagido no sistema. Faz uma grande diferença calcular a similaridade entre duas pessoas quando a maioria das interações se concentram em poucos itens do sistema, ou se as interações estão distribuídas pela maioria dos itens da base. Logo, as matrizes de interações isoladas (conjunto de histórico e conjunto de etiquetas) da base de treinamento são muito mais esparsas quando comparadas de forma unificada, conforme apresentado na Figura 5.6, onde foi possível reduzir o número de itens sem nenhum tipo de interação no conjunto.

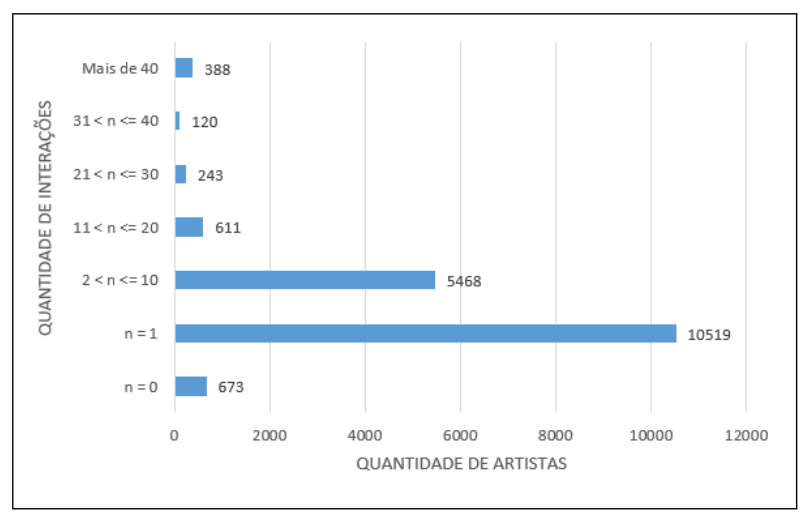

Figura 5.4: Histórico de visualização.

Nas comunidades virtuais com grande quantidade de usuários e de itens, é comum que a matriz de avaliação usuário $\times$ item seja esparsa, pois os usuários geralmente avaliam uma pequena quantidade de artefatos do total existente, gerando uma grande porcentagem de células vazias. Para reduzir este problema neste trabalho, procurou-se levar em conta diferentes tipos de interação do usuário a fim de tornar a matriz mais completa. 


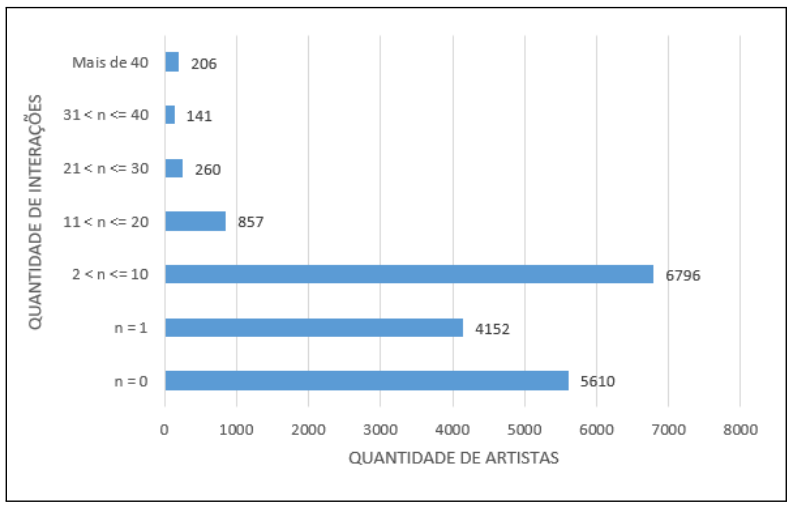

Figura 5.5: Atribuição de etiquetas.

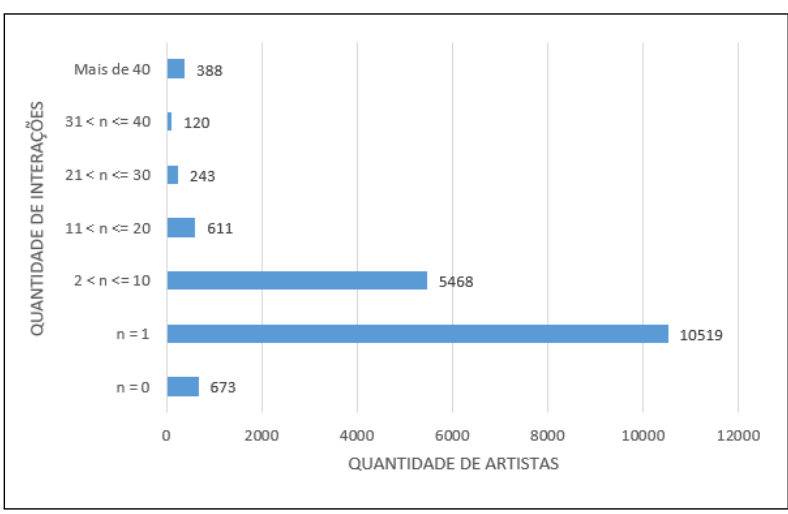

Figura 5.6: Conjuntos concatenados.

\subsubsection{Experimentos Realizados}

Nesta seção são apresentados os quatro experimentos realizados com o objetivo de testar a ferramenta proposta, e comparar com os métodos tradicionais de recomendação. Os experimentos estão divididos em:

a) Técnicas existentes na literatura;

b) Técnicas baseadas em heurísticas;

c) Técnica baseada em aprendizagem;

d) Técnica de recomendação colaborativa baseada em grupos.

Para a realização dos experimentos foi utilizada a análise off-line. Nesta análise, são utilizados conjuntos de dados de histórico de visualização e de etiquetas provenientes da base Het Rec LastFM $2 k$, onde se realizam testes para comparações de resultados. Uma das vantagens da análise off-line é a realização de testes rápidos, pois não necessitam do envolvimento direto do usuário e podem ser facilmente repetidos. Inicialmente são apresentados os resultados de cada técnica isoladamente, e posteriormente, são discutidos e comparados todos os resultados gerados. 


\subsubsection{Técnicas Existentes na Literatura}

O primeiro experimento tem por objetivo observar o comportamento individual de cada tipo de interação processado por algoritmos de recomendação tradicionais. Nesta etapa, utilizou-se o algoritmo BPR MF, apresentado na Seção 2.3.3.3, para processar as interações implícitas abordadas no conjunto de dados. Este algoritmo foi escolhido por fornecer bons resultados para os tipos de interações que foram consideradas, quando comparadas com outros algoritmos. Além disso, é um algoritmo muito testado e reconhecido para geração de ranques em sistemas de recomendação, sendo também de fácil entendimento e implementação, assim como rápida execução no sistema. As Figuras 5.7 e 5.8 representam os resultados de MAP e precisão, respectivamente, gerados pelo BPR MF para cada tipo de interação individualmente.

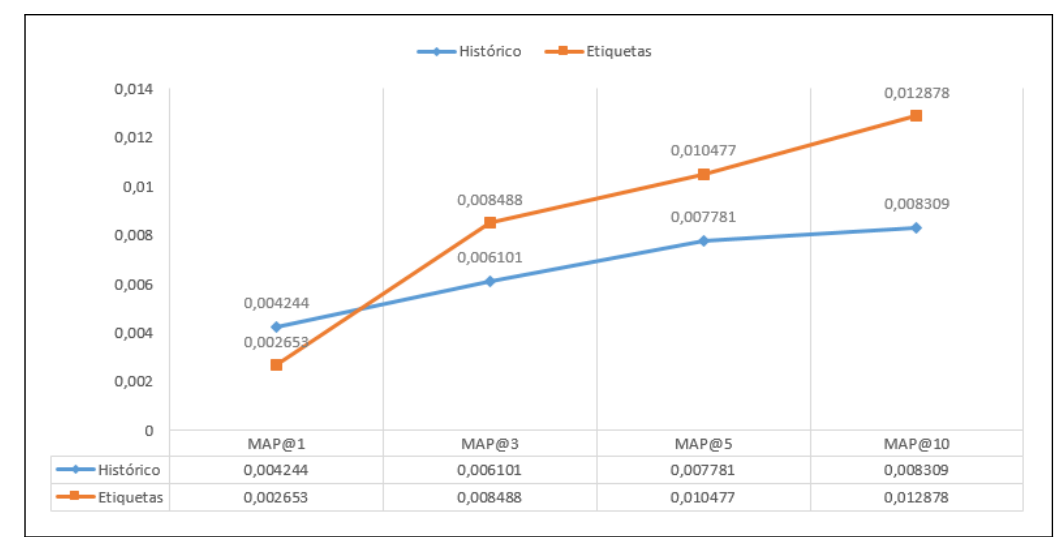

Figura 5.7: Gráficos e tabelas comparativas de MAP em cada tipo de interação na base do LastFM.

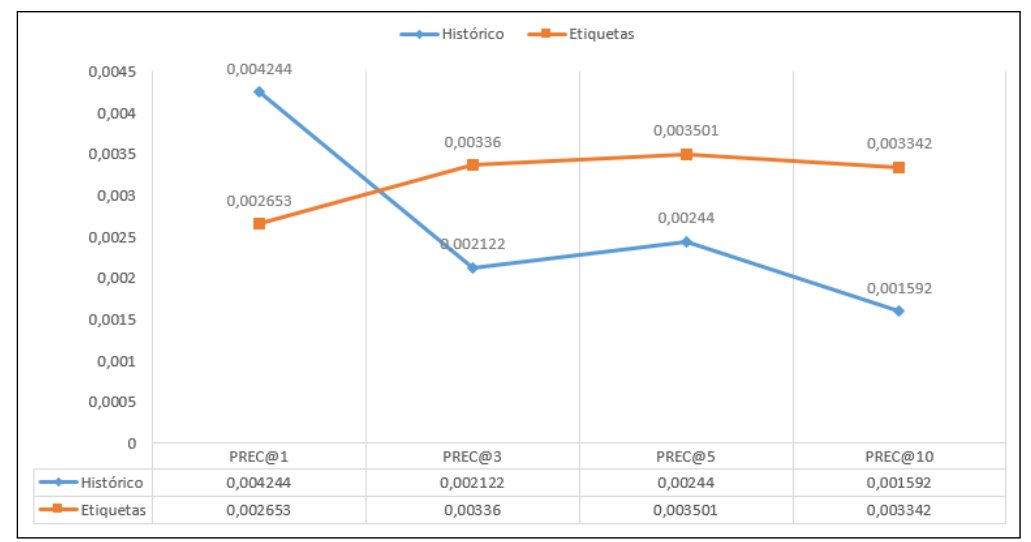

Figura 5.8: Gráficos e tabelas comparativas de precisão em cada tipo de interação na base do LastFM.

Com esses experimentos, pode-se perceber que o conjunto de atribuição de etiquetas gera melhores resultados que o conjunto de histórico de visualização. Isso ocorre porque 
as interações de atribuição de etiquetas tem um valor mais relevante do que o histórico de visualizações de um artista, uma vez que atribuir uma etiqueta a um determinado artista demanda muito mais esforço por parte do usuário do que simplesmente visualizar um item.

Através dos gráficos gerados por estes experimentos, também pode-se perceber que o MAP tem a tendência de retornar valores maiores à medida em que se consideram novas posições no ranque, ao contrário da precisão. Isso pode ser explicado pois o MAP considera apenas os itens relevantes e suas posições no ranque; assim, quanto mais itens são retornados, maior será o número de itens relevantes. No caso da precisão, por sua vez, já que é uma medida baseada em conjunto (a ordem dos itens é irrelevante), quanto maior o número de itens for recomendado aos usuários, maior também será o número de itens falsos positivos retornados, assim consequentemente, afetando a medida de precisão. Neste contexto, pode-se afirmar que o MAP é a medida mais precisa e adequada para se avaliar o resultados retornados em um ranque com $N$ posições.

\subsubsection{Técnicas Baseadas em Heurísticas}

O segundo experimento consistiu em combinar os resultados gerados por cada tipo de interação através da proposta de combinação baseada em heurísticas, como apresentado na Seção 4.3. A técnica baseada em etiquetas pondera com maior peso aqueles itens que contêm pelo menos uma etiqueta atribuída, enquanto a técnica baseada em médias leva em conta somente aqueles pares com maiores pesos que foram recomendados por ambos os tipos de interação. Os resultados gerados por estes experimentos estão representados nas Figuras 5.9 e 5.10 .

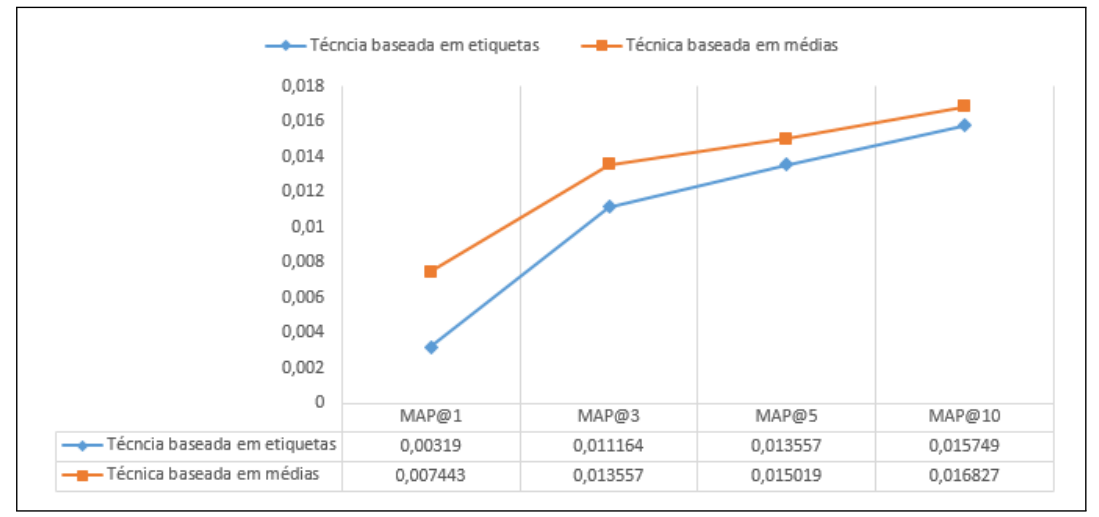

Figura 5.9: Gráficos e tabelas comparativas de MAP nas técnicas baseadas em heurísticas na base do LastFM.

De acordo com os resultados, pode-se observar que a técnica baseada em médias se sobressai à baseada em etiquetas, demonstrando que considerar somente os pares que foram recomendados em ambas interações é mais importante do que ponderar somente 


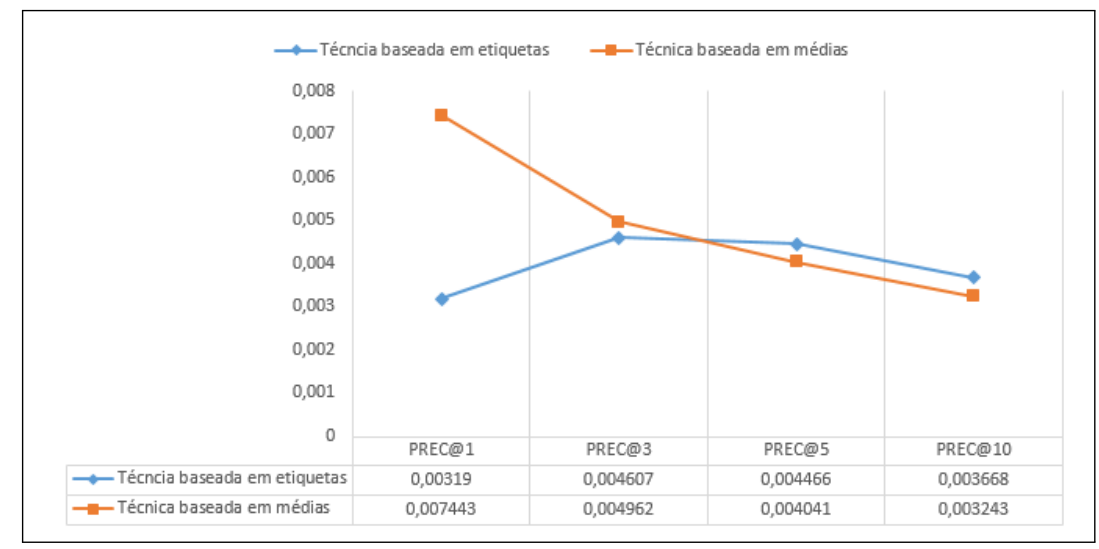

Figura 5.10: Gráficos e tabelas comparativas de precisão nas técnicas baseadas em heurísticas na base do LastFM.

um tipo de interação utilizando heurísticas, tendo em vista que quanto maior a frequência de um item nos ranques, maior será a probabilidade de um usuário ter afinidade por ele.

\subsubsection{Técnica Baseada em Aprendizagem}

Para realizar o terceiro experimento, utilizou-se a técnica de aprendizagem proposta na Seção 4.4, que baseia-se na aprendizagem de máquina para predizer pesos responsáveis por ponderar cada tipo de interação utilizada. Esta técnica tem como objetivo combinar os tipos de interações feitas por um usuário a determinado artista, dando maior relevância à interação através da qual o usuário demonstra suas preferências com mais precisão. Nesta técnica, o que determina qual interação deve ser considerada como mais importante é o algoritmo de aprendizagem que processa todas as interações de todos os tipos feitas pelo usuário, e calcula através dos pesos destas interações o tipo que mais define suas preferências. A Figura 5.11 apresenta os resultados de MAP e precisão, gerados por esta abordagem.

\subsubsection{Técnica de Recomendação Colaborativa Baseada em Grupos}

Por fim, no quarto experimento aplicou-se ao conjunto de treinamento da base de dados uma técnica de recomendação baseada na similaridade de usuários classificados em grupos. Como proposto e apresentado na Seção 4.5, esta técnica consiste em uma etapa de pré-processamento responsável por agrupar os usuários de acordo com a similaridade de suas interações através do cálculo de cosseno e gerar recomendações para cada grupo isoladamente, a fim de eliminar artistas com os quais os usuários não tenham nenhuma afinidade, e aumentar a probabilidade de retornar artistas mais relevantes para os usuários. Neste experimento, foram utilizados quatro valores para $k$ (número de grupos), com base em experimentos automatizados pela ferramenta, que definem estes valores como os 


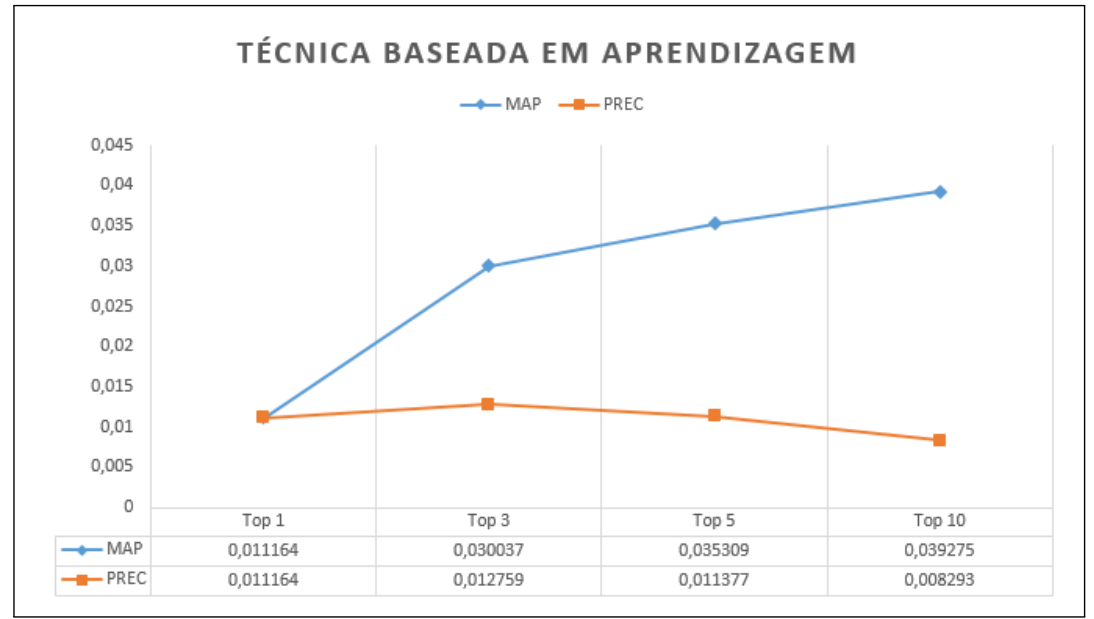

Figura 5.11: Gráfico comparativo de MAP e precisão na técnica baseada em aprendizagem na base do LastFM.

melhores para a base de dados em que este experimento está sendo aplicado. A ferramenta considera os melhores valores para $k$ em um intervalo entre 2 e 100, executando o algoritmos várias vezes, avaliando a soma dos erros quadráticos para se obter os valores estipulados. Os resultados gerados são ilustrados através dos gráficos das Figuras 5.12 e 5.13 .

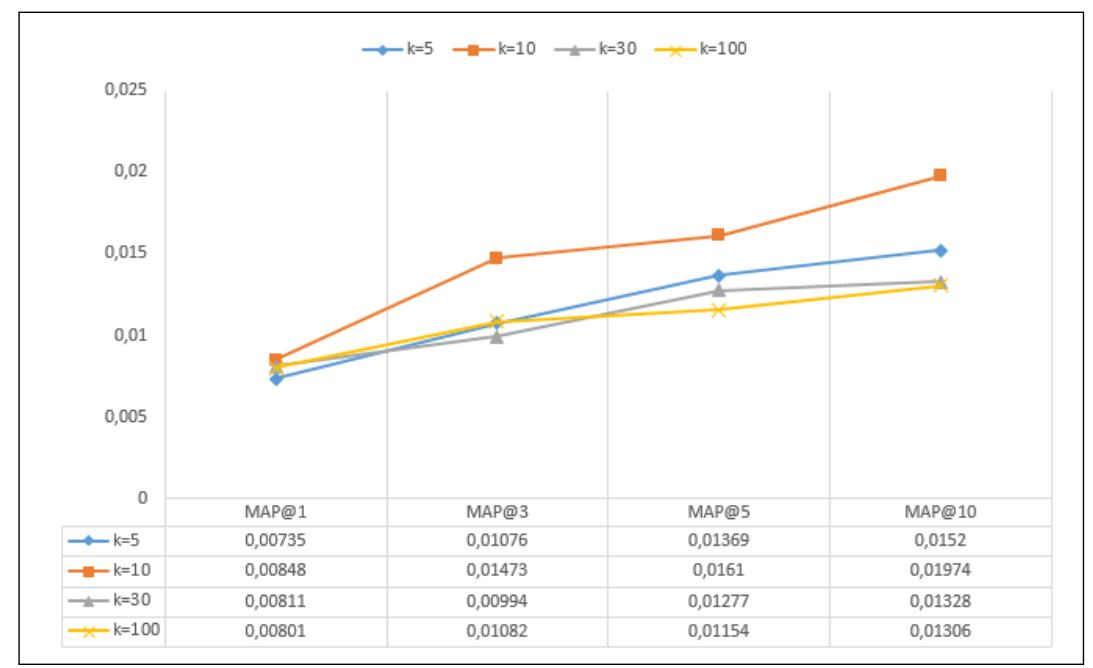

Figura 5.12: Gráficos e tabelas comparativas de MAP na técnica baseada em grupos na base do LastFM.

A utilização de dez grupos de usuários retorna itens mais relevantes que os demais números de grupos testados na base do LastFM; dessa maneira, definiu-se este valor como o valor padrão desta técnica. Esta ocorrência deve-se pela disposição dos dados dos usuários na base, sendo que, dadas as interações feitas pelos usuários, essas refletem suas preferências. Com a utilização do algoritmo de agrupamento, conseguiu-se representar 


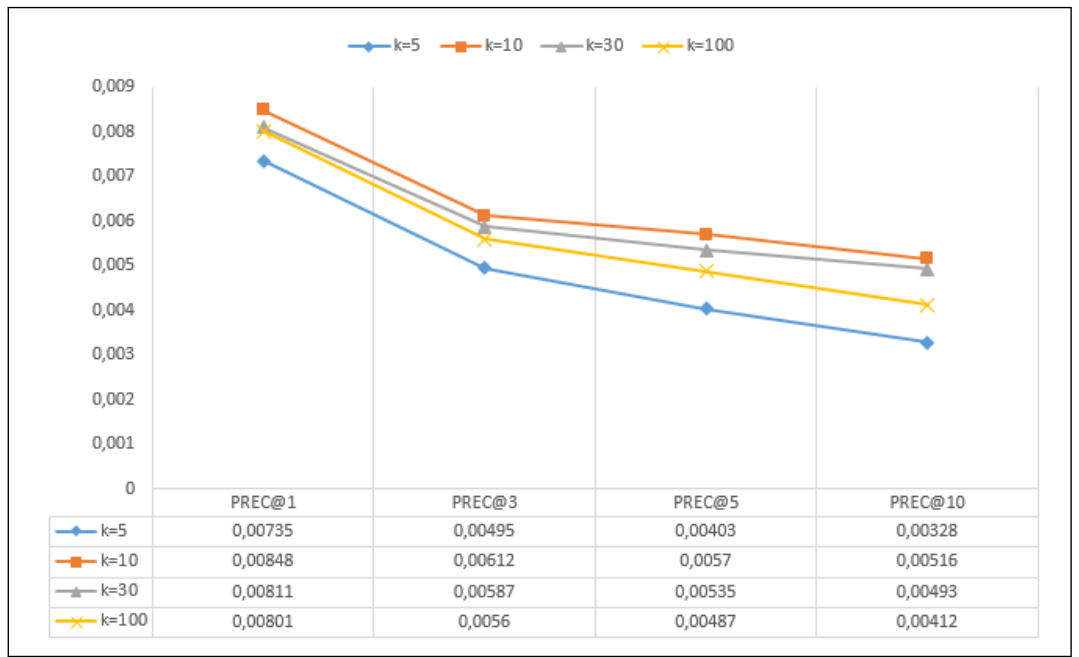

Figura 5.13: Gráficos e tabelas comparativas de precisão na técnica baseada em grupos na base do LastFM.

um número aproximado de grupo de usuários baseados em suas preferências de acordo com suas interações, e assim, recomendar itens mais relevantes para os usuários.

A seguir, são comparados os resultados obtidos pelos quatro experimentos conduzidos, acompanhados das conclusões para o Estudo 1.

\subsubsection{Conclusões do Estudo 1}

Este estudo teve como objetivo demonstrar que a combinação de diferentes tipos de interação implícitas (histórico de visualização e etiquetas) conseguem gerar melhores resultados do que técnicas existentes na literatura. Com o intuito de mostrar evidências que comprovam a hipótese desta pesquisa, as Figuras 5.14 e 5.15 apresentam os resultados dos quatro experimentos desenvolvidos durante este estudo.

De acordo com os resultados gerados pela ferramenta proposta, pode-se notar que a combinação dos dois tipos de interação fornecidos pela base do LastFM (histórico e etiquetas), gera melhores resultados na maioria das posições $N$ do ranque. Isto acontece pois essas técnicas procuram combinar todas as interações dos usuários a fim de tornar seu perfil mais preciso, fazendo com que as recomendações sejam mais adequadas com suas preferências.

Os resultados obtidos e descritos neste estudo apresentam valores baixos em decorrência do protocolo de avaliação utilizado. O protocolo All-but-one esconde um item de cada usuário no conjunto de teste e considera estes itens ocultos, como o conjunto verdade (Breese et al., 1998). Como nestes experimentos recomenda-se $N$ itens para cada usuário, a probabilidade dos itens do conjunto verdade serem retornados é pequena, o que reflete nos valores de precisão e MAP. Desta maneira, é importante contar apenas com as diferenças entre os resultados apresentados pelos experimentos. Para realizar a validação 


\section{CAPÍTULO 5. EXPERIMENTOS E RESULTADOS}

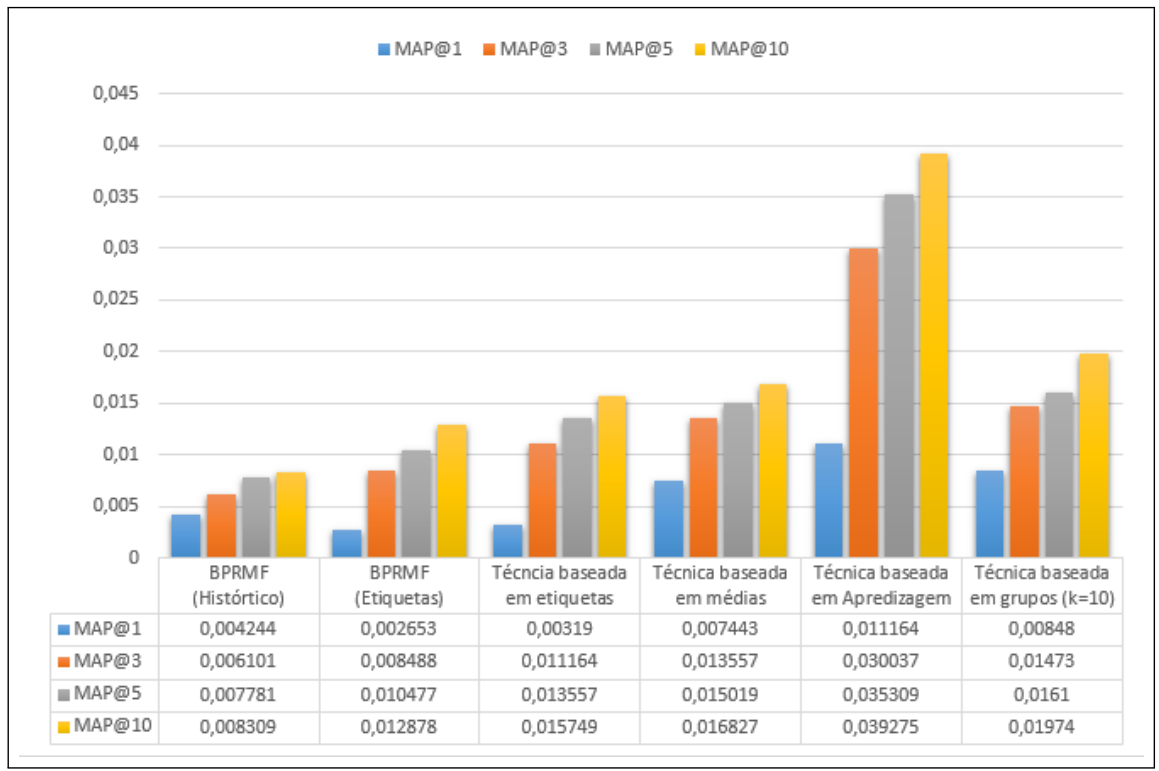

Figura 5.14: Gráfico e tabela comparativa de MAP entre as técnicas apresentadas na base do LastFM.

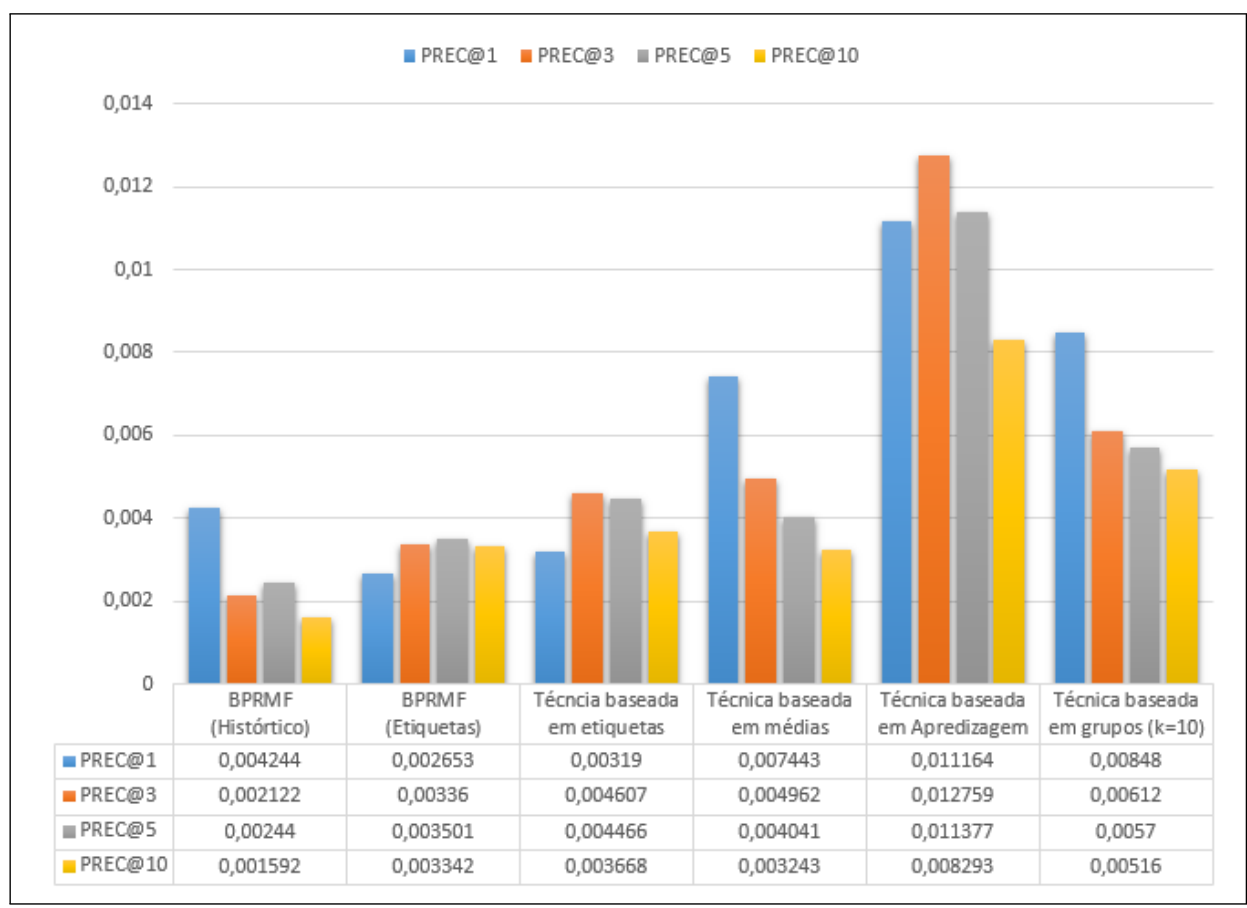

Figura 5.15: Gráfico e tabela comparativa de precisão entre as técnicas apresentadas na base do LastFM.

estatística destes experimentos, realizou-se o teste T-Student para rejeitar ou não uma hipótese nula, quando a estatística de teste $(t)$ segue uma distribuiçãoT-Student $(p<$ 0.05). Os valores apresentados nas Tabelas 5.3 e 5.4 representam os resultados dos cálculo de desvio padrão para cada técnica, indicando que os resultados de cada uma delas são estatisticamente diferentes e não nulos. 
CAPÍTULO 5. EXPERIMENTOS E RESULTADOS

Tabela 5.3: Desvio Padrão para a métrica de MAP.

\begin{tabular}{|c|l|l|l|l|}
\hline Técnica & MAP@1 & MAP@3 & MAP@5 & MAP@10 \\
\hline BPRMF (Histórico) & 0,000121 & 0,000064 & 0,000169 & 0,000201 \\
\hline BPRMF (Etiquetas) & 0,000143 & 0,000529 & 0,000287 & 0,000458 \\
\hline $1^{\text {a }}$ T. baseada em heurística & 0.000143 & 0.000529 & 0.000287 & 0.000458 \\
\hline $2^{\text {a }}$ T. baseada em heurística & 0,000497 & 0,000123 & 0,000075 & 0,000192 \\
\hline T. baseada em aprendizagem & 0,000428 & 0,000137 & 0,000065 & 0,000236 \\
\hline T. baseada em grupos $(\mathrm{k}=10)$ & 0,000753 & 0,0000487 & 0,000131 & 0,000095 \\
\hline
\end{tabular}

Tabela 5.4: Desvio Padrão para a métrica de precisão.

\begin{tabular}{|c|l|l|l|l|}
\hline Técnica & PREC@1 & PREC@3 & PREC@5 & PREC@10 \\
\hline BPRMF (Histórico) & 0,000012 & 0,000037 & 0,000108 & 0,000055 \\
\hline BPRMF (Etiquetas) & 0,000142 & 0,000122 & 0,000087 & 0,000105 \\
\hline $1^{\text {a }}$ T. baseada em heurística & 0,000032 & 0,000187 & 0,000098 & 0,000131 \\
\hline $2^{\text {a }}$ T. baseada em heurística & 0,000217 & 0,000320 & 0,000063 & 0,000081 \\
\hline T. baseada em aprendizagem & 0,000098 & 0,000123 & 0,000027 & 0,000032 \\
\hline T. baseada em grupos (k=10) & 0.000052 & 0.0000478 & 0.000138 & 0.000067 \\
\hline
\end{tabular}

Com base nos experimentos realizados neste estudo, a técnica baseada em aprendizagem apresenta uma melhor qualidade nas recomendações, quando comparada às demais técnicas da ferramenta e às já existentes na literatura. Isto se deve pela capacidade que o algoritmo tem de aprender as preferências dos usuários através de suas interações, e utilizar esta informação para combinar as recomendações geradas individualmente para cada tipo de interação. As demais abordagens apresentam melhores resultados quando comparadas com as técnicas já existentes na literatura, que no caso deste estudo, é um algoritmo responsável por processar interações unimodais. As abordagens baseadas em heurísticas, apesar de apresentarem bons resultados, podem apresentar um desempenho não tão promissor em outros domínios, pois foram desenvolvidas para os tipos de interação contidos nesta base de dados. Já a técnica baseada em grupos, que utiliza um algoritmo de agrupamento para reduzir a dimensionalidade das matrizes nos algoritmos tradicionais de recomendação, combinando usuários através de suas preferências, obteve melhores resultados quando comparada às técnicas tradicionais e baseadas em heurísticas. Isto ocorre em decorrência da sua capacidade de eliminar itens que o usuário não tem nenhum tipo de afinidade, e aumentar as chances de recomendar itens que mais se aproximam com as preferências dele.

Os quatro experimentos do Estudo 1 foram de extrema importância para validação da ferramenta proposta, uma vez que permitiram:

1. Verificar o funcionamento da ferramenta em uma comunidade virtual com mais de um tipo de interação de usuário; 
2. Verificar que a aplicação das diferentes técnicas demostram a flexibilidade do modelo, viabilizando sua aplicação com outras técnicas de recomendação;

3. Verificar se as recomendações produzidas pelas técnicas da ferramenta proposta oferecem melhor qualidade do que as recomendações produzidas pelos algoritmos tradicionais;

4. Publicação de trabalhos apresentando os resultados individuais da primeira técnica baseada em heurísticas e da técnica baseada em aprendizagem.

\subsection{Estudo 2: Base de Dados MovieLens}

A fim de validar a solução proposta diante dos objetivos da pesquisa em uma base mais robusta, aplicaram-se as técnicas desenvolvidas na base de dados do MovieLens. Tal base contém uma grande quantidade de interações implícitas, como histórico de visualização e atribuição de etiquetas e de interações explícitas, como avaliação de filmes através de notas. Este estudo tem como finalidade obter informações para a análise dos resultados relacionados aos seguintes objetivos:

- Observar a generalidade das técnicas da ferramenta quando aplicadas em outro domínio;

- Validar o uso da ferramenta em bases com grande quantidade de interações;

- Validar as técnicas utilizando tanto interações implícitas quanto explícitas.

\subsubsection{Base de Dados Experimental}

A escolha da base de dados do MovieLens (Cantador et al., 2011) baseou-se na necessidade de se ter uma base com um grande número de interações por parte dos usuários, e uma diversidade de tipos de interações contendo tanto interações explícitas, quanto implícitas. Neste estudo, extraíram-se como interações implícitas o histórico de visualização (se o usuário visualizou ou não um filme) e atribuições de etiquetas (atribuiu ou não uma palavra-chave a um filme), e como informações explícitas as notas que os usuários atribuíram a um filme. Esta base de dados é uma extensão da base de dados MovieLens 10M, publicado pelo grupo de pesquisa GroupLeans ${ }^{4}$.

Adotando-se as estratégias definidas na Seção 5.2.1 em decorrência dos métodos de avaliação, as configurações da base de dados após a divisão e processamento dos requisitos ficaram conforme as Tabelas 5.5 e 5.6 .

\footnotetext{
${ }^{4}$ http://www.grouplens.org
} 
Tabela 5.5: Configuração da base de dados MovieLens após sua divisão em Teste e Treino com usuários ativos.

\begin{tabular}{|l|l|l|l|}
\hline & Interações & Usuários & Filmes \\
\hline MovieLens & 1.746 .011 & 2.113 & 10.133 \\
\hline Treino & 1.396 .809 & 2.113 & 10.133 \\
\hline Teste & 349.202 & 2.113 & 8.595 \\
\hline
\end{tabular}

Tabela 5.6: Representação individual de cada tipo de interação, no qual foram eliminados aqueles usuários com um só interação na base MovieLens (usuários não ativos).

\begin{tabular}{|l|l|l|l|l|}
\hline Tipo de Interação & Quantidade & \% & Usuários & Filmes \\
\hline Histórico de Visualização & 862.702 & 49,41 & 2.113 & 10.133 \\
\hline Etiquetas & 26.763 & 1,53 & 1.165 & 5.908 \\
\hline Notas & 855.598 & 49,00 & 2.113 & 10.109 \\
\hline
\end{tabular}

As seções a seguir apresentam a avaliação dos dados presentes na base do MovieLens, além de uma análise detalhada dos resultados gerados por cada experimento feito neste estudo.

\subsubsection{Avaliação da Base de Dados de Treino}

Nesta seção, é apresentado um estudo inicial da base de dados com objetivo de mostrar a eficiência da ferramenta proposta quando aplicada sobre problemas clássicos na área de sistemas de recomendação. Além disso, apresenta uma análise de alguns dados quantitativos, referentes à quantidade de interações por usuários e filmes, distribuição das interações, entre outros.

\section{Problema do Novo Usuário}

Com o propósito de evidenciar o problema do novo usuário, na base do MovieLens, foram feitas análises individuais sobre cada conjunto de treinamento. Devido ao maior número de interações e diversidade de gêneros de filmes na base do MovieLens, no estudo 2 adotaram-se como novos usuários aqueles que fizeram menos de 20 interações. As Figuras 5.16(a), 5.16(b) e 5.16(c) demonstram gráficos que consideram cada tipo de interação individualmente apresentando 20 usuários (0,95\%) do conjunto de notas, 1899 usuários $(89,87 \%)$ do conjunto de etiquetas e 13 usuários (0,61\%) do conjunto de histórico, como novos usuários.

A concatenação dos três conjuntos de treinamento de interações resultam em aumentar o número de interações de cada usuário com a base, fazendo com que todos os usuários 


\section{CAPÍTULO 5. EXPERIMENTOS E RESULTADOS}

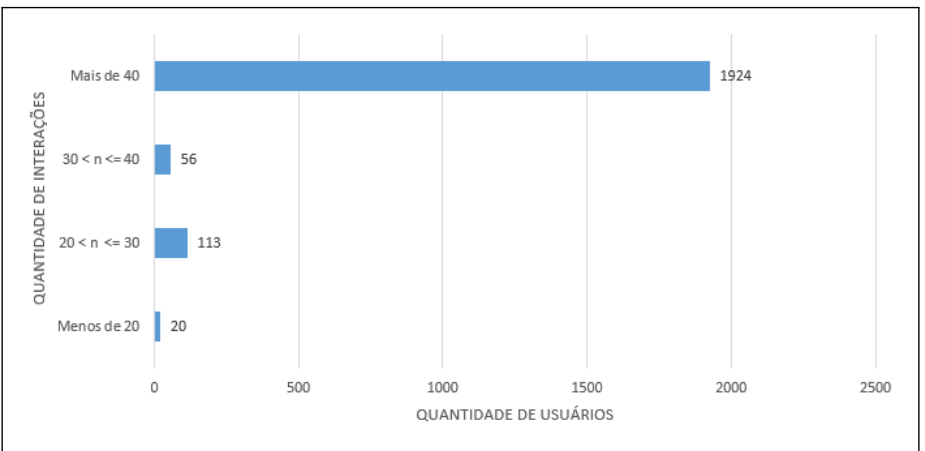

(a) Notas.

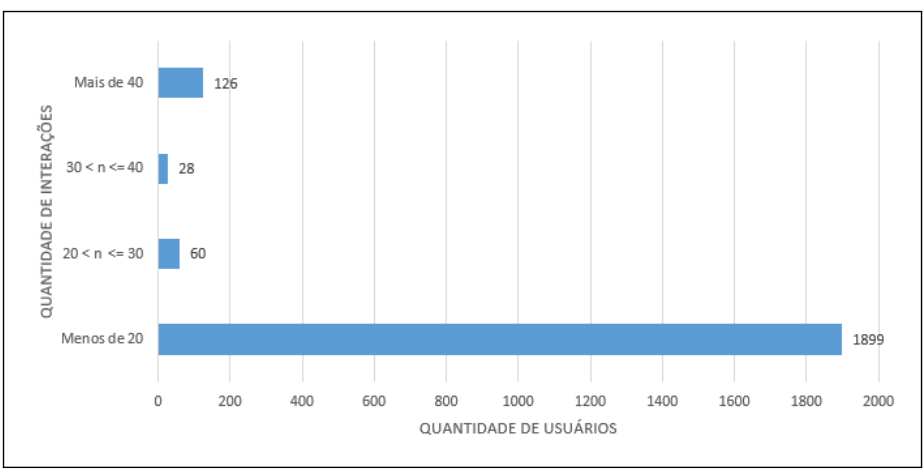

(b) Atribuição de etiquetas.

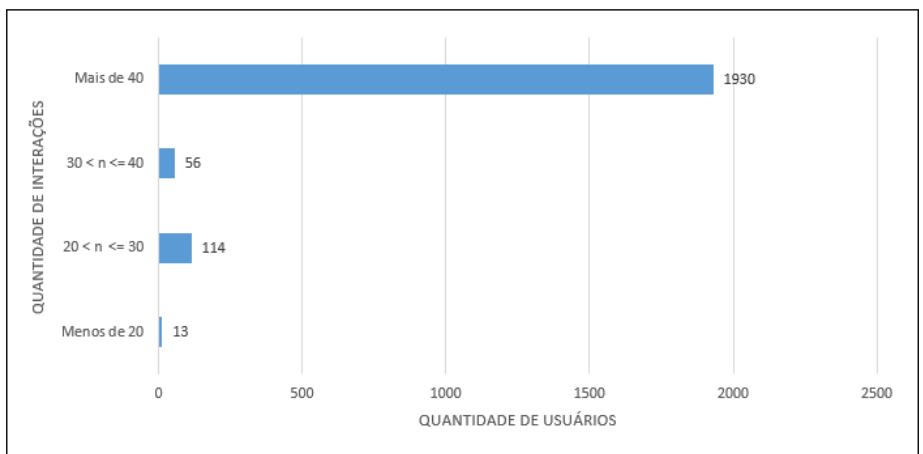

(c) Histórico de visualizção.

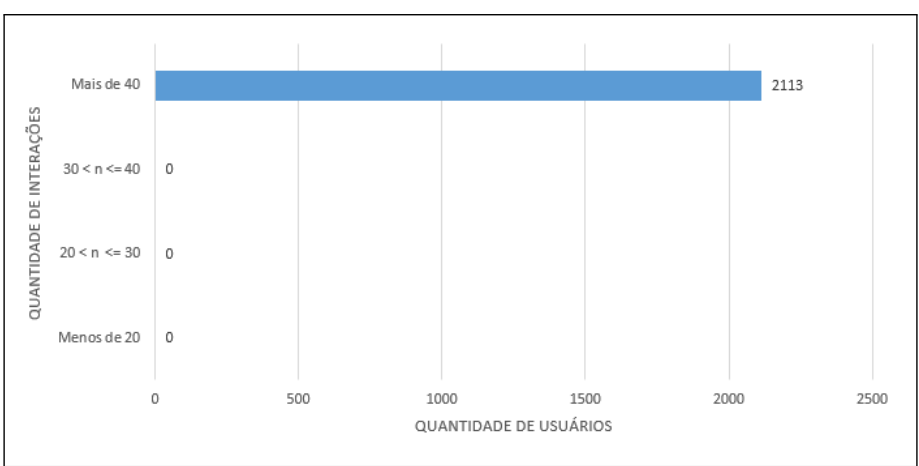

(d) Conjuntos concatenados.

Figura 5.16: Número de interações feitas por usuários nas bases de treinamento do MovieLens ( $n$ representa o número de interações). 
possuam mais de quarenta interações com os filmes do MovieLens ocasionando a inexistência de novos usuários na base, como pode ser visto na Figura 5.16(d). Isso mais uma vez, reforça a proposta do trabalho que é a utilização de múltiplas interações no processo de recomendação.

\section{Matrizes Esparsas}

Considerando o problema de esparsidade de matrizes, foram feitas análises quantitativas individuais a respeito de cada tipo de interação que cada filme obteve. O conjunto treinamento de notas representado na Figura 5.17 contém 24 (0,23\%) de filmes sem nenhuma interação, 502 (5,94\%) com apenas uma interação e 93,83\% filmes com duas ou mais interações. No conjunto de treinamento de atribuição de etiquetas apresentado na Figura 5.18, 4225 (41,69\%) dos filmes não receberam nenhuma interação, 1997 (19,71\%) obtiveram apenas uma interação associada e $61,4 \%$ dos filmes obtiveram mais de duas interações. Já no conjunto de treinamento de histórico de navegação, todos os filmes tiveram pelo menos uma interação, como pode ser visto na Figura 5.19

Ao utilizar todos os tipos de interações contidos na base de dados, é possível considerar mais interações para o preenchimento das matrizes, reduzindo assim o número de itens que não obtiveram nenhuma avaliação. A Figura 5.20 ilustra o cenário descrito, apresentando o uso de todas as interações disponíveis na base de dados.

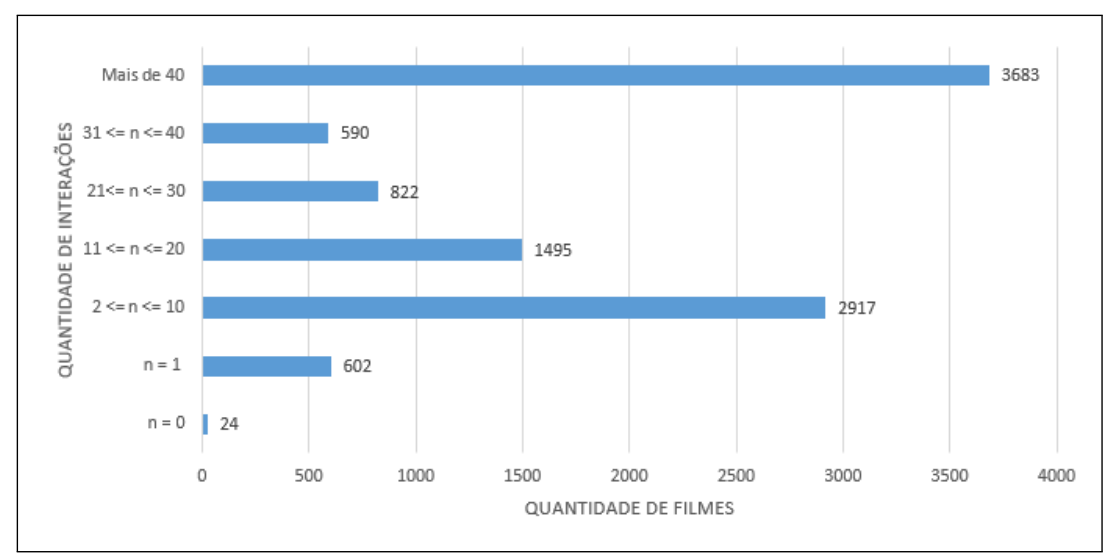

Figura 5.17: Avaliação das notas sobre filmes nos conjuntos de treinamento do MovieLens ( $n$ representa o número de interações).

\subsubsection{Experimentos Realizados}

Nesta seção são apresentados os resultados dos experimentos realizados utilizando as técnicas existentes na literatura e as propostas na ferramenta. Para a realização dos experimentos foi utilizada a análise off-line dos dados, utilizando as interações de histórico de navegação, atribuição de etiquetas e avaliação através de notas. Inicialmente são 


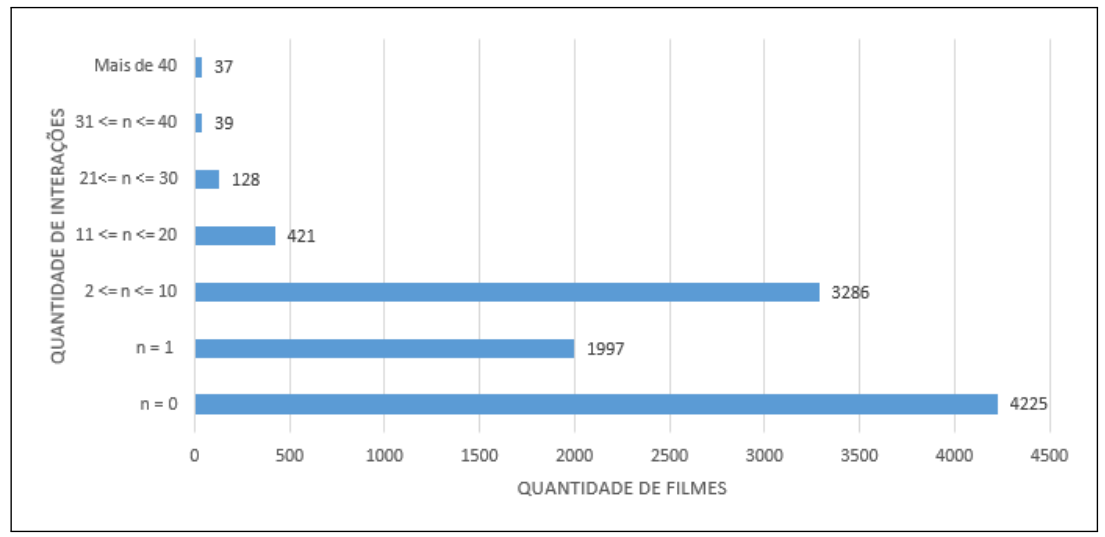

Figura 5.18: Avaliação das atribuições de etiquetas sobre filmes nos conjuntos de treinamento do MovieLens ( $n$ representa o número de interações).

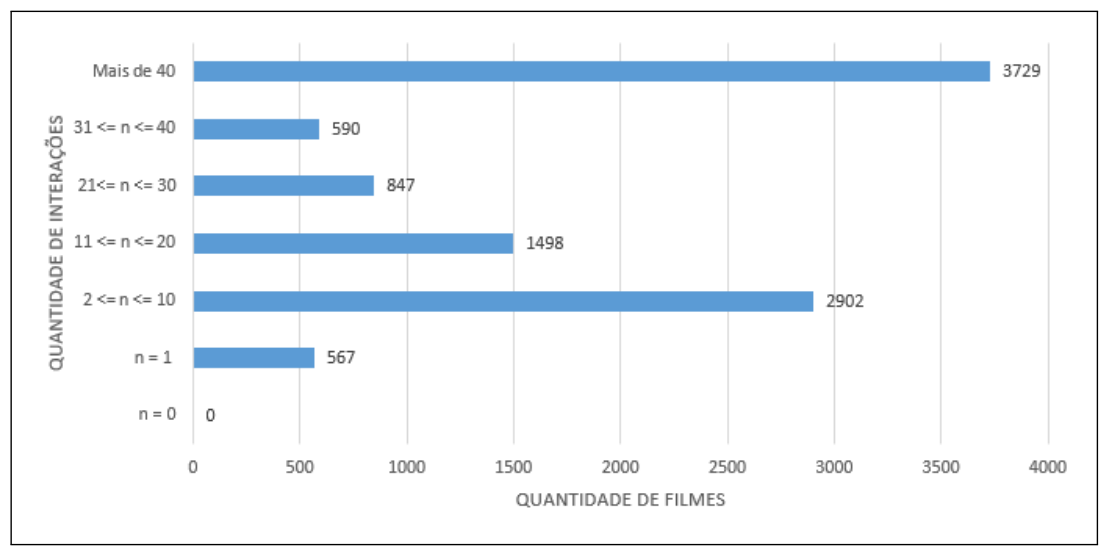

Figura 5.19: Avaliação do histórico de visualização sobre filmes nos conjuntos de treinamento do MovieLens ( $n$ representa o número de interações).

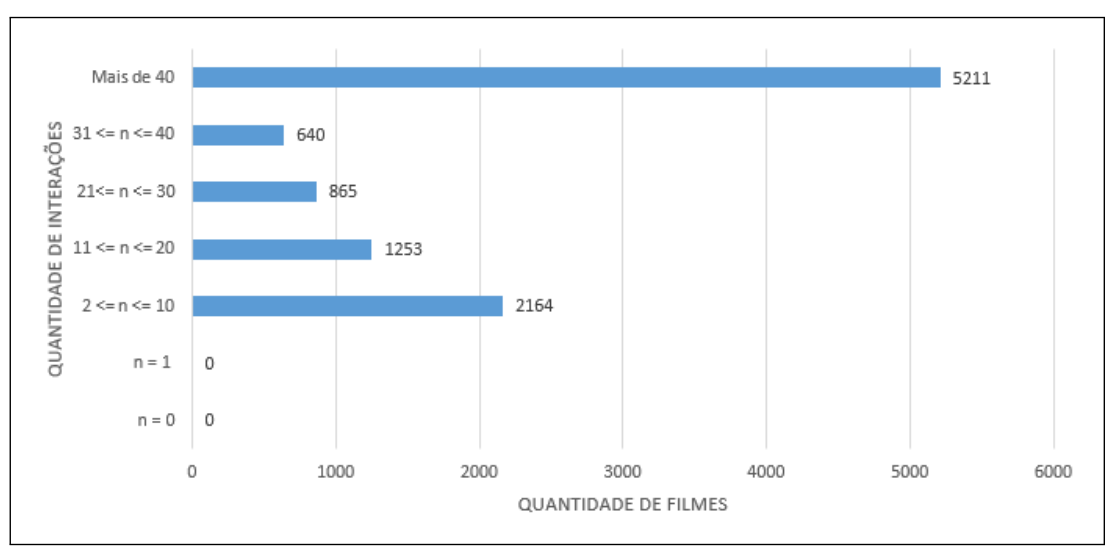

Figura 5.20: Avaliação do conjunto de todas as interações sobre filmes nos conjuntos de treinamento do MovieLens ( $n$ representa o número de interações).

apresentados os resultados de cada técnica isoladamente e, posteriormente, faz-se uma comparação e discussão dos resultados obtidos. 


\subsubsection{Técnicas Existentes na Literatura}

Para o desenvolvimento deste experimento, utilizou-se novamente o algoritmo BPR MF para processar as interações implícitas e o algoritmo SVD++, apresentado na Seção 2.3.3.2, para as interações explícitas. Durante o processo de recomendação, o SVD++ utiliza também informações implícitas, como as interações do histórico de visualização, que são inferidas através das interações explícitas passadas a ele. Este algoritmo foi utilizado por ser híbrido e obter melhores resultados com as interações consideradas, além de ser amplamente reconhecido na literatura.

Nas Figuras 5.21(a) e 5.21(b) são representados através de gráficos os resultados de MAP e precisão gerados pelo BPR MF para as interações implícitas e pelo SVD++ para a interação explícita considerada. Uma justificativa para os resultados dos experimentos com notas e histórico de visualização serem muito baixos, é que o número de interações por usuário na base do MovieLens é bem maior e mais diversificada que os da base do LastFM; além disso, como o método de avaliação é baseado no protocolo All-but-one, recomendar um item a um usuário que tenha um 'gosto' variado, ocasiona resultados com valores baixos. Outro ponto é que o ranque de notas é construído através da ordenação decrescente das notas preditas no algoritmo $\mathrm{SVD}++$, com isso, como o item escondido aleatoriamente pelo All-but-one pode ter uma nota baixa, os resultados das métricas para essa interação podem ser muito baixos.

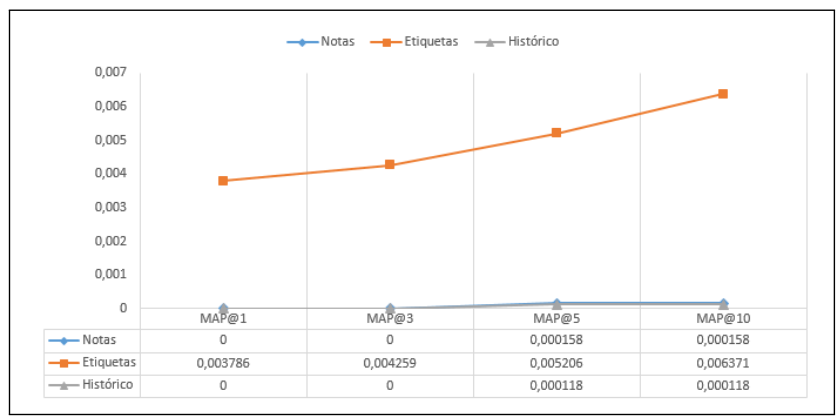

(a) MAP.

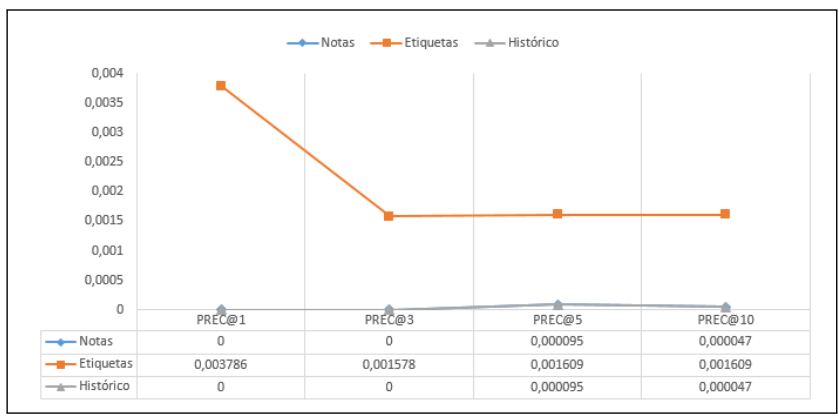

(b) Precisão.

Figura 5.21: Gráficos e tabelas comparativas de MAP e precisão em cada tipo de interação na base do MovieLens. 
Com base nos resultados gerados, pode-se perceber que o conjunto de atribuição de etiquetas gera melhores resultados do que o conjunto de histórico de visualização e de notas. Isso ocorre porque a atribuição de etiquetas apresenta um valor mais relevante do que os demais tipos de interação contidos na base do MovieLens, justificando mais uma vez que a atribuição de uma etiqueta a um determinado item demanda um maior esforço por parte do usuário.

\subsubsection{Técnicas Baseadas em Heurísticas}

A Figura 5.22 apresenta os resultados gerados pela combinação dos tipos de interação utilizando as técnicas baseadas em heurísticas, descritas na Seção 4.3.

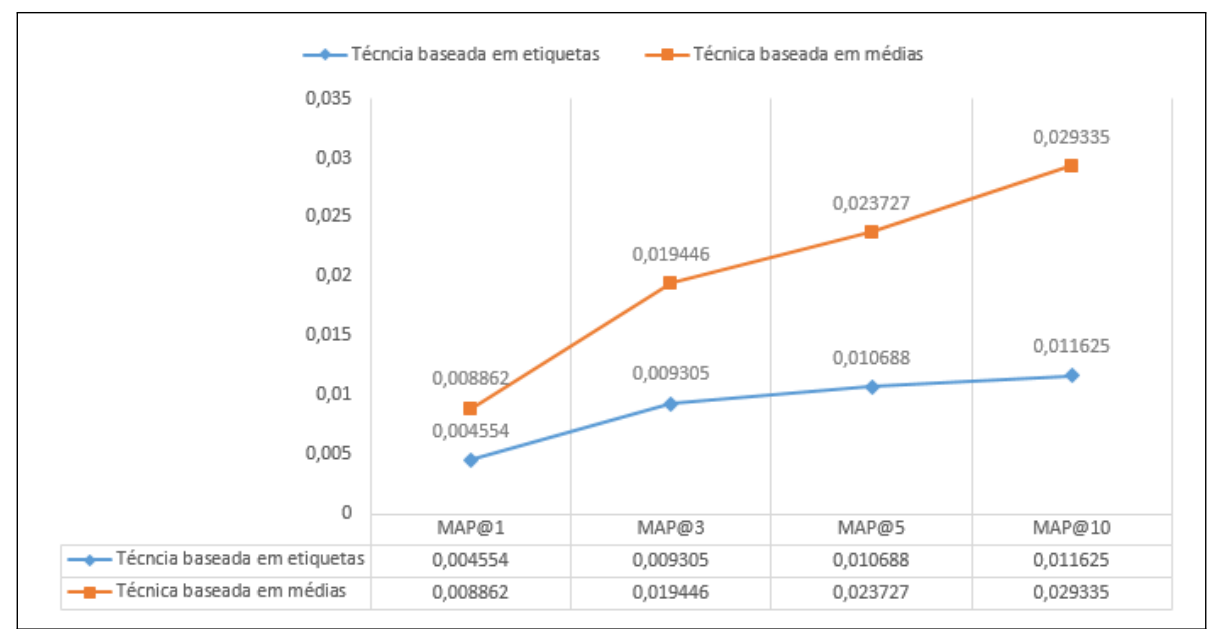

(a) MAP.

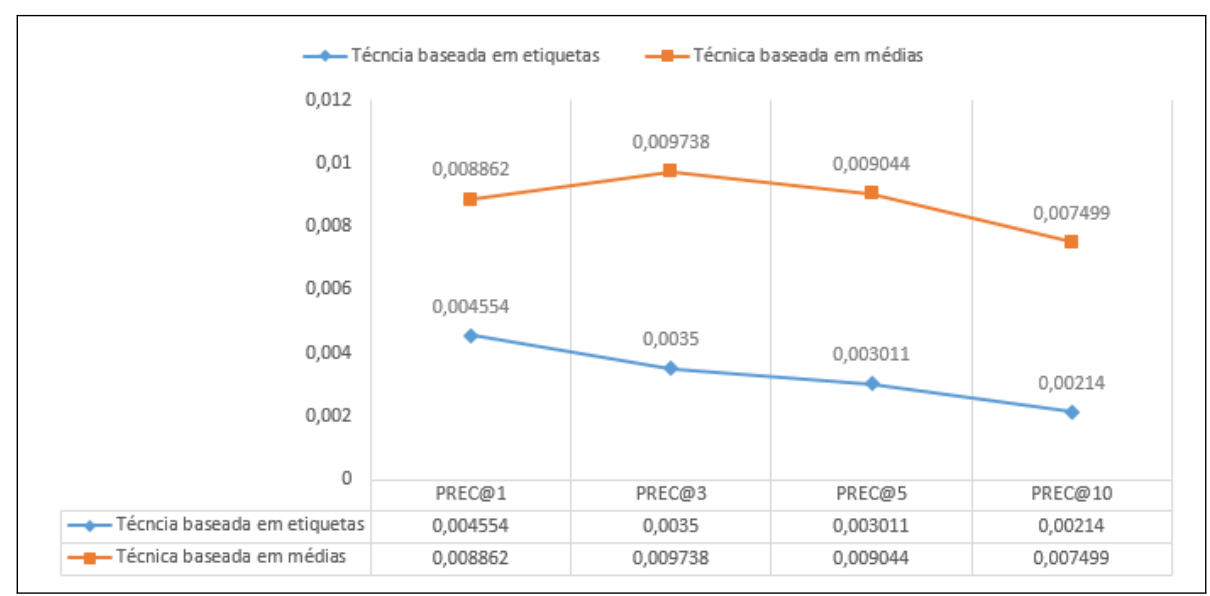

(b) Precisão.

Figura 5.22: Gráficos e tabelas comparativas de MAP e precisão nas técnicas baseadas em heurísticas na base do MovieLens. 
Neste experimento, assim como no Estudo 1, a utilização da técnica baseada em médias teve melhores valores que a baseada em etiquetas, demonstrando que o uso da intersecção dos tipos de interação consegue representar melhor as preferências do usuário.

\subsubsection{Técnicas Baseadas em Aprendizagem}

Utilizando o processo de aprendizagem na base do MovieLens, descrito na Seção 4.4, ponderou-se cada tipo de interação durante a combinação dos ranques a fim de representar com qual tipo de interação o usuário consegue expressar melhor suas preferências. Os resultados deste experimento estão representados na Figura 5.23, que apresenta as medidas de MAP e precisão.

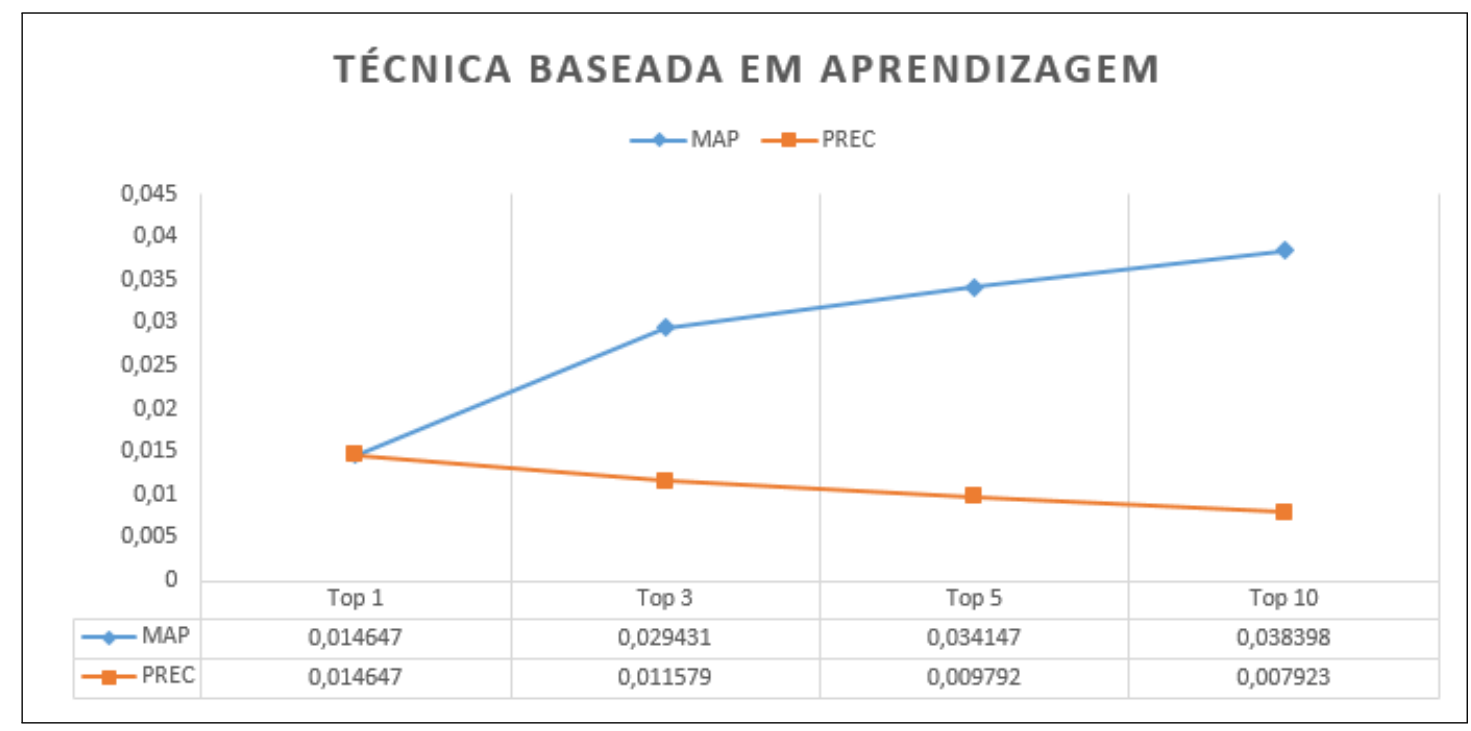

Figura 5.23: Gráfico comparativo de MAP e precisão na técnica baseada em aprendizagem na base do MovieLens.

\subsubsection{Técnica de Recomendação Colaborativa Baseada em Grupos}

No último experimento, utilizou-se a técnica de combinação baseada em grupo, descrita na Seção 4.4.1, na qual agrupam-se os usuários de acordo com suas interações através de um cálculo de distância de similaridade, a fim de gerar recomendações para cada grupo. A Figura 5.24 apresenta os gráficos dos resultados gerados para cada valor de $k$ do experimento, no qual $k$ é o número de grupos. Os valores de $k$ estão entre 2 e 100, e são definidos automaticamente pela ferramenta por apresentarem os melhores resultados.

De acordo com a técnica, na base do MovieLens a utilização de quinze grupos de usuários para gerar recomendação retorna itens mais relevantes que os demais números de grupos. Esta ocorrência deve-se pela disposição dos dados dos usuários na base, sendo que, dadas as interações feitas pelos usuários, essas refletem suas preferências. A utiliza- 


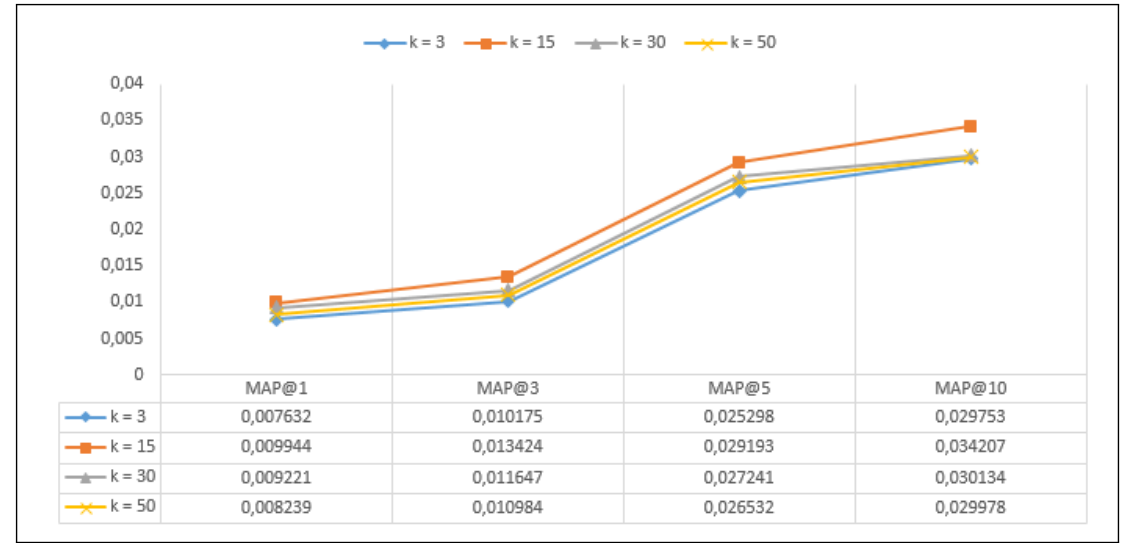

(a) MAP.

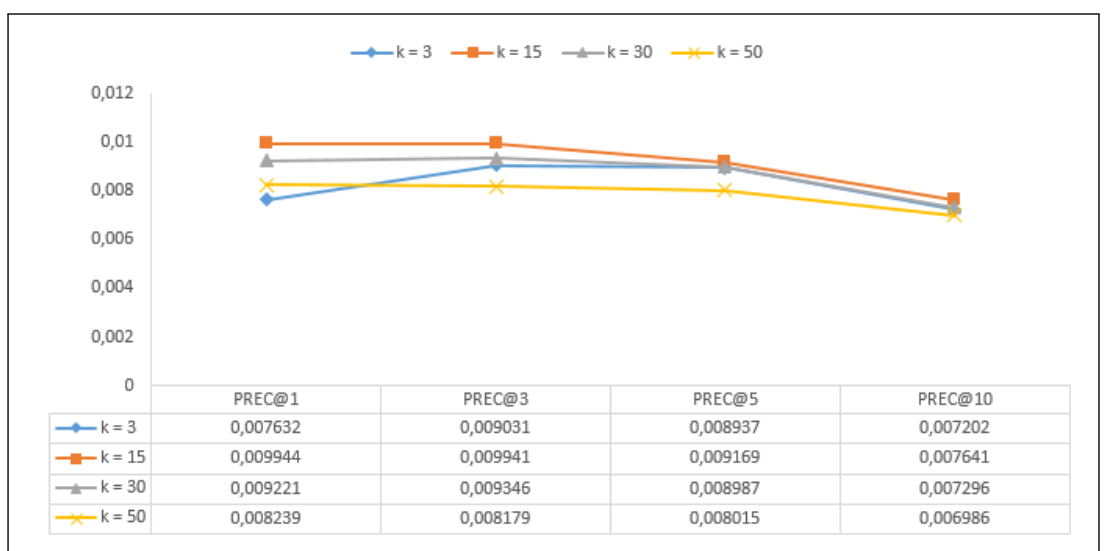

(b) Precisão.

Figura 5.24: Gráficos e tabelas comparativas de MAP e precisão na técnica baseada em grupos na base do MovieLens.

ção do algoritmo de agrupamento neste experimento definiu a representação do número aproximado de grupos de usuários na base, logo utilizou-se o valor de $k$ igual a 15 como valor padrão desta técnica.

$\mathrm{Na}$ seção a seguir serão discutidos os resultados de forma geral e apresentadas as conclusões relacionadas ao Estudo 2.

\subsubsection{Conclusões do Estudo 2}

O Estudo 2 consistiu em abordar um maior número de interações por parte dos usuários, além de considerar interações explícitas a fim de validar o uso da ferramenta desenvolvida em outro domínio de aplicação. As avaliações neste estudo também foram realizadas offline utilizando o protocolo All-but-one, juntamente com a validação cruzada em 10 folds. As Figuras 5.25 e 5.26 apresentam um gráfico comparativo entre os resultados das avaliações das quatro abordagens utilizadas neste estudo, enquanto as Tabelas 5.7 e 5.8 


\section{CAPÍTULO 5. EXPERIMENTOS E RESULTADOS}

apresentam os valores do desvio padrão das amostras de cada técnica utilizada no teste de significância estatística $(p<0.05)$.

Nos gráficos, o MAP apresenta uma tendência a retornar melhores valores na medida em que mais itens são retornados no ranque, e também permite a conclusão de que é uma medida mais eficaz para avaliação de ranques, dado que a métrica leva em consideração a posição na qual o item foi retornada no ranque, como ressaltado no Estudo 1. Os resultados obtidos nestes experimentos demonstro que a contribuição das interações de atribuição de notas e histórico de visualização, apesar de terem valores baixos, contribuem positivamente para o resultado final da combinação.

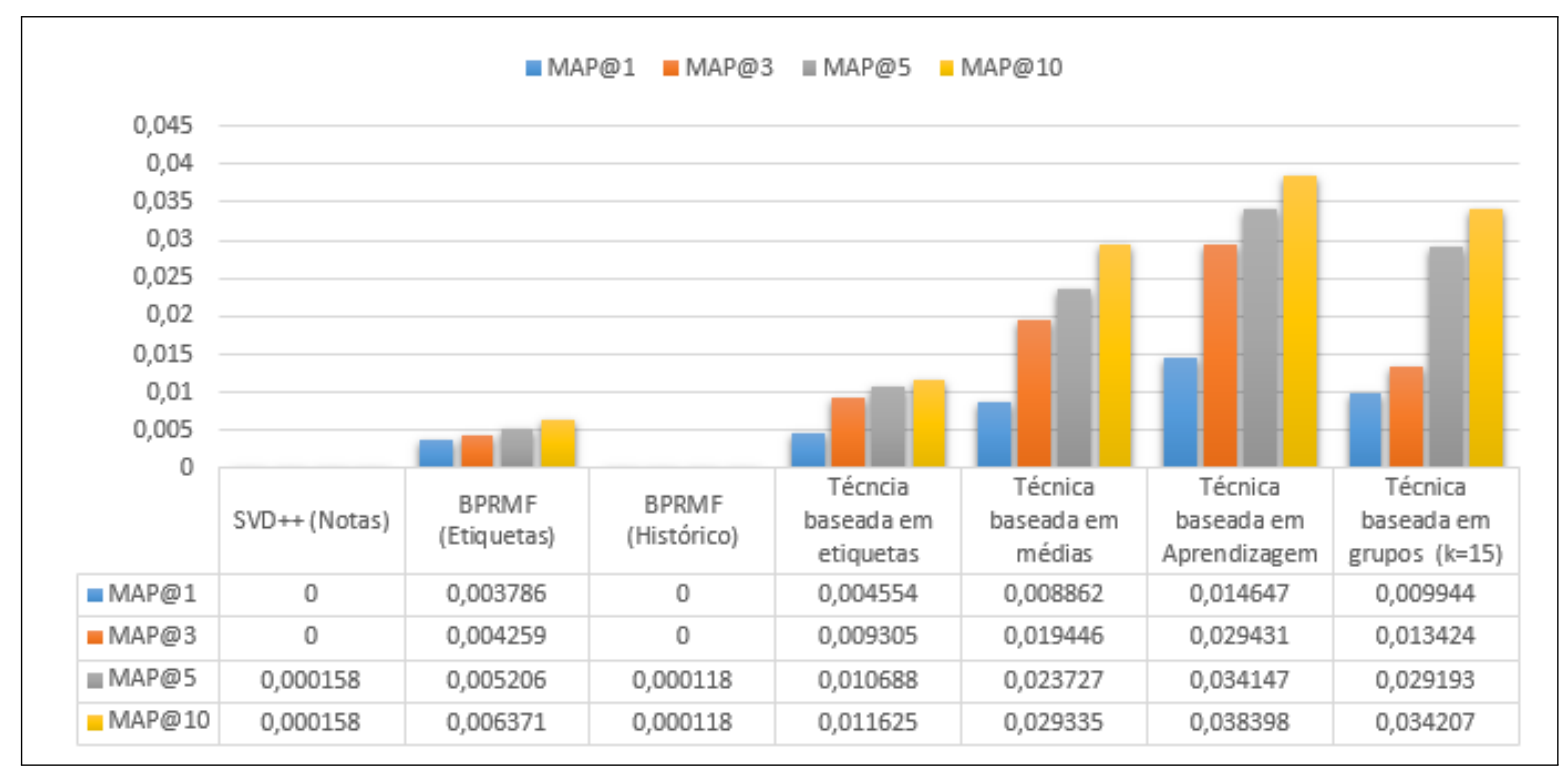

Figura 5.25: Gráfico e tabela comparativa de MAP entre as técnicas apresentadas na base do MovieLens.

Tabela 5.7: Desvio Padrão para a métrica de MAP.

\begin{tabular}{|c|l|l|l|l|}
\hline Técnica & MAP@1 & MAP@3 & MAP@5 & MAP@10 \\
\hline SVD++ (Notas) & 0,000102 & 0,0000210 & 0,00089 & 0,000054 \\
\hline BPRMF (Histórico) & 0,000032 & 0,0000121 & 0,00089 & 0,000341 \\
\hline BPRMF (Etiquetas) & 0,000210 & 0,000875 & 0,000012 & 0,000812 \\
\hline $1^{\text {a }}$ T. baseada em heurística & 0.000153 & 0.000231 & 0.000123 & 0.000312 \\
\hline $2^{\text {a }}$ T. baseada em heurística & 0,000474 & 0,000326 & 0,000084 & 0,0000437 \\
\hline T. baseada em aprendizagem & 0,000623 & 0,000134 & 0,000104 & 0,000321 \\
\hline T. baseada em grupos $(\mathrm{k}=15)$ & 0,000632 & 0,0000389 & 0,000043 & 0,000532 \\
\hline
\end{tabular}




\section{CAPÍTULO 5. EXPERIMENTOS E RESULTADOS}

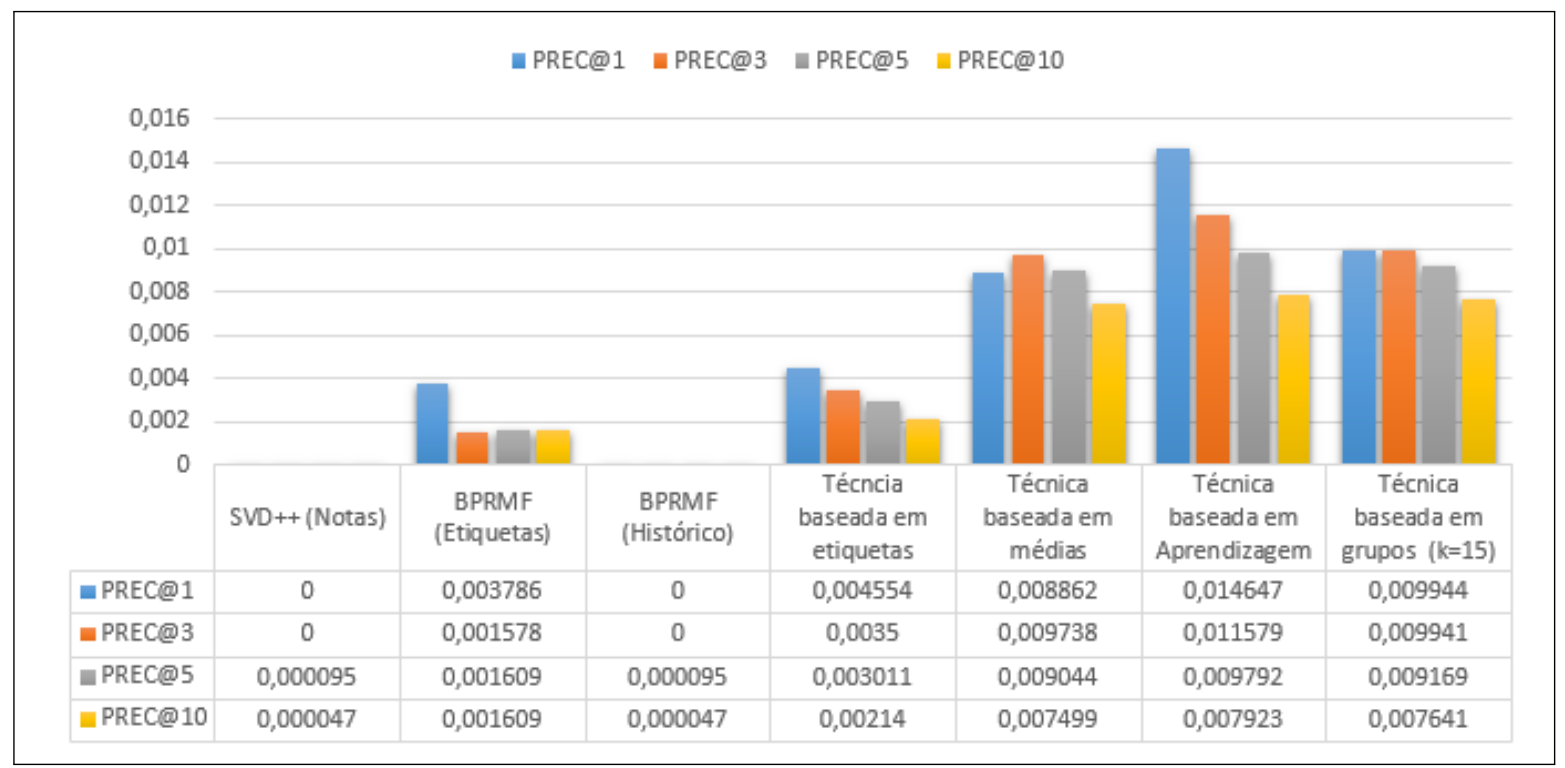

Figura 5.26: Gráfico e tabela comparativa de precisão entre as técnicas apresentadas na base do MovieLens.

Tabela 5.8: Desvio Padrão para a métrica de precisão.

\begin{tabular}{|c|l|l|l|l|}
\hline Técnica & PREC@1 & PREC@3 & PREC@5 & PREC@10 \\
\hline SVD++ (Notas) & 0,000076 & 0,0000187 & 0,000146 & 0,0000654 \\
\hline BPRMF (Histórico) & 0,000019 & 0,000032 & 0,000215 & 0,000077 \\
\hline BPRMF (Etiquetas) & 0,000168 & 0,000062 & 0,0000107 & 0,000085 \\
\hline $1^{\text {a }}$ T. baseada em heurística & 0,000032 & 0,000187 & 0,000098 & 0,000131 \\
\hline $2^{\text {a }}$ T. baseada em heurística & 0,000217 & 0,00045 & 0,000124 & 0,000076 \\
\hline T. baseada em aprendizagem & 0,000115 & 0,000745 & 0,000032 & 0,000054 \\
\hline T. baseada em grupos $(\mathrm{k}=15)$ & 0.000047 & 0.0000527 & 0.000238 & 0.000088 \\
\hline
\end{tabular}

Os resultados gerados pela ferramenta na base do MovieLens também apresentaram bons resultados em relação às técnicas já existentes na literatura. Nota-se que as abordagens de combinação propostas neste trabalho, conseguiram melhorar visivelmente os cenários dos ranques de notas e histórico de visualização que não puderam sequer retornar algum item relevante para o usuário nas três primeiras posições. Dentre as três técnicas de combinação apresentadas, a que retornou itens mais relevantes, assim como no Estudo 1, foi a técnica baseada em aprendizagem, demostrando resultados superiores aos demais em todas as posições do ranque. As técnicas baseadas em heurísticas, assim como a técnica baseada em grupos, também apresentaram bons resultados em suas combinações, demonstrando que seu uso pode ser expandido para outros domínios.

Os experimentos e avaliações realizados no Estudo 2 proporcionaram resultados relevantes para a pesquisa, uma vez que permitiram:

1. Verificar o funcionamento da ferramenta em uma base de dados com interações explícitas e implícitas; 
2. Reforçar a generalidade do modelo baseado em aprendizado, uma vez que esta abordagem teve bons resultados em bases de dados com domínios diferentes;

3. Verificar que as recomendações produzidas pelas técnicas da ferramenta proposta oferecem melhor qualidade do que as recomendações produzidas pelos algoritmos tradicionais em outro domínio;

4. Publicação de trabalho apresentando os resultados da técnica baseada em médias.

\subsection{Considerações Finais}

Neste capítulo foram apresentados os principais resultados encontrados durante o desenvolvimento dos experimentos, dos quais apontaram-se as principais implicações para a prática do processo de implementação das técnicas de combinação nos sistemas de recomendação, além das implicações metodológicas usadas nos estudos. Inicialmente apresentaram-se as metodologias de avaliação empregadas nos estudos, descrevendo as ferramentas e bases de dados que seriam utilizadas, além das métricas e protocolos de avaliação a serem utilizados.

Em seguida, expuseram-se os resultados gerados por cada técnica da ferramenta na base de dados do LastFM. Neste estudo, apresentaram-se os fatores que contribuíram e limitaram os experimentos, além de apresentar uma análise geral de todas as técnicas quando confrontadas umas com as outras, e com as técnicas já existentes na literatura. No Estudo 2 foram repetidos os mesmo experimentos do estudo anterior, porém com uma base de dados mais robusta, contendo um maior número de tipos de interação. Ao final de cada estudo, apresentaram-se as conclusões a respeito das experiências realizadas e as principais contribuições de cada um. Por fim, discutiu-se sobre as principais limitações encontradas durante o desenvolvimento dos experimentos, destacando os principais motivos pelos quais elas existiram.

Os estudos apresentados neste capítulo mostram que as técnicas da ferramenta proposta foram eficazes com relação à redução do problema abordado nesta dissertação em diferentes domínios de aplicação. O próximo capítulo apresenta as considerações finais deste trabalho, assim como as contribuições e trabalhos futuros. 


흥

\section{Conclusões e Trabalhos Futuros}

Neste capítulo é apresentado o resumo da pesquisa descrita nessa dissertação, discutindo as suas contribuições, problemas encontrados ao longo do desenvolvimento e sugestões para prosseguimento do trabalho.

\subsection{Resumo do trabalho}

Com a quantidade crescente de informações e sua facilidade de acesso na Internet, os sistemas de busca na Web têm sido amplamente utilizados. Esses sistemas, por retornarem um número grande de dados, geram para o usuário tarefas cansativas e propensas a erros, como a filtragem manual do conteúdo oferecido, a fim de encontrar informações de seu interesse. Uma possível solução para esse problema seria a utilização dos sistemas de recomendação, responsáveis por melhorar o processo de indicação. Nestes sistemas, os usuários são auxiliados na procura das informações, recebendo indicações baseadas no seu perfil de interesses, em notas atribuídas por demais usuários, em etiquetas de busca, entre outras formas.

Porém, com a evolução dos sistemas de recomendação, novas questões surgiram principalmente relacionadas à identificação dos interesses do usuário. Nestes sistemas, para gerar recomendações, é necessário que se tenha um perfil com suas preferências. Isso afeta principalmente os novos usuários de uma comunidade que não podem receber recomendações, pois o sistema não consegue identificar suas preferências devido ao número reduzido 
de interações daqueles usuários. Nessa linha de pesquisa, foram desenvolvidas inúmeras técnicas que utilizam diferentes informações do usuário para construir seu perfil de interesses, como a utilização de palavras-chave provenientes dos metadados do conteúdo, o armazenamento do histórico de navegação, a utilização de notas de avaliação produzidas pelo usuário, entre outras. Entretanto, a literatura apresenta uma lacuna em técnicas que unifiquem as diversas formas de interação do indivíduo em um único modelo.

Com isso, nesta dissertação, foi proposto uma ferramenta de recomendação que utiliza a filtragem colaborativa somada a técnicas de combinação, com o objetivo de processar diferentes tipos de interação de usuários, a fim de gerar recomendações mais precisas, além de diminuir os clássicos problemas da filtragem colaborativa. A ferramenta é composta por quatro abordagens de combinação nas quais utilizam técnicas de pós e pré-processamento dos dados para fazer a recomendação.

Além das técnicas de combinação, foram desenvolvidos os módulos de tratamento da base de dados e o de avaliação de resultados. A ferramenta proposta baseia-se em processar diferentes tipos de interação dos usuários objetivando contribuir na construção de um perfil mais consistente do usuário, e com isso, gerar recomendações mais próximas às preferências dos usuários.

Para avaliar a viabilidade da solução proposta, foram conduzidos dois estudos. No Estudo 1 utilizou-se a base do LastFM, contendo somente interações implícitas dos usuários, na tentativa de validar as técnicas propostas e verificar sua eficácia quanto à cobertura e precisão das recomendações. O Estudo 2 envolveu a validação da hipótese da pesquisa com a aplicação das técnicas na base do MovieLens, que contém um maior número de interações tanto implícitas, quanto explícitas.

Os dois estudos foram aplicados com o objetivo de analisar as contribuições desta ferramenta em comparação com os algoritmos tradicionais de filtragem colaborativa, quando aplicados em diferentes domínios. Os resultados obtidos com estes estudos foram importantes para demonstrar a viabilidade da abordagem proposta no que se refere a gerar recomendações baseadas em interações multimodais dos usuários, apresentando evidências que validam a hipótese que orienta essa pesquisa.

\subsection{Contribuições da Pesquisa}

Dentre as principais contribuições deste trabalho, pode-se destacar:

- O emprego de diferentes tipos de interação do usuário como fator importante para gerar recomendações; 
- A possibilidade de integração mais rápida de novos usuários na comunidade, um problema relativo a sistemas de recomendação pela filtragem colaborativa, onde o usuário precisa avaliar vários itens para começar a receber recomendações. Este trabalho apresenta uma solução que possibilita aos usuários novos na comunidade receberem recomendações a partir de qualquer interação que ele faça no sistema;

- A apresentação de uma ferramenta de recomendação contendo quatro técnicas de combinação de interações;

- A indicação de caminhos para aprofundamento de pesquisas com sistemas de recomendação utilizando a combinação de diferentes tipos de interação;

- A apresentação dos resultados obtidos a partir de dois estudos que contribuíram para verificar a viabilidade da solução apresentada para o problema da dissertação e que podem servir como base para a realização de novos estudos e trabalhos futuros.

As seções a seguir apresentam e discutem as aplicações de cada técnica da ferramenta proposta, além dos trabalhos publicados no decorrer desta pesquisa.

\subsubsection{Conclusões e Aplicações}

Durante o desenvolvimento da proposta, o protótipo inicial originou quatro técnicas de recomendação, sendo que cada uma delas apresenta sua especialidade em determinado domínio. A técnica baseada em etiquetas aplica-se bem em situações onde os usuários atribuem uma grande quantidade de etiquetas aos itens. Assim, esta técnica é melhor aplicada quando o número de interações relacionadas a etiquetas é maior que o número dos demais tipos de interação. Exemplos de sistemas que poderiam se beneficiar dessa técnica são o Flickr ${ }^{1}$ e o Delicious ${ }^{2}$, por serem sistemas de compartilhamento que utilizam-se de etiquetas para descrição de itens.

A técnica baseada em médias, diferente da abordagem anterior, é melhor aplicada quando o número de interações de diferentes tipos estão balanceadas em uma base de dados. Neste cenário, esta técnica conseguirá ponderar aquelas interações com as quais os usuários tem mais afinidade, levando em consideração o número e o tipo de interações que ele teve com determinado item. Esta técnica funciona bem em sistemas em que usuário tenha todas as interações disponível com um item, como por exemplo sites simples de compras, no qual o usuário pode acessar um item e comprar um item.

Na tentativa de generalizar as outras duas técnicas para diferentes domínios de aplicação, desenvolveu-se a técnica baseada em aprendizagem. Nesta técnica procurou-se

\footnotetext{
${ }^{1}$ https://www.flickr.com/

${ }^{2}$ https://www.delicious.com
} 
ponderar cada tipo de interação do usuário, de acordo com as interações que ele já havia feito. Como pode ser observado no experimentos desta dissertação, a técnica conseguiu obter bons resultados em bases com domínios completamente diferentes, sendo uma de filmes e outra de música. Com isso, prova-se a generalidade dessa técnica para diversos tipos de domínio.

Por fim, a técnica baseada em grupos foi desenvolvida para domínios relacionados com redes sociais, para detectar e recomendar itens para usuários com preferências similares. Esta técnica ainda pode ser aperfeiçoada, com técnicas de agrupamento de dados, como biclusterização e com a própria técnica de aprendizagem apresentada nesta pesquisa. Está técnica aplica-se em domínios em que os usuários podem ser agrupados em comunidades, como por exemplo as redes sociais (Facebook, Twitter, LinkedIn).

Os resultados dos experimentos apresentados no capítulo anterior demonstram a capacidade das técnicas de combinação na área de sistemas de recomendação, ficando claro que mesmo o uso de técnicas mais simples de combinação de interações apresentam melhoras significativas no resultado final da recomendação. Com isso, a principal contribuição desta pesquisa foi uma ferramenta de recomendação, baseado na combinação de interações multimodais, sendo aplicado em uma diversidade de domínios de aplicação.

\title{
6.2.2 Trabalhos Publicados
}

Ao longo do desenvolvimento desta pesquisa desenvolveram-se quatro trabalhos relacionados às técnicas propostas na ferramenta. Os três primeiros, relacionados às técnicas baseadas em heurística e a técnica baseada em aprendizado, já foram aceitos e publicados. O último trabalho descreve a técnica baseada em grupos será submetido a uma conferência internacional (SIGIR 2015).

A seguir esses trabalhos são apresentados:

\section{- Improving Personalized Ranking in Recommender Systems with Multi- modal Interactions}

\begin{abstract}
This paper proposes a conceptual framework which uses multimodal user feedback to generate a more accurate personalized ranking of items to the user. Our technique is a response to the actual scenario on the Web, where users can consume content following different interaction paradigms, such as rating, browsing, sharing, etc. We developed a post-processing step to ensemble rankings generated by unimodal-based state-of-art algorithms, using a set of heuristics which analyze the behavior of the user during consumption. We provide an experimental evaluation using the MovieLens 10M dataset, and the results show that better recommendati-
\end{abstract}


ons can be provided when multimodal interactions are considered for profiling the preferences of the users.

Referência: Fortes, C. A.; Manzato, Marcelo G; Domingues, Marcos A.; Rezende, Solange O. Improving Personalized Ranking in Recommender Systems with Multimodal Interactions. Web Intelligence (WI) and Intelligent Agent Technologies (IAT), 2014 IEEE/WIC/ACM International Joint Conferences on, v. 1, p. 198-204, 2014.

\title{
- Multimodal Interactions in Recommender Systems: An Ensembling Ap- proach
}

\begin{abstract}
In this paper, we present a technique that uses multimodal interactions of users to generate a more accurate list of recommendations optimized for the user. Our approach is a response to the actual scenario on the Web which allows users to interact with the content in different ways, and thus, more information about his preferences can be obtained to improve recommendation. The proposal consists of an ensemble technique that combines rankings generated by unimodal recommenders based on particular interaction types. By using a combination of implicit and explicit feedback from users, we are able to provide better recommendations, as shown by our experimental evaluation presented in this paper.
\end{abstract}

Referência: Fortes, C. A.; Manzato, Marcelo G. Multimodal Interactions in Recommender Systems: An Ensembling Approach. In: Brazilian Conference on Intelligent Systems, 2014, São Carlos, São Paulo. Brazilian Conference on Intelligent Systems (BRACIS 14). Los Alamitos: IEEE, 2014.

\section{- Ensemble Learning in Recommender Systems: Combining Multiple User Interactions for Ranking Personalization}

\begin{abstract}
In this paper, we propose a technique that uses multimodal interactions of users to generate a more accurate list of recommendations optimized for the user. Our approach is a response to the actual scenario on the Web which allows users to interact with the content in different ways, and thus, more information about his preferences can be obtained to improve recommendation. The proposal consists of an ensemble learning technique that combines rankings generated by uni-
\end{abstract}


modal recommenders based on particular interaction types. By using a combination of different types of feedback from users, we are able to provide better recommendations, as shown by our experimental evaluation.

Referência: Fortes, C. A.; Manzato, Marcelo G. Ensemble Learning in Recommender Systems: Combining Multiple User Interactions for Ranking Personalization. In: XX Simpósio Brasileiro de Sistemas Multimídia e Web (Webmedia), 2014, João Pessoa - PB. Anais do XX Simpósio Brasileiro de Sistemas Multimídia e Web. New York: ACM, 2014.

\title{
- Group-based Collaborative Filtering with Multiple Users' Interactions
}

\begin{abstract}
This paper proposes a framework for recommender systems based on preferences of users' groups. To improve the quality of recommendation, we calculate the similarity between users using multiple types of feedback, and use this distance to cluster users with similar interests. The advantage of this approach is that relevant items will be suggested based only on the subjects of interest of each group of users. Using this framework, we use a state-of-art collaborative filtering algorithm to generate a personalized ranking of items according to the preferences of an individual within each cluster. The experimental results show that the proposed algorithm has a higher precision than the traditional model without clustering.
\end{abstract}

\subsection{Trabalhos Futuros}

Essa dissertação aponta algumas sugestões para trabalhos futuros, tanto em nível teórico, como no desenvolvimento de novas aplicações e realização de novos estudos de caso. A seguir, são apresentadas as perspectivas para o prosseguimento dessa pesquisa:

- Estudo de outras técnicas para incentivar a integração de novos usuários dentro de comunidades virtuais;

- Uso de informações de contexto dos itens para gerar recomendações ainda mais precisas;

- Utilizar informações semânticas de interações explícitas dos usuários como comentários e etiquetas; 
- Integração das abordagens baseada em grupos e em aprendizagem, afim de considerar todos os tipos de interações individualmente;

- Investigação e desenvolvimento da ferramenta proposta em outras áreas de aplicação para avaliar sua flexibilidade quanto à área de atuação;

Por fim, acredita-se que a ferramenta proposta nesta dissertação referente a sistemas de recomendação tem um grande potencial não só relacionado à aplicação em Comunidades Virtuais, como também em outros ambientes que envolvam um grande número de informações e diferentes tipos de interação de usuários, visto que quanto maior o número de informações, maior será a dificuldade em encontrar itens relevantes, e quanto mais interações um usuário tiver no sistema, melhor representado estará seu perfil. 


\section{Referências}

Adomavicius; G., Mobasher, B.; Ricci, F.; Tuzhilin, A. Context-aware recommender systems. AI Magazine, p. 67-80, 2011.

Amatriain, X.; Pujol, J. M.; Oliver, N. I like it... i like it not: Evaluating user ratings noise in recommender systems. In: Proceedings of the 17th International Conference on User Modeling, Adaptation, and Personalization: formerly UM and AH, UMAP '09, Berlin, Heidelberg: Springer-Verlag, 2009, p. 247-258 (UMAP '09, ).

Anand, S. S.; Kearney, P.; Shapcott, M. Generating semantically enriched user profiles for web personalization. ACM Trans. Internet Technol., v. 7, n. 4, 2007.

Arapakis, I.; Moshfeghi, Y.; Joho, H.; Ren, R.; Hannah, D.; Jose, J. M. Integrating facial expressions into user profiling for the improvement of a multimodal recommender system. In: Proceedings of the 2009 IEEE international conference on Multimedia and Expo, Piscataway, NJ, USA: IEEE Press, 2009, p. 1440-1443.

Bar, A.; Rokach, L.; Shani, G.; Shapira, B.; Schclar, A. Improving simple collaborative filtering models using ensemble methods. In: Zhou, Z.-H.; Roli, F.; Kittler, J., eds. Multiple Classifier Systems, v. 7872 de Lecture Notes in Computer Science, Springer Berlin Heidelberg, p. 1-12, 2013.

Boim, R.; Milo, T. Methods for boosting recommender systems. In: Data Engineering Workshops (ICDEW), 2011 IEEE 27th International Conference on, 2011, p. 288-291.

Breese, J. S.; Heckerman, D.; Kadie, C. Empirical analysis of predictive algorithms for collaborative filtering. In: Proceedings of the Fourteenth Conference on Uncertainty in Artificial Intelligence, UAI'98, San Francisco, CA, USA: Morgan Kaufmann Publishers Inc., 1998, p. 43-52 (UAI'98, ). 
Cantador, I.; Brusilovsky, P.; Kuflik, T. 2nd workshop on information heterogeneity and fusion in recommender systems (hetrec 2011). In: Proceedings of the 5th ACM conference on Recommender systems, RecSys 2011, New York, NY, USA: ACM, 2011 (RecSys 2011, ).

Cazella, S. C.; Reategui, E.; Machado, M.; Barbosa, J. Recomendação de objetos de aprendizagem empregando filtragem colaborativa e competências. Simpósio Brasileiro de Informática na Educação (SBIE), 2009.

Da Costa, A.; Domingues, M.; Rezende, S.; Manzato, M. Improving personalized ranking in recommender systems with multimodal interactions. In: International Joint Conferences on Web Intelligence (WI) and Intelligent Agent Technologies (IAT), 2014 IEEE/WIC/ACM, IEEE, 2014, p. 198-204.

Da Costa, A.; Manzato, M. Multimodal interactions in recommender systems: An ensembling approach. In: Brazilian Conference on Intelligent Systems (BRACIS), 2014, IEEE, 2014, p. 67-72.

Da Costa Fortes, A.; Manzato, M. G. Ensemble learning in recommender systems: Combining multiple user interactions for ranking personalization. In: Proceedings of the 20th Brazilian Symposium on Multimedia and the Web, WebMedia '14, New York, NY, USA: ACM, 2014, p. 47-54 (WebMedia '14, ).

Domingues, M.; Gouyon, F.; Jorge, A.; Leal, J.; Vinagre, J.; Lemos, L.; Sordo, M. Combining usage and content in an online recommendation system for music in the long tail. International Journal of Multimedia Information Retrieval, v. 2, n. 1, p. 3-13, 2013.

Durao, F.; Dolog, P. Extending a hybrid tag-based recommender system with personalization. In: Proceedings of the 2010 ACM Symposium on Applied Computing, New York, NY, USA, 2010, p. 1723-1727.

Gantner, Z.; Rendle, S.; Freudenthaler, C.; Schmidt-Thieme, L. Mymedialite: A free recommender system library. In: Proceedings of the Fifth ACM Conference on Recommender Systems, RecSys '11, New York, NY, USA: ACM, 2011, p. 305-308 (RecSys '11, ).

Goldberg, D.; Nichols, D.; Oki, B. M.; Terry, D. Using collaborative filtering to weave an information tapestry. Commun. ACM, v. 35, n. 12, p. 61-70, 1992. 
Heckmann, D.; Krueger, A. A user modeling markup language (UserML) for ubiquitous computing. In: User Modeling 2003, v. 2702 de Lecture Notes in Computer Science, Springer Berlin Heidelberg, p. 393-397, 2003.

Herlocker, J.; Konstan, J.; Borchers, A.; Riedl, J. Explaining collaborative filtering recommendations. In: In Proceedings of ACM 2000 Conference on Computer Supported Cooperative Work, Philadelphia, PA, USA, 2000, p. 241-250.

Jahrer, M.; Töscher, A.; Legenstein, R. Combining predictions for accurate recommender systems. In: Proceedings of the 16th ACM SIGKDD International Conference on Knowledge Discovery and Data Mining, KDD '10, New York, NY, USA: ACM, 2010, p. 693-702 (KDD'10, ).

Jawaheer, G.; Szomszor, M.; Kostkova, P. Comparison of implicit and explicit feedback from an online music recommendation service. Proceedings of the 1st International Workshop on Information Heterogeneity and Fusion in Recommender Systems, p. $47-51,2010$.

Johansson, P. Madfilm - a multimodal approach to handle search and organization in a movie recommendation system. Proceedings of the 1st Nordic Symposium on Multimodal Communication, p. 53-65, 2003.

Kajimoto, T.; Osawa, A.; Matsuura, Y.; Abaimov, A. P.; Zyryanova, O. A.; Kondo, K.; Tokuchi, N.; Hirobe, M. Individual-based measurement and analysis of root system development: case studies for larix gmelinii trees growing on the permafrost region in siberia. Journal of Forest Research, v. 12, n. 2, p. 103-112, 2007.

Kautz, H.; Selman, B.; Shah, M. Referral web: Combining social networks and collaborative filtering. Commun. ACM, v. 40, n. 3, p. 63-65, 1997.

Kobsa, A. Generic user modeling systems. In: The Adaptive Web, v. 4321 de Lecture Notes in Computer Science, Springer Berlin Heidelberg, p. 136-154, 2007.

Koren, Y.; Bell, R.; Volinsky, C. Matrix Factorization Techniques for Recommender Systems. IEEE Computer, v. 42, n. 8, p. 30-37, 2009.

Manzato, M.; Domingues, M. A.; Marcacini, R. M.; Rezende Oliveira, S. Improving personalized ranking in recommender systems with topic hierarchies and implicit feedback. International Conference on Pattern Recognition - ICPR, 2014.

Manzato, M. G. gSVD++: Supporting implicit feedback on recommender systems with metadata awareness. In: Proceedings of the 28th Annual ACM Symposium on Applied Computing, SAC '13, New York, NY, USA: ACM, 2013, p. 908-913 (SAC '13, ). 
Massa, P.; Hayes, C. Page-rerank: using trusted links to re-rank authority. In: Web Intelligence, 2005. Proceedings. The 2005 IEEE/WIC/ACM International Conference on, 2005, p. 614-617.

Mitchell, T. M. Machine learning. 1 ed. New York, NY, USA: McGraw-Hill, Inc., 1997.

Mobasher, B. Recommender systems, v. 3. Kunstliche Intelligenz, Special Issue on Web Mining, 41-43 p., 2007.

Morais, S. Sistemas de recomendação em rapid miner: um caso de estudo. Dissertação de Mestrado, Universidade do Porto, 2012.

Musto, C.; Narducci, F.; Gemmis, M. D.; Lops, P.; Semeraro, G. A tag recommender system exploiting user and community behavior. ACM RecSys Workshop on Recommender Systems and the Social Web, 2009.

Paiva, A.; Self, J. A. Tagus - a user and leamer modeling workbench. User Model. User-Adapt. Interact., v. 4, n. 3, p. 197-226, 1995.

Parra, D.; Amatriain, X. Walk the talk: Analyzing the relation between implicit and explicit feedback for preference elicitation. UMAP'11 Proceedings of the 19th international conference on User modeling, adaption, and personalization, p. 255-268, 2011.

Peska, L.; Vojtas, P. Negative implicit feedback in e-commerce recommender systems. In: Proceedings of the 3rd International Conference on Web Intelligence, Mining and Semantics, New York, NY, USA: ACM, 2013, p. 45:1-45:4 (WIMS '13, v.45).

Poo, D.; Chng, B.; Goh, J.-M. A hybrid approach for user profiling. In: Proceedings of the 36th Annual Hawaii International Conference on System Sciences (HICSS'03) Track 4 - Volume 4, HICSS '03, Washington, DC, USA: IEEE Computer Society, 2003, p. 1-9 (HICSS '03, ).

Rein, G. Reputation information systems: A reference model. In: System Sciences, 2005. HICSS '05. Proceedings of the 38th Annual Hawaii International Conference on, 2005, p. 26a-26a.

Rendle, S. Factorization machines with libFM. ACM Trans. Intell. Syst. Technol., v. 3, n. 3, p. 57:1-57:22, 2012.

Rendle, S.; Freudenthaler, C.; Gantner, Z.; Schmidt-Thieme, L. BPR: bayesian personalized ranking from implicit feedback. UAI '09 Proceedings of the Twenty-Fifth Conference on Uncertainty in Artificial Intelligence, p. 452-461, 2009. 
Resnick, P.; Iacovou, N.; Suchak, M.; Bergstrom, P.; Riedl, J. Grouplens: An open architecture for collaborative filtering of netnews. In: Proceedings of the 1994 ACM Conference on Computer Supported Cooperative Work, New York, NY, USA: ACM, 1994, p. 175-186 (CSCW'94, v.10).

Resnick, P.; Kuwabara, K.; Zeckhauser, R.; Friedman, E. Reputation systems. Commun. $A C M$, v. 43, n. 12, p. $45-48,2000$.

Resnick, P.; Varian, H. R. Recommender systems. Commun. ACM, v. 40, n. 3, p. 56-58, 1997.

Ricci, F.; Rokach, L.; Shapira, B. Introduction to recommender systems handbook. In: Recommender Systems Handbook, p. 1-35, 2011.

Ristoski, P.; Loza, E. M.; Paulheim1, H. A hybrid multi-strategy recommender system using linked open data. ESWC, 2014.

Rousseau, B.; Browne, P.; Malone, P.; ÓFoghlú, M.; Foster, P.; Mendis, V. Personalised resource discovery searching over multiple repository types. In: Enterprise Information Systems VI, Springer Netherlands, p. 316-324, 2006.

Shardanand, U.; Maes, P. Social information filtering: Algorithms for automating "Word of Mouth". In: Proceedings of the SIGCHI Conference on Human Factors in Computing Systems, New York, NY, USA: ACM Press/Addison-Wesley Publishing Co., 1995, p. 210-217 (CHI'95, v.22).

Shepitsen, A.; Gemmell, J.; Mobasher, B.; Burke, R. Personalized recommendation in social tagging systems using hierarchical clustering. In: Proceedings of the 2008 ACM conference on Recommender systems, New York, NY, USA, 2008, p. 259-266.

Terveen, L.; Hill, W.; Amento, B.; Mcdonald, D.; Creter, J. Phoaks: A system for sharing recommendations. Communications of the ACM, v. 40, n. 3, p. 59-62, 1997.

Terveen, L.; McDonald, D. W. Social matching: A framework and research agenda. ACM Trans. Comput.-Hum. Interact., v. 12, n. 3, p. 401-434, 2005.

Thakur, B.; Abbas, S.; Trivedi, A. Netpersonal: A recommender system to personalize the environment of web user. In: Advance Computing Conference, 2009. IACC 2009. IEEE International, 2009, p. 702-705.

Tiroshi, A.; Kuflik, T.; Kay, J.; Kummerfeld, B. Recommender systems and the social web. In: UMAP'11 - Proceedings of the 19th International Conference on Advances in User Modeling, Berlin, Heidelberg: Springer-Verlag, 2012, p. 60-70. 
Töscher, A.; Jahrer, M.; Legenstein, R. Improved neighborhood-based algorithms for large-scale recommender systems. In KDD-Cup and Workshop, 2008.

Voorhees, E. M.; Harman, D. K. Trec: Experiment and evaluation in information retrieval (digital libraries and electronic publishing). The MIT Press, 2005.

Zhang, Z.-K.; Zhou, T.; Zhang, Y.-C. Personalized recommendation via integrated diffusion on user-item-tag tripartite graphs. Physica A-statistical Mechanics and Its Applications, v. 389, p. 179-186, 2010. 